\title{
CONCEPTS OF SPIRITUALITY IN THE WORKS OF ROBERT HOULE AND OTTO ROGERS WITH SPECIAL CONSIDERATION TO IMAGES OF THE LAND
}

\author{
by
}

Nooshfar B. Afnan, BCom

$\sim$

\author{
A thesis submitted to \\ the Faculty of Graduate Studies and Research \\ in partial fulfillment of \\ the requirements for the degree of \\ Master of Arts
}

Department of Art History

Carleton University

Ottawa, Ontario

6 December 2000

(C) 2000, Nooshfar B. Afnan 
INatıonal Library

of Canada

Acquisitions and

Bibliographic Services

395 Wellington Street

Ottawa ON K1A ON4

Canada
Bibliothèque nationale du Canada

Acquisitions et services bibliographiques

395 , rue Wellington Ottawa ON K1A ON4 Canada
The author has granted a nonexclusive licence allowing the National Library of Canada to reproduce, loan, distribute or sell copies of this thesis in microform, paper or electronic formats.
L'auteur a accordé une licence non exclusive permettant à la Bibliothèque nationale du Canada de reproduire, prêter, distribuer ou vendre des copies de cette thèse sous la forme de microfiche/film, de reproduction sur papier ou sur format électronique.

L'auteur conserve la propriété du droit d'auteur qui protège cette thèse. $\mathrm{Ni}$ la thèse ni des extraits substantiels de celle-ci ne doivent être imprimés ou autrement reproduits sans son autorisation.

$0-612-57696-5$

\section{Canadà}




\begin{abstract}
This thesis examines the use of landscape motifs by two contemporary Canadian artists to express their spiritual aspirations. Both Robert Houle and Otto Rogers, inspired by the Canadian prairie landscape, employ its abstracted form to convey their respective spiritual ideas. The attitude of the Saulteaux (Plains Ojibway) toward the land is explored, as well as other significant aspects of their spiritual life to gain a better understanding of the spiritual iconography in Houle's art. Similarly the Bahá'í Faith's point of view toward the land is discussed together with some of its teachings that find expression in Rogers's work. There is also a discussion of their choice of abstraction as the formal conveyor of a spiritual message. A thorough analysis of several of their works is been provided to establish how both artists employ the landscape and its features to convey a sense of spirituality.
\end{abstract}




\section{DEDICATION}

To A.B.R.K. (1910-2000),

who was a great promoter of the arts and had a special love for the Native peoples of Canada. 


\section{ACKNOWLEDGEMENTS}

I would like to express my heartfelt thanks to my two supervisors Diana Nemiroff and Carol Payne. Both have been instrumental in the creation of this thesis by giving generously of their time. Their expert advice, stimulating ideas and encouragement have helped to bring this thesis to its final stage. I would like to especially thank Mrs. Nemiroff for encouraging me to make study trips in order to see and study, firsthand, as many of the works of the artists as possible. Without these trips much of the analysis of these paintings would have been impossible.

The study of the art works, access to curatorial and artists' files and consequent email and phone inquiries were facilitated by a number of gallery staff to whom I feel greatly indebted: Marla Garen at the Mendel Art Gallery, Saskatoon; Anneke SheaHarrison and Catherine Mattes at the Winnipeg Art Gallery; Linda Tanaka at the McMichael Canadian Art Collection; Kleinburg, Melanie Johnston at the Robert McLaughlin Gallery; Christine Braun at the Art Gallery of Hamilton; Victoria Henry and Suzanne Wolf at the Canada Council Art Bank, Ottawa; Barry Simpson at the Art Gallery of Ontario, Toronto; Margot Reid at the Canadian Museum of Civilization, Hull, Quebec; Blair Barbeau at the Kenderdine Gallery, University of Saskatchewan. Sockett.

I am also most grateful to the insightful editorial advice of my friend, director Rob

A most special thanks goes to my best friend and husband Omid who has been a source of great encouragement throughout this thesis. His support has been on many different levels from editorial comments and computer know-how to the much needed back rubs. 


\section{TABLE OF CONTENTS}

Title Page.

Acceptance Form.

Abstract .iii

Dedication. iv

Acknowledgements .$v$

Table of Contents. .vi

List of Illustrations. .vii

INTRODUCTION. . .1

CHAPTER I-Historical Underpinnings: Landscape and Abstraction as Modern Spiritual Languages.....15 CHAPTER II-Robert Houle

The artist. . .

Houle's understanding of spirituality. 37

Houle's view of the land. 42

The spiritual symbology of Houle's art.

Parfleches for the Last Supper. .55

The Place Where God Lives. 62

Sandy Bay.

\section{CHAPTER III—Otto Rogers}

The artist. .77

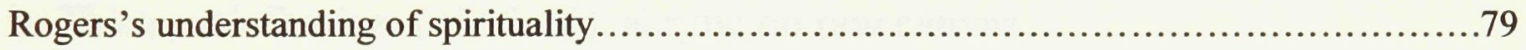

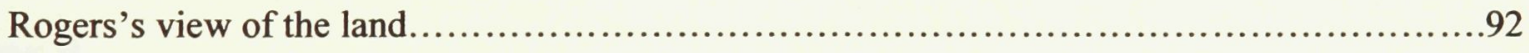

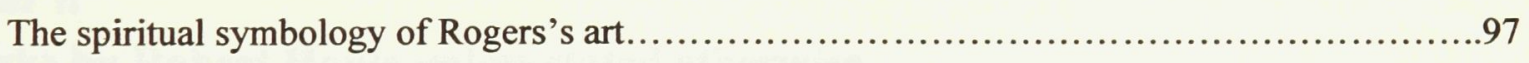

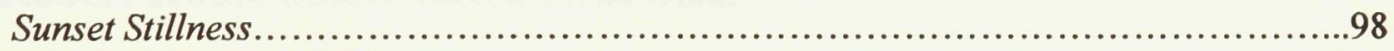

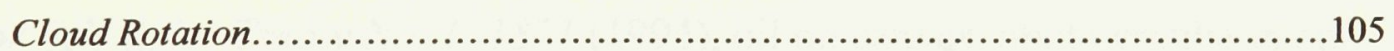

Movement of Light through Darkness...........................................109

Ascending Landscape...................................................... 112

Approaching the Shore of the Sea of Grandeur.................................. 115

CONCLUSION. 122

ILLUSTRATIONS. 129

APPENDIX I Quotations from the Gospels describing the discourses during the Last Supper for Parfleches

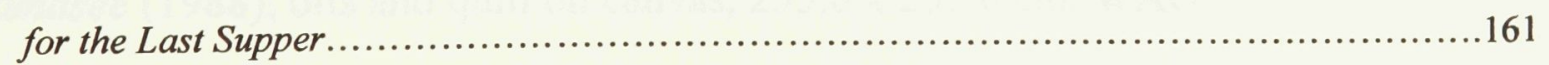




\section{LIST OF ILLUSTRATIONS}

Key: $\quad$ AGO, Art Gallery of Ontario, Toronto

CCAB - Canada Council Art Bank, Ottawa, Ontario

LAG-London Art Gallery, Ontario

MAG-Mendel Art Gallery, Saskatoon, Saskatchewan

MCAC - McMichael Canadian Art Collection, Kleinburg, Ontario

NGC - National Gallery of Canada, Ottawa, Ontario

VAG-Vancouver Art Gallery, Vancouver, British Columbia

WAG-Winnipeg Art Gallery, Winnipeg Manitoba

\section{Chapter I}

1. Lawren S. Harris, From the North, Lake Superior (1923), oil on canvas, $122 \times 152.4$ $\mathrm{cm}, \mathrm{LAG}$

2. Emily Carr, The Mountain, (1933), oil on canvas, 114.4 x $68.0 \mathrm{~cm}, \mathrm{MCAC}$

3. Caspar David Friedrich, The Cross in the Mountains (1808), oil on canvas, $115 \mathrm{x}$ $110.5 \mathrm{~cm}$, Gemäldegalerie Neue Meister, Staatliche Kunstsammlung, Dresden

4. Caspar David Friedrich, Monk by the Sea (1809), oil on canvas, $110 \times 171.5 \mathrm{~cm}$, Staatliche Schlösser und Gärten, Schloss Charlottenburg, Berlin

5. Lawren S. Harris, Composition No. 1 (1941), canvas, 157.5 x 160.7, VAG

6. Barnett Newman, Stations of the Cross, (1958-1966), Magna, acrylic, oil, duco on raw canvas, each $198.12 \times 152.4 \mathrm{~cm}$.

a. First Station, (1958), magma on raw, unsized canvas

b. Thirteenth Station, (1965-66), acrylic on raw canvas

\section{Chapter II}

\section{All works by Robert Houle unless stated otherwise.}

7. Premises for Self Rule: Treaty No. 1, 1871 (1994), oil on canvas, photo emulsion on canvas, laser cut vinyl, $152.0 \times 152.0 \mathrm{~cm}, \mathrm{WAG}$

8. Piet Mondrian, Composition. Bright Colour Planes with Grey Lines (1919), oil on canvas, diagonal $84 \mathrm{~cm}$, Rijksmuseum Kröller-Müller, Otterlo

9. Yves Gaucher, Le Cercle de Grande Reserve (1965), canvas, 215.9 x $215.9 \mathrm{~cm}$, AGO

10. Yamasee (1988), oils and quill on canvas, $235.0 \times 235.0 \mathrm{~cm}$, WAG

11. Parfleches for the Last Supper, (1983), acrylic, porcupine quills. $56 \times 56 \mathrm{~cm}$, WAG

a. Parfleche \# 1 Matthew

b. Parfleche \# 2 James the Less

c. Parfleche \# 3 Jude 

d. Parfleche \# 4 Simon
e. Parfleche \# 5 Philip
f. Parfleche \# 6 Andrew
g. Parfleche \# 7 Bartholomew
h. Parfleche \#8 Thomas
i. Parfleche \# 9 James
j. Parfleche \#10 John
k. Parfleche \# 11 Judas
1. Parfleche \# 12 Jesus
m. Parfleche \# 13 Peter

12. The Place Where God Lives (1989), oil on canvas, 4 panels, each $244.0 \times 182.4 \mathrm{~cm}$, NGC

13. Seven in Steel (1989), oil on steel and maple, $130.9 \times 644.0 \times 9.5 \mathrm{~cm}$ overall, NGC

14. Sandy Bay (1998-1999), oil on canvas, two photos drymounted on masonite, approx. $300.0 \times 550.0 \mathrm{~cm}$ (whole installation), WAG

\section{Chapter III}

\section{All works by Otto Rogers unless stated otherwise.}

15. El Greco Fervor (1986), acrylic on canvas, $152.4 \times 152.4 \mathrm{~cm}$, Private collection, Toronto, Ontario

16. Untitled (Still Life) (1961), gouache on paper, $76.0 \times 55.7 \mathrm{~cm}$, WAG. Image courtesy WAG.

17. Mark Tobey, Meditative Series VIII (1954), tempera, 45.4 x $30.2 \mathrm{~cm}$, Private collection

18. Cloud Rotation (1970), acrylic on canvas, $152.5 \times 213.5 \mathrm{~cm}, \mathrm{CCAB}$

19. Sunset Stillness (1966), oil on canvas, 152.4 x $152.4 \mathrm{~cm}$, MAG

20. Harris, Lake Superior (c. 1924), oil on canvas, $102 \times 127.3 \mathrm{~cm}$ AGO

21. Movement of Light through Darkness (1981), acrylic, modelling paste and charcoal on canvas, $183 \times 152.8 \mathrm{~cm}$, MAG

22. Hilma af Klint, Group 6, No. 15 from the Series W.U.S./Pleiad (1908), oil on canvas, 104 x $134 \mathrm{~cm}$, Stiftelsen Hilma af Klints Verk

23. Ascending Landscape (1980), acrylic, charcoal, paper collage, $77.5 \times 56.7 \mathrm{~cm}$, MAG 
24. Approaching the Shore of the Sea of Grandeur (1981), acrylic and charcoal on canvas, $152.9 \times 177.8 \mathrm{~cm}$, MAG

25. Bertram Brooker, Sounds Assembling (1928), oil on canvas, 113.0 x $91.4 \mathrm{~cm}$, WAG

26. In Celebration of the Nightingale's Song (1981), acrylic and charcoal on canvas, $152.6 \times 183.4 \mathrm{~cm}, \mathrm{MAG}$ 


\section{INTRODUCTION}

Within the discipline of Canadian art history, the spiritual significance of the landscape in the art of the first part of the twentieth-century, as well as the relationship between certain spiritual ideologies and abstraction have been examined extensively in the work of several artists. ${ }^{1}$ However this investigation has only been extended to the study of contemporary Canadian art to a limited degree. As these relationships are still relevant today, it is timely to apply this line of inquiry to the work of contemporary Canadian artists. This thesis will address that void by investigating the spiritual meaning in the landscape works of two artists: Robert Houle (b. 1947) and Otto Rogers (b. 1935). Houle and Rogers have repeatedly demonstrated in their work that they have spiritual aspirations which they wish to convey to their respective audiences. In fact, it is no longer adequate to discuss their works from a purely formal point of view; instead, a thorough understanding of their work necessitates an exploration of the topic of spirituality.

Robert Houle was born in St. Boniface, Manitoba, into a Saulteaux (or Plains Ojibway) family. Most of his childhood was spent in a Catholic residential school at the Sandy Bay Indian Reservation. Rogers was born and raised on a farm near Kerrobert, Saskatchewan, by a family that was Protestant Christian but not affiliated with a specific

\footnotetext{
${ }^{1}$ Such as Lawren S. Harris, Emily Carr, Bertram Brooker and Lionel LeMoine FitzGerald.
} 
denomination. Since 1960 Rogers has been a member of the Bahá'í Faith. Despite their obvious differences - in terms of cultural background and spiritual ideology - these two artists have much in common. Perhaps the most obvious experience they share is that both were born and raised in the flat landscape of the Canadian prairies. But there are other important points of convergence. First, an interest in spirituality as inflected by their respective cultural and religious beliefs is a common trait. Secondly, they both understand the land to be of spiritual significance, either in reflecting another reality or in its interconnectedness with spiritual health. Hence it is not surprising that the landscape motif, most often recalled simply through the use of a horizon line in an otherwise abstracted composition, features so prominently in both of their works. Landscape features are employed by both artists to convey some of the spiritual concepts they see as important. Finally, they also share a commitment to abstracted representation as central to their formal vocabulary.

Whenever landscape works of a spiritual nature have been discussed, throughout the history of art both in Canada and internationally, the treatment has been almost exclusively confined to artists from the Judeo-Christian tradition or those artists who where interested in the anti-materialist ${ }^{2}$ movements that became popular towards the end

\footnotetext{
${ }^{2}$ According to Maurice Tuchman, "visual artists, from the generation born in the 1860 s to contemporary times, have turned to a variety of antimaterialist philosophies..." All of these philosophies share "concepts of mysticism or occultism." He further states that for artists and art historians "mysticism refers to the search for the state of oneness with ultimate reality. Occultism depends upon secret, concealed phenomena that are accessible only to those who have been appropriately initiated." Among these anti-materialist philosophies are Theosophy, Anthroposophy, Rosicrucianism and Transcendentalism. "Hidden Meanings in Abstract Art," Tuchman et.al., The Spiritual in Art: Abstract Painting 1890-1985, (New York: Abbeville Press, 1986), 19.
} 
of the nineteenth century and the beginning of the twentieth century, such as Theosophy and Transcendentalism. Similarly, the documentation in the literature of art history with regards to spirituality in the works of nineteenth- and early twentieth-century Symbolist and abstract artists is almost exclusively concerned with the influence of Theosophy, Rosicrucianism and Anthroposophy. A study of the philosophical stances of Houle and Rogers will expand the scholarship to be more reflective of the diversity of the Canadian population and some of the other spiritual beliefs that influence its artists today. In particular it will allow for a discussion of some of the oldest spiritual teachings and a look at one of the newest religious movements shaping the spiritual life and the artistic output of some of Canada's artists.

A review of the existing literature will show that scholarly studies have repeatedly sought to prove the intrinsic link between landscape and spirituality, as well as that among spirituality, landscape and abstraction in the work of Canadian artists of the first part of the twentieth century. The first comprehensive study linking the mystical concerns of a Canadian artist with landscape was Jeremy Adamson's 1978 study Lawren S. Harris: Urban Scenes and Wilderness Landscapes 1906-1930. Adamson traces Harris's spiritual search, starting in his student years in Germany with his introduction to 
anti-materialist philosophies such as Transcendentalism and Theosophy. He discusses how the artist turned to landscape to express inner perceptions of a mystical reality. ${ }^{3}$

Whereas Adamson looks at the first part of Harris's artistic career, in a 1985 study Dennis Reid examines his later work. Atma Buddhi Manas: The Later Work of Lawren S. Harris is particularly concerned with the artist's struggle between his love for the land and its representational depiction on one hand and, on the other, the use of abstracted forms as suggested in Theosophical writings. Reid demonstrates that Theosophy was the most important influence in Harris's work and recounts how the artist eventually moved toward abstraction to express the interconnectedness of all things. ${ }^{4}$

In 1992 Ann Davis extended the study of Canadian mystical painting to include four other artists besides Harris: Emily Carr, Fred Varley, Bertram Brooker, and Jock Macdonald. In her Logic of Ecstasy: Canadian Mystical Painting 1920-1940 Davis states that an understanding of the mystical experiences and ideas of these artists is necessary to appreciate their different artistic approaches. She establishes a clear link between their interest in spiritual philosophies and their love for the Canadian landscape. Davis identifies several different strands of mysticism which affected the art and life of

\footnotetext{
${ }^{3}$ Jeremy Adamson, Lawren S. Harris: Urban Scenes and Wilderness Landscapes 1906-1930, (Toronto: Art Gallery of Ontario, 1978). There are also earlier studies that link Theosophy to Harris's artistic output such as Dennis Reid's article "Lawren Harris," Artscanada, Vol. 25, no. 5 (Dec 1968), 9-16.

${ }^{4}$ Dennis Reid, Atma Buddhi Manas: The Later Work of Lawren S. Harris, (Toronto: Art Gallery of Ontario, 1985).
} 
these five painters. It was the influence of these mystical theories that led the four artists she examines to depict the landscape repeatedly. ${ }^{5}$

In 1984 Roald Nasgaard in his exhibition catalogue The Mystic North: Symbolist Landscape Painting in Northern Europe and North America 1890-1940, discusses how Symbolist artists moved toward the depiction of a figure-free landscape that would give expression to their mystical interests. Nasgaard establishes the existence of a common interest between the Northern European and North American artists in implying the existence of unseen meanings in their landscape images. Through his study a continuous chain of influence is forged from the artists of the Northern Romantic movement to the members of Canada's Group of Seven - all shared an interest in spirituality and used the landscape as a metaphor to express it. ${ }^{6}$

Other studies have carried this line of inquiry into the second half of the twentieth century. Though it does not address Canadian artists, Robert Rosenblum's influential study, Modern Painting and the Northern Romantic Tradition: Friedrich to Rothko (1975), provides a useful link between the Northern Romantic figurative strain represented by Caspar David Friedrich and other painters of his generation to the Abstract Expressionists. Rosenblum discusses the importance of landscape in the

${ }^{5}$ Ann Davis, The Logic of Ecstasy: Canadian Mystical Painting 1920-1940, (Toronto: University of Toronto Press, 1992).

${ }^{6}$ Roald Nasgaard, The Mystic North: Symbolist Landscape Painting in Northern Europe and North America 1890-1940, (Toronto: University of Toronto Press, 1984). 
expression of spiritual ideas in the works of many artists starting with Friedrich and extending to the anti-realist and anti-materialist interpretations of Barnett Newman, Mark Rothko and other Abstract Expressionists, all of whose work is rooted in Symbolism. They all were interested in exploring spiritual themes in their works but without making use of the usual iconography associated with religious subject matter. What distinguished this second generation of American abstract artists was their engagement with such diverse non-Christian sources as Native art, Zen, and the Jewish Kabbalah. ${ }^{7}$

There are a few, yet significant studies that have considered spirituality in the works of contemporary Canadian artists. The National Gallery of Canada made an important contribution to this field of inquiry in 1992 when it organized its first major international exhibition of contemporary art produced by Native North American artists. Land, Spirit, Power: First Nations at the National Gallery of Canada, co-curated by Diana Nemiroff, Robert Houle and Charlotte Townsend-Gault, acknowledges the land as an important element in the work and life of contemporary artists of Native ancestry. The authors recognize that this recurring theme has not only political ramifications but also spiritual ones for these artists. ${ }^{8}$ Partly due to the fact that the exhibition looks at artists with a Native heritage, it allows for a brief exploration into the spiritual ideologies of some artists who are not necessarily from a purely Judeo-Christian background or

\footnotetext{
${ }^{7}$ Robert Rosenblum, Modern Painting and the Northern Romantic Tradition: From Friedrich to Rothko, (New York: Harper \& Row, 1975).

${ }^{8}$ Diana Nemiroff, et.al., Land, Spirit, Power: First Nations at the National Gallery of Canada, (Ottawa: National Gallery of Canada, 1992).
} 
followers of those anti-materialist philosophies that became popular around the turn of the nineteenth century.

Another example in recent Canadian scholarship is Maureen Korp's 1991 Ph.D. dissertation entitled "Earthworks: Shamanism in the religious experiences of contemporary artists in North America.” Korp investigates whether contemporary earthworks are a religious statement by the artists who make them, just as earlier, archaic earthworks are agreed to have had a spiritual function. ${ }^{9}$ Her study is significant as it looks at the work of contemporary North American artists, their attitudes toward the land and their spiritual/religious experiences.

In the past thirty years, there has been a growing literature dealing with abstraction as a means to express metaphysical ideas. A 1985 exhibition at the Los Angeles County Museum of Art, The Spiritual in Art: Abstract Painting 1890-1985, was devoted exclusively to this subject. The accompanying exhibition catalogue discusses at great length many themes related to this topic, including the influence of Symbolist art as well as Theosophy, Anthroposophy, and Rosicrucianism, the Jewish Kabbalah, and North West-Coast Aboriginal art on the works of many of the leading abstractionists in Europe, the United States and Canada. Maurice Tuchman, the curator and editor of the exhibition catalogue, firmly believes that the development of abstract art was tied to spiritual ideas

\footnotetext{
${ }^{9}$ Maureen Korp, "Earthworks: Shamanism in the religious experience of contemporary artists in North America," (Ph.D. diss., Ottawa University, 1991), Vol. I.
} 
as artists yearned to express deeper ideas with a new language_-one that would no longer rely on traditional pictorial terms. ${ }^{10}$

Important earlier studies that established a solid relationship between mystical teachings and abstraction include Sixten Ringbom's article "Art in 'the Epoch of the Great Spiritual': Occult Elements in the Early Theory of Abstract Art," (1966). Here the author establishes the influence of Anthroposophy and Theosophy on artists such as Kandinsky, Franz Marc, Paul Klee and Piet Mondrian. He explains that the age-old pictorial terms were no longer sufficient for what these artists hoped to convey. Communicating otherworldly realities with depictions of the material world in figural terms was not a satisfactory solution and hence they moved toward non-objective art. ${ }^{11}$

As demonstrated above, there is a body of literature that has established connections between spirituality and landscape as well as among spirituality, landscape and abstraction. Likewise, literature specifically on Houle and Rogers, as well as the artists' own writings and statements, make mention of their interest in spirituality and the evocation of the landscape in their art. Houle is convinced that spirituality is necessary for the survival of his culture. His Native culture inextricably binds spirituality and the land together. In his essay for the Land, Spirit, Power: First Nations at the National

\footnotetext{
${ }^{10}$ Maurice, Tuchman, "Hidden Meanings in Abstract Art."

${ }^{11}$ Sixten Ringbom, "Art in the 'Epoch of the Great Spiritual': Occult Elements in the Early Theory of Abstract Painting." Journal of the Warburg and Courtauld Institutes 29, (1966), 386-418.
} 
Gallery of Canada exhibition catalogue he makes the reader aware that many Western societies have lost a sense of the sacredness of nature. ${ }^{12}$ With his art, Houle hopes to rekindle this sense of sacredness toward the land. For an earlier project, Houle interviewed several First Nations artists in the United States and Canada and found that, despite their differences, the sacred relationship to the land was a common bond. ${ }^{13}$

For Houle, the land - due to its spiritual significance and because of its importance to survival - takes on a political dimension, and this is an aspect of his art that has been discussed frequently and at length. However, his continual use of references to both Christian theology and Sun Dance traditions in his art proves that the artist is very much influenced by and interested in expressing spiritual ideas. In her essay for the exhibition catalogue Robert Houle: Indians from A to Z (1990), Clara Hargittay states that Houle's 1983 work Parfleches for the Last Supper, for example, successfully combines the artist's two-at times opposing — spiritual traditions. With regards to his continued interest in the land she writes, "he is profoundly aware of the interconnectedness of man and nature, and he is not afraid to find spirituality in the land."14 In the same catalogue, curator Shirley Madill states that there are new perceptions of spirit in twentieth-century culture and that these have had an impact on contemporary art, including the work of Robert

${ }^{12}$ Robert Houle, "The Spiritual Legacy of the Ancient Ones," in Nemiroff, Diana, et.al., Land, Spirit, Power: First Nations at the National Gallery of Canada, 48.

${ }^{13}$ Robert Houle, "Sovereignty over Subjectivity," C Magazine, (summer 1991), 30.

${ }^{14}$ Clara Hargittay, "Robert Houle: His Creative and Spiritual Journey, 1980-1990," in Winnipeg Art Gallery, Robert Houle: Indians from A to Z, (Winnipeg, 1990), 14. 
Houle. ${ }^{15}$ Another contributor to the exhibition catalogue, curator and artist Gerald McMaster, explains that Houle's search for spirituality led him first to the art of modern artists such as Mondrian, but that the artist later discovered that a closer understanding of the land was what he was really looking for. ${ }^{16}$ In 1999 writer Peggy Gale, in her essay for the exhibition catalogue Robert Houle: Sovereignty over Subjectivity, confirms that the land continues to be of great importance to the artist and his art. ${ }^{17}$

Similarly, Rogers's works have been termed "landscapes of the soul" by art critic Robert Enright. ${ }^{18}$ Curator Terrence Heath in turn referred to them as "cosmic landscapes." ${ }^{\prime 19}$ Although the artist does not see himself as a landscape or prairie painter, the landscape or some of its essential features are his most important means of expressing metaphysical subject matter. Rogers himself has reiterated the importance of the landscape as a perfect metaphor for the spiritual. In his own writings, as well as in numerous interviews, Rogers has expressed the importance of his religious beliefs to his art. The artist believes that contemplation of many of the teachings and principles of the Bahá'í Faith, especially the concept of "unity," has directed him in his art. In addition, he is convinced of the general importance of the arts for uplifting souls.

\footnotetext{
${ }^{15}$ Shirley Madill, "Robert Houle: A Dual State of Being," in Winnipeg Art Gallery, Robert Houle: Indians from $A$ to $Z, 22$.

${ }^{16}$ Gerald McMaster, "The Persistence of Land Claims," in Winnipeg Art Gallery, Robert Houle: Indians from $A$ to $Z, 39$.

${ }^{17}$ Peggy Gale, "Robert Houle: Recording," in Winnipeg Art Gallery, Robert Houle: Sovereignty over Subjectivity, (Winnipeg, 1999), 23.

${ }^{18}$ Robert Enright, "Landscapes of the soul," MacLean's, (11 Oct. 1982), 71.

${ }^{19}$ Terrence Heath, "The Cosmic Landscapes of Otto Rogers," Artscanada, Vol. 30, no. 1 (Feb./Mar. 1973), 28-33.
} 
In an exhibition catalogue of 1982, Otto Rogers: A Survey 1973-1982, Norman Zepp states that any discussion of Rogers's work has to consider three elements: formalism, landscape and religion. He believes that an analysis that ignores any of these elements would be incomplete. He sets out to understand whether Rogers is primarily a formalist, a landscape artist, or a religious painter. ${ }^{20}$ Although Zepp touches on all of these areas, a deeper exploration, especially regarding the influence of Rogers's religious beliefs and repeated use of the landscape motif, is necessary.

This thesis will argue that a more precise and detailed analysis of the nature of the spiritual beliefs of both Houle and Rogers is necessary for a proper understanding of their achievements. In addition, a discussion of their view of the land will help determine why the landscape acts as a powerful metaphor for spirituality in their works. Moreover, the thesis will show that their work cannot be understood in isolation, but should be placed in relation to the tradition of mystical abstract painting both in Canada and internationally.

This thesis relies upon texts and scholarship of spiritual and religious traditions as well as strictly art-historical literature. A link will be made between these philosophical studies and purely art historical texts, such as those mentioned above, on landscape, spirituality and abstraction. The spiritual traditions of the Western Ojibway people will

${ }^{20}$ Norman Zepp, "Formalism, landscape and religion in the painting of Otto Rogers," in Mendel Art Gallery, Otto Rogers: A Survey 1973-1982,(Saskatoon, Saskatchewan, 1982), 26. 
be examined, particularly to understand their attitude toward the land. It will become apparent that through colonization, the influence of Christianity and the passage of time, these traditions have evolved. The thesis will show to what extent Native spiritual traditions and Christianity have together influenced Robert Houle's thinking and artistic output. It will also allow for a clear understanding of the importance of the land in Native spiritual traditions and as a result in his work. In turn, a study of the Bahá'í teachings will be undertaken, with emphasis on those that seem that have had the greatest impact on Otto Rogers's artistic output. A look at the artist's childhood will reveal that his association with nature led him to become an active seeker of spirituality. Therefore, a brief discussion on the Bahá'í attitude toward the physical world is also included. The bulk of the discussion, however, concentrates on an analysis of the works of the two artists and their use of spiritual symbolism in their art. This interdisciplinary study is of an analytical nature, synthesizing formal, spiritual and philosophical ideas. Conclusions will be based on a review of the existing literature, interviews with the artists, and, most importantly, a detailed visual analysis of some of their key works. Additional data and information gathered at several art institutions and galleries make up a good portion of the primary and secondary data.

The first chapter will examine the influence of anti-materialist philosophies on Canadian artists in the earlier twentieth century, and the roots of their landscape painting in the Northern Romantic tradition, in order to show both continuities and divergence in 
the later work of Houle and Rogers. It will also look at how an interest in anti-materialist philosophies led artists at the end of the nineteenth and the beginning of the twentieth centuries toward non-figurative art, art that was devoid of any reference to the material world. This spiritual reading of abstraction, which until recently was eclipsed by formalist interpretations, will be shown to have direct relevance to Houle's and Rogers's own understanding of their intentions.

In the second and third chapters respectively, a theoretical basis from which to discuss the works of Houle and Rogers will be established. It will discuss the philosophical stances of the artists. Their definition of spirituality is examined through the artists' works and voices-Houle's in light of the syncretic nature of Ojibway traditions due to the Catholic influence and Rogers's in relation to his belief in the Bahá'í teachings. However, a comprehensive study of Ojibway and Bahá'í spiritual beliefs is beyond the scope of this thesis. Both artists' attitudes toward the land are explored, taking into account their upbringing in the prairie landscape and the spiritual ideologies that shape their lives. Several of their works that illuminate the spirituality-landscape framework will be discussed at length, synthesizing their formal, spiritual and philosophical aspects.

The conclusion of the thesis will focus on how the work of Houle and Rogers can be situated within the art-historical tradition of the twentieth century. It will also 
conclude that spirituality and the landscape motif, albeit in an abstracted form, have been and are continuing to be closely meshed together in the work of contemporary Canadian artists. It will make the reader aware that the subject of spirituality is of ongoing vitality in the art world both in Canada and in an international context. 


\section{CHAPTER I}

\section{HISTORICAL UNDERPINNINGS:}

\section{LANDSCAPE AND ABSTRACTION AS MODERN SPIRITUAL LANGUAGES}

Close your bodily eye, so that you may see your picture first with the spiritual eye. ${ }^{1}$

Robert Houle and Otto Rogers are two contemporary Canadian artists who have repeatedly demonstrated an interest in conveying their spiritual aspirations in their art. The chief vehicle for the expression of these concepts for both artists is landscape, usually in an abstracted form. This chapter will argue that their choice of the landscape to convey their respective approaches to spirituality is not an isolated one. The modern history of art in Canada, Europe and the United States has a long tradition of artists using the landscape to express spirituality. Similarly, the more recent history of abstraction in visual art is linked to the rise of interest in anti-materialist philosophies. Ultimately it will become evident that the spiritual aspirations and interests of some artists are crucial to the understanding of their works of art.

In Canada before World War II there were several well-known Canadian artists who expressed a sense of spirituality through the depiction of the landscape. Among these are Lawren S. Harris, Emily Carr, Fred Varley, Bertram Brooker, and Jock Macdonald. The landscape was a point of departure for all of them and was an integral

\footnotetext{
${ }^{1}$ Caspar David Friedrich, as quoted in Roald Nasgaard, The Mystic North: Symbolist Landscape Painting in Northern Europe and North America 1890-1940, (Toronto: University of Toronto Press, 1984), 9.
} 
part of their search for a new mystical visual language. Each of them was involved to a certain degree with one or more of the various Christian churches, Transcendentalism, Theosophy, or Anthroposophy. Some of their most celebrated works are those which they approached with spiritual aspirations and these have been described by art historian Ann Davis as "launching pad[s] for the spirit."

Transcendentalism had a profound effect not only on these artists, but on all of North America as well. According to Davis, that form of Transcendentalism propounded by Walt Whitman was of particular interest to Canadian artists such as Carr, Harris, Macdonald and Brooker. ${ }^{3}$ One dominant aspect of his ideas that appealed to these artists is his assertion that closeness to nature is necessary to bring the best out in individuals. Whitman promoted the idea that nature is formed and informed by the spirit, meaning that every tree, mountain or lake is a symbol of a greater spiritual reality, and that God not only created nature but also is immanent in nature. Therefore for Transcendentalists the physical world acted both as "fact and symbol." Whitman was also convinced that a divine unity pervaded all art and all life and that great art reflects reality. ${ }^{5}$ Such ideas provided a clear call for these artists to engage fully with the Canadian landscape. For example, we are reminded of the numerous northern sketching trips Harris, MacDonald

\footnotetext{
2 Ann Davis, The Logic of Ecstasy: Canadian Mystical Painting 1920-1940, (Toronto: University of Toronto Press, 1992), preface, i-xvii.

${ }^{3}$ Although Ralph Waldo Emerson and David Henry Thoreau are more readily associated with Transcendentalism, according to Ann Davis, Whitman's writings were more influential to the thinking of these Canadian artists.

${ }^{4}$ Ibid., 62.

${ }^{5}$ Donald N. Koster, Transcendentalism in America, (Boston: Twayne Publishers, 1975), 63.
} 
and the other members of the Group of Seven undertook, starting in 1914 with a trip to Algonquin Park, resulting in some of the best-known landscape paintings in Canadian art.

To look for tangible effects of transcendental theories in the art of these Canadian artists is difficult. Their influence according to Davis, unlike that of Theosophy, was of a purely philosophic nature and hence one cannot find any specific transcendental iconography in their art. Its impact is mostly discernible in the writings and attitudes of the artists. For example, reading Transcendentalist writings reinforced Harris's fondness for the Canadian landscape. On numerous occasions he wrote about the invigorating and healing powers of the land and especially those of the North. Harris, reflecting ideas found in Transcendentalism, believed that "visible nature is but a distorted reflection of a more perfect world..." His painting From the North Shore, Lake Superior (1923) [Fig. 1] is an attempt to show the viewer more of that perfect world by combining "fact and symbol." Harris's approach to landscape draws on empirical evidence; as the title suggests, he refers to a specific, "factual" site. Yet it is also symbolic, because the artist has deviated significantly from the actual scene, colour and mood to create an otherworldly feeling, especially through the use of "unnatural clouds and unexpected light."

\footnotetext{
${ }^{6}$ Harris as quoted in Davis, Logic of Ecstasy, 62.

${ }^{7}$ Davis, Logic of Ecstasy, 62.
} 
Another Canadian artist who was a great admirer of Whitman was Emily Carr. Besides the example of the Native people of the West Coast, whom Carr believed to have an inherent understanding of nature due to their close association with it, her search for the spirit of nature was helped along by Whitman's writings as Davis has demonstrated. They taught her, in particular, to seek the "flowing urge of life" repeatedly tried to translate into visual form. Her 1933 painting The Mountain [Fig. 2] for example, captures this urge of life, created through a sense of movement and growth. ${ }^{9}$

The desire of these Canadian artists to express their spiritual aspirations through the depiction of their landscape was shared with their spiritual predecessors in Europe - the artists of the Northern Romantic movement. These artists were in search of a new language to express religious devotion. They decided that the landscape was a wellsuited symbol for evoking spiritual or mystical responses. As early as the 1760 s and 1770 s, northern European artists turned to natural sites that would elicit awe and wonder to prove the mightiness of God to their audiences. One can see in their paintings a move away from anthropocentric depictions, towards the portrayal of a sublime landscape that would dwarf the human or animal staffage depicted.

\footnotetext{
${ }^{8}$ Emily Carr commenting on Fred Housser's manuscript Whitman to America, as quoted in Davis, Logic of Ecstasy, 53.

${ }^{9}$ Davis, Logic of Ecstasy, 52-57.
} 
The German Romantic painter Caspar David Friedrich (1774-1840) was one of the artists who, in the increasingly secular world of the 1800 s, tried to revive spirituality through the use of new images. Traditional themes such as the Adoration and the Crucifixion needed, in his view and in that of his contemporaries such as Philip Otto Runge (1777-1810) and William Blake (1757-1827), to be exchanged for new images that would convey spiritual experience in the Age of Enlightenment. Leaving traditional Christian iconography behind, these artists instead used landscape or everyday situations and converted them into scenes addressing time-honoured Christian subjects. ${ }^{10}$ For example, in 1808 Friedrich painted the altarpiece The Cross in the Mountains [Fig. 3] depicting a sculpture of the crucified Christ in a rugged Nordic landscape. Simon Schama explains that German critics attacked Friedrich's work, complaining that it obliterated the difference between sacred art and landscape painting. Friedrich supplied his critics with the explicit meanings of his symbols, where, for example, the fir trees stand for the eternal life that is granted by the Resurrection. ${ }^{11}$ Such explicit use of landscape features to supplant Christian iconography was augmented by the employment of more general spiritual themes. Friedrich's image Monk by the Sea (1809) [Fig. 4] is one such example. It features a miniscule figure in a vast, almost featureless landscape. Here the artist was striving to represent nature in such a way as to evoke the grandeur and power of God. ${ }^{12}$

${ }^{10}$ Robert Rosenblum, Modern Painting and the Northern Romantic Tradition: Friedrich to Rothko, (New York: Harper \& Row, 1975), 14-15.

${ }^{11}$ Simon Schama, Landscape and Memory, (New York: Vintage Books, 1995), 207, 238.

${ }^{12}$ Rosenblum, Modern Painting, 14. 
Like Northern Romanticism, the Symbolist movement at the end of the nineteenth century also used landscape as a vehicle to convey spiritual ideas. Although originally a literary movement, Symbolism took hold in the visual arts. It arose in reaction to the positivist and scientific ideologies that pervaded the nineteenth century and were particularly evident in Naturalist art and literature. This prompted some artists to explore more mystical subjects such as inner states of being and to develop a reduced formal vocabulary. Symbolist artists were now primarily concerned with "objectify[ing] the subjective (the exteriorization of the idea)"13 and were no longer interested in copying nature mimetically. Landscape painting was considered a minor genre in Symbolism. However, for Symbolist-influenced Post-Impressionists such as Seurat, van Gogh, Gauguin and the Nabis in France, as well as Symbolists outside of France, especially in northern Europe, such as Edvard Munch and Ferdinand Hodler, the landscape continued to be the primary subject matter. According to art historian Roald Nasgaard, "the true Symbolists do not so much search out new themes and subjects as invest the given ones with subjective and transcendental meaning." ${ }^{\prime 4}$ Hence instead of investing figurative subjects with a mystical mood, they employed the landscape to that end. The wilderness landscape in particular appealed to them, as they regarded it a place for spiritual revelation.

${ }^{13}$ Symbolist poet and critic Gustav Kahn, as quoted in Nasgaard, Mystic North, 5.
${ }^{14}$ Nasgaard, Mystic North, 5 . 
This sentiment could also be found among Canadian artists. Scholarship shows that there is a definite link between Scandinavian and Canadian Symbolist painting. Symbolist landscape painting came to the fore in about 1890 in Scandinavia and after 1913 in Canada when, according to Nasgaard, it became "the pre-eminent national style." The Scandinavian Symbolists chose the "brave barren promontories, impenetrable forests, and high mountain peaks in order to produce new work that depended on the cleansing effect of unspoiled wilderness." Their choice of composition, subject matter and ideology reflected those of the earlier Northern Romantic artists such as Friedrich, creating a historical continuum over two centuries. ${ }^{15}$

In Canada, artists such as Tom Thomson and the Group of Seven could readily identify not only with the use of wilderness landscape but also with the general interest in transcendental ideas as expressed in Scandinavian Symbolist art. Another idea that bound these groups together was the belief that the North was the source of both spiritual and cultural revival; this belief was supported by Theosophical thought which interested Lawren Harris. Crucial to the transfer of ideas from northern Europe to Canada was the 1913 Armory Show in Buffalo, New York visited by Harris and J.E.H. MacDonald. There they saw in the landscape art of the Scandinavians a model that fulfilled both their nationalistic and their spiritual aspirations. In what Nasgaard terms the second phase of the northern Symbolist landscape tradition, which he considers continued in Canada and

${ }^{15}$ Ibid., 4, 6. 
the United States from about 1919 to 1940, the artists had the same intention as their predecessors: to use the depiction of the landscape as a metaphor for the supernatural. What distinguishes it from other portrayals of the landscape is that it "possesses an inner coherence based on striving for the expression of affective or transcendental content through close communion with an intimately experienced landscape."16

Symbolism was one of the crucial movements in the development of modern art, as it provided an important stepping stone toward non-representational art. Symbolist works set the stage for artists such as Wassily Kandinsky (1866-1944). Symbolist artists were interested in representing subjects other than those found in the tangible world. They moved away from traditional iconography hoping to go beyond an object's literal meaning. Their aim was to delve into an ideal world and render the invisible in a way that would make it visible. The newly employed forms and symbols were meant to convey new and often transcendental meanings to their viewers. ${ }^{17}$ One natural outcome was the use of reduced forms and pure colours, leading to abstraction. Hence the inchoate abstraction of the Symbolists was - next to an interest in spirituality-one of the decisive influences that led subsequent generations of artists to pure abstraction. ${ }^{18}$

\footnotetext{
${ }^{16}$ Ibid., 7-8.

${ }^{17}$ The term transcendent has been defined as, "transcending the universe or material existence," as opposed to immanent which is described as meaning "inherent...having existence or effect only within the mind or consciousness." Merriam Webster's Collegiate Dictionary, $10^{\text {th }}$ ed. (Springfield, MA: Merriam Webster Inc., 1994), 1253, 579.

${ }^{18}$ An example of a work by a Symbolist artist can been seen in the painting of the Dutch artist Johan Thorn Prikker (1868-1932) The Bride of Christ (1892-93). Although the bride is depicted in an abstracted form, yet the painting also contains more readily recognizable references to the natural world such as leaves.
} 
Besides the link that has been established between spirituality and landscape, recent art historical scholarship has also provided ample proof that anti-materialist philosophies propelled artists to make a decisive move toward non-representational art. One of the earliest studies that established an undeniable link between abstract art and occult teachings was that undertaken by Sixten Ringbom in 1966. Ringbom links Kandinsky, Franz Marc, Paul Klee and Mondrian in particular to the occult, to Theosophy and to Anthroposophy. ${ }^{19}$ More recent studies include the numerous essays included in the exhibition catalogue accompanying the exhibition organized by Maurice Tuchman entitled The Spiritual in Art: Abstract Painting 1890-1985.

In Canada, Lawren Harris was the artist of the twentieth century most openly committed to Theosophy; as a result his work grew increasingly more abstract over his career. Harris wrote and lectured extensively on art and Theosophy and tried to reflect its teachings in his art until the end of his life. The International Theosophical Society was founded in New York in 1875; its most influential founding member was Mme. Helena Petrovna Blavatsky (1831-1891). Theosophy is a blend of Eastern and Western thought. Perhaps its strongest influence on artists can be found in the doctrine of colour, which

${ }^{19}$ Sixten Ringbom, "Art in 'the Epoch of the Great Spiritual': Occult Elements in the Early Theory of Abstract Art," Journal of the Warburg and Courtauld Institutes, Vol. 29, 1966, 386-418. Other early studies: Rose-Carol Washton Long, "Kandinsky and Abstraction: The Role of the Hidden Image," Artforum 10 (June 1972), 42-49; and Kandinsky: The Development of an Abstract Style, (Oxford: Clarendon Press, 1980); Robert P. Welsh, Piet Mondrian 1872-1944, (Toronto: Art Gallery of Ontario, 1966); and Welsh, "Mondrian and Theosophy," In Piet Mondrian 1872-1944: A Centennial Exhibition. (New York: Solomon R. Guggenheim Museum, 1971); and Rosenblum, Modern Painting. An even earlier study linking artists such as Kandinsky to Theosophy is Terrence Harold Robsjohn-Gibbings's book Mona Lisa's Mustache: A Dissection of Modern Art. (New York: Alfred A. Knopf, 1947). This book does not, however, provide a detailed analysis of works as for example Ringbom's study does. 
some, like Harris, adopted in their art. The British Theosophical teachers Annie Besant and C. W. Leadbeater wrote Thought Forms (1901) which related each of the "seven strata of consciousness" to a particular colour. For example, their colour chart suggests that the red shades are associated with emotion and sensuality and blue tones are regarded as being spiritual in nature. ${ }^{20}$ Another aspect of Theosophy that worked itself into the art of its followers was its teachings on the symbolism of geometric form or "sacred geometry." Blavatsky in her The Secret Doctrine (1888) explains the significance of triangles, crosses, circles and squares. ${ }^{21}$ These charts and writings gave artists who were interested in Theosophy tangible examples of how to construct non-objective paintings that would make no reference to the material world, yet intimate the spiritual one.

Harris used the colour theory suggested by Theosophical writings as well as geometric forms such as circles and triangles in his paintings. They can be found regularly in his abstractions but also, perhaps in a more concealed way, in his later landscape works. Not only did Theosophy help Harris to move toward abstraction by using the suggested thought forms and colour symbolism, but its underlying philosophy - the emphasis on the spiritual rather than the material, the universal rather than the particular-had helped Harris detach himself from the landscape and embrace abstraction, resulting in such works as Composition No. 1 [Fig. 5] of 1941. However, his interest in abstraction does not diminish the importance of landscape to his work. In fact,

\footnotetext{
${ }^{20}$ Jeremy Adamson, Lawren S. Harris: Urban Scenes and Wilderness Landscapes 1906-1930, (Toronto: Art Gallery of Ontario, 1978), 132-133.

${ }^{21}$ Davis, Logic of Ecstasy, 101.
} 
most art historians agree that Harris's abstract works are dependent on earlier transcendental landscapes of the North Shore, the Rocky Mountains and the Arctic or argue that the forms seem to be derived from natural processes such as erosion or crystallization. ${ }^{22}$

Brooker was also influenced by Theosophy and was particularly interested in the concept of synaesthesia, which suggests the confluence of the senses. He, for example, experimented with music as a source for initiating abstract art in such works as Abstraction-Music (c. 1927). ${ }^{23}$

In Europe, Kandinsky was another artist who made use of the concept of synaesthesia and was interested in how one art form could evoke another. Synaesthesia appealed to Kandinsky, because he himself had experienced the evocation of colours while listening to Richard Wagner's Lohengrin. ${ }^{24}$ His spiritual and artistic legacy is summarized in his book Concerning the Spiritual in Art (1912) which had a profound effect on generations of artists. Among the ideas that Kandinsky expresses in his book is the belief that the end of the nineteenth and the beginning of the twentieth century mark the beginning of one of the greatest spiritual epochs in the life of humanity and hence he terms it the "Epoch of the Great Spiritual." For him, the role of the arts and the artist are

\footnotetext{
${ }^{22}$ Adamson, Lawren S. Harris, p. 203, Dennis Reid, Atma Buddhi Manas: The Later Work of Lawren S. Harris, (Toronto: Art Gallery of Ontario, 1985), 25, 26, 50 and Christopher Jackson, North by West: The Arctic and Rocky Mountain Paintings of Lawren Harris 1924-1931, (Calgary: Glenbow Museum, 1991), 9. For an interesting comparison see the work of Frank Kupka (1871-1957).

${ }^{23}$ Oil on board, 43.2 x $60.9 \mathrm{~cm}$, collection London Regional Art Gallery, London, Onatrio.

${ }^{24}$ Ringbom, "Art in 'the Epoch of the Great Spiritual'," 398, 401.
} 
fundamentally spiritual in nature. He suggests that "art is a matter of the spirit."25

Kandinsky believes that the world is in need of a spiritual movement that will negate the rise of materialism. For him, the solution is found to a great extent in the teachings of Theosophy. He believes that the "Epoch of the Great Spiritual" demands a new form of artistic expression.

The problem that faced Kandinsky was how to express the spiritual in a material form and to find the answer, he consciously moved toward non-representational art. It is not surprising that during the time period when Kandinsky was most preoccupied with spiritual ideas, from 1908 to 1912, there is a gradual shift in his art away from objective art toward depicting abstract forms that represented his "inner aspirations." ${ }^{926} \mathrm{He}$ was interested in emancipating colours and forms from the objects with which they were associated. His first wholly abstract watercolour work was executed in 1910.

More recent abstraction has been influenced by a variety of anti-materialist philosophies. In New York Barnett Newman, Jackson Pollock, Adolph Gottlieb and Mark Rothko formed, according to Maurice Tuchman, "a second wave of abstract pioneers, searching for expressive means appropriate to their generation and asserting the need for universal truths. ${ }^{27}$ What differentiated them from the earlier abstract artists

${ }^{25}$ Ibid., 394.

${ }^{26}$ Ringbom, "Transcending the Visible: The Generation of the Abstract Pioneers," in Tuchman et.al., The

Spiritual in Art, 136.
${ }^{27}$ Maurice Tuchman, "Hidden Meanings in Abstract Art," in Tuchman et.al., The Spiritual in Art, 49. 
were their sources of inspiration. They did not align themselves with, for example, Theosophy or Anthroposophy, but instead pledged kinship to the art of Native and nonWestern cultures such as that of the North West Coast art, Zen and theories proposed by Carl Gustav Jung. These artists were adamant that their art was more than mere ornamentation and that there was indeed an underlying meaning which was of a spiritual character.

Another notable artist who showed interest in conveying spiritual themes in his work at this time could be found on the West Coast. Mark Tobey (1890-1976) was greatly influenced by religion, according to former curator at the Museum of Modern Art in New York, William C. Seitz. ${ }^{28}$ Tobey joined the Bahá'í Faith in 1918, and in 1934 he studied Zen Buddhism in conjunction with Japanese calligraphy, which augmented his knowledge of Chinese brush painting and his interest in Persian and Arabic calligraphic styles. All these influences and interests led him in 1935 to "white writing," the nonfigurative style he is perhaps best known for. Like Rogers, Tobey was very much interested in the principle of "unity" as proposed in the writings of the Bahá'í Faith. His "white writing" style demonstrated this spiritual aspiration by reconciling Eastern and Western artistic styles in a single work of art.

${ }^{28}$ William C. Seitz, "Tobey's World View," in Dahl, Arthur L. et.al., Mark Tobey: Art and Belief, (Oxford: George Ronald, 1984), 15. 
Another artist who looked at non-Christian sources was Abstract Expressionist Barnett Newman. Thomas Hess discussed the Kabbalah as the source of many of the artist's concepts in 1971. This was the first time that his work was analyzed in light of the Jewish mystical teachings. ${ }^{29}$ Newman himself never spoke about the Kabbalah as a basis for his art and this might be part of its very secretive nature. However, Hess's analysis makes it clear that an interpretation of Newman's work cannot just focus on the formal elements of his work while ignoring its mystical content. The artist's writings seem to support this line of arguing. As he stated in 1971:

The present painter is concerned not with his own feelings or with the mystery of his own personality but with the penetration into the world mystery. His imagination is therefore attempting to dig into metaphysical secrets. To that extent his art is concerned with the sublime. It is a religious art which through symbols will catch the basic truth of life. ${ }^{30}$

Newman's The Stations of the Cross (1958-1966) [Fig. 6 a \& b] demonstrates this overt religious content. It is a series that directly influenced Robert Houle's seminal work Parfleches for the Last Supper (1983). Here Newman transforms the sequence of the Passion of Christ into fully abstract works. Robert Rosenblum believes that it was partly Newman's Jewishness that allowed him to depict Christ's martyrdom in an abstracted way. Rosenblum suggests that since images of the deity are proscribed in the Jewish faith, an abstract depiction, which would represent the essence and the spirit of the Passion, was the only pictorial solution open to the artist. ${ }^{31}$ It is true that Newman is

\footnotetext{
${ }^{29}$ Thomas Hess, Barnett Newman. (New York: Museum of Modern Art, 1971). There are some who argue that "neither the artist nor the biographer used the Kabbalah from a normative Jewish point of view..." Matthew Baigell, "Barnett Newman's Stripe Paintings and Kabbalah: A Jewish Take," American Art, Vol. 8 , no. 2 spring 1994, 32-43.

${ }^{30}$ Barnett Newman as quoted in Tuchman, "Hidden Meanings in Abstract Art," 49.

${ }^{31}$ Rosenblum, Modern Painting, 212.
} 
Jewish, and we do not know how he regarded Jesus, but the pictorial tradition he comes from would probably influence his approach to a work that deals with the Passions of Christ.

As has been demonstrated, twentieth-century artists have not only inherited a landscape tradition that lent itself to the expression of spiritual ideas, but also the quintessential twentieth-century visual language, abstraction, was itself motivated in part by a desire to depict a reality beyond appearance. In Canada and elsewhere, mystical philosophies and religions have directly or indirectly influenced artists. Some of these philosophies, like Transcendentalism, promoted the already present love for the land. Artists regarded the qualities of the land and landscape features as perfect metaphors for conveying various spiritual concepts and ideas. They often acted as a symbol for a greater reality or they evoked in their onlookers a sense of the might of its Creator. Another theme that runs through the discussion of artists engaged with spiritual ideology is their move toward or adoption of a non-figurative language. Anti-materialist philosophies in the early part of the twentieth century proposed that it was no longer enough to depict the material world and hope that it would evoke a spiritual atmosphere. A new language was necessary, one that had no relation to the physical world, and hence abstraction became favoured. These artists also shared the conviction that the arts can 
and should be used for the uplifting of humanity and that the artist can play a crucial role in this process. ${ }^{32}$

Houle's interest in abstract art was reinforced due to his affinity for the works of Newman and the spirituality expressed in them. Rogers has been striving to become more abstract in his expressions and to move away from any references to the physical world. Tobey, who also professed the same spiritual ideology, shared this attitude. Both Rogers and Houle consider that their interest in religion and spirituality has led them to consider the landscape as a perfect metaphor for conveying their spiritual aspirations. And both artists have chosen the formal language of abstraction as it demonstrates their desire to go beyond the physical appearance of the material world.

However, their respective sources of spiritual ideology - the spiritual teachings of the Ojibway and the teachings of the Bahá'i Faith—distinguish them from artists inspired by the Judeo-Christian tradition or the various mystical philosophies cobbled from Eastern and Western spiritual traditions and science. In the history of Canadian art and artists relatively little attention has been given to the influence of indigenous spiritual traditions $\mathrm{s}^{33}$ in art, and even less to that of a young religion such as the Bahá'i Faith. The particular blend of landscape motifs with the language of abstraction, together with their

${ }^{32}$ Some see in this thinking the influence of the Arts and Crafts Movement and possibly that of the Bauhaus.

${ }^{33}$ Exceptions to this, as noted above, include the exhibition and accompanying catalogue Diana Nemiroff et.al., Land, Spirit, Power: First Nations at the National Gallery of Canada, (Ottawa: National Gallery of Canada, 1992) and Maureen Korp, "Earthworks: Shamanism in the religious experiences of contemporary artists in North America," (Ph.D. diss., Ottawa University, 1991). 
profoundly spiritual ideologies, makes the work of Robert Houle and Otto Rogers an important subject of study for Canadian art history. 


\section{CHAPTER II}

\section{ROBERT HOULE}

As demonstrated in the previous chapter, there is a prominent history of artists whose interest in spiritual matters has led them to turn to the landscape as a metaphor for mystical ideas. This tradition continues today, as can be seen in the work of the contemporary Canadian artist Robert Houle. Since the early 1980s, Houle has shown an interest in infusing many of his works with spiritual significance using abstracted references to landscape. This chapter will explore the link between spirituality and the land in Houle's works and how he translates this idea into abstracted landscapes. It will also examine the influence of the inter-cultural nature of his personal experience as an individual who was raised in a Roman Catholic residential school but came from an Ojibway-Saulteaux culture, as well as his more recent endeavours to embrace the traditions of the Sun Dance.

\section{THE ARTIST}

... as a painter, I am always conscious of the danger of letting myself approach the application of paint as a ceremonial performance, an end by which meaningless materialism can remove the human aspect of art.

To me, the struggle to survive and maintain a human dimension to [sic] an increasingly atheistic and materialistic computerized existence is what has given the need to express my deepest thoughts and emotions. It is a way of proving to myself that I am alive. ${ }^{1}$

Robert Houle's work has been predominantly exhibited in Canada and the United States, but it has also been shown in Europe, the Middle East and Australia. Houle has

${ }^{1}$ Robert Houle, "Artist's statement," New Work by a New Generation, (Regina, Norman Mackenzie Art Gallery,1982), 49. 
curated and co-curated significant exhibitions including New Work by a New Generation at the Mackenzie Art Gallery in Regina in cooperation with the Saskatchewan Indian Federated College, in 1982, and Land, Spirit, Power: First Nations at the National Gallery of Canada in 1992. Several artist-in-residence opportunities at various galleries both in Canada and abroad have been important to his development. Houle also served from 1977-1980 as the first "curator of contemporary Indian art" of the National Museum of Man, now the Canadian Museum of Civilization. He resigned because of philosophical differences with the Museum's administration. The impact of his time at that institution still reverberates in Houle's work. Those concerns will be discussed later in this chapter. Currently, Houle teaches at the Ontario College of Art and Design in Toronto.

Houle holds Bachelors of Arts degrees in both Art History and Art Education. Early on in his career Houle admired the Dutch abstract artist, Piet Mondrian. Eventually he turned away from Mondrian's work because, in his own words, "[i]t was European and based on the Christian idea that man was the measure of all things. I couldn't come to grips with that. I came from a holistic belief system that was not man-centered and so I turned to Barnett Newman, responding to his spirituality."2 Since then he has moved away from a highly abstract, modernist position to a culturally informed postmodernist

\footnotetext{
${ }^{2}$ Robert Houle in an interview with Nancy Baele, "Cultural extinction and renewal," Ottawa Citizen, 29 March 1990.
} 
one. In his art one finds a host of contemporary media, such as collage, text, sound, and works in mixed media, but painting remains his most important form of expression.

Houle's experiences as a child and youth have influenced his art and are worth exploring, as they also shed light on spiritual ideas that have informed him and on attitudes toward the land. Robert Houle was born in 1947 in St. Boniface, Manitoba. He belongs to the plains Ojibway or Saulteaux bands that now live along the shores and inflowing rivers of Lake Winnipeg. ${ }^{3}$ Houle is a descendant of the Ojibway people who migrated to the western part of Canada from the Great Lakes area in the late eighteenth century. ${ }^{4}$ His early childhood years were spent with his extended family on the Sandy Bay Reservation in southern Manitoba, where he spoke his native language and experienced traditional ceremonies, especially as performed by his grandparents.

The time when his loving family surrounded him soon came to an end. Like many Native children of his generation, Houle was forced to attend a mission-run residential school and hence was removed both from his Ojibway language and as well as his native spiritual traditions. He attended the Sandy Bay residential school, the same school his

\footnotetext{
${ }^{3}$ Jack H. Steinbring, "Saulteaux of Lake Winnipeg," June Helm, vol.ed., Handbook of North American Indians, vol. 6, (Washington, D.C.: Smithsonian Institution, 1981), 244.

${ }^{4}$ In the eastern part of their territory they prefer to be referred to as Ojibwa or Anishinabeg (spelt in many different ways), while communities to the west prefer plains Ojibway or Saulteaux. In the literature these terms are used interchangeably with little discrimination. As to the origin of the names, when the French encountered the ancestors of the western Ojibwa in the Sault Ste. Marie region, they referred to them as Saulteurs (later became Saulteaux) and Outchibouec (became Ojibwa or Chippewa). For more details see Laura Peers, The Ojibwa of Western Canada 1780 to 1870, (Winnipeg: University of Manitoba Press, 1994), xv, ix.
} 
father had attended and greatly disliked. ${ }^{5}$ Residential schools were the government's solution to the perceived need to "assimilate" or "integrate" the Native population. The great damage that these schools have done to Native individuals, their communities and culture has been well documented in the past few decades. Like other children, these school years had a profound effect on Houle. ${ }^{6}$ He still remembers "the constant punishments by the nuns and priests, punishments for speaking in Ojibway, for attending the Sun Dance with his parents, for not eating the lumps in his porridge." ${ }^{\prime 7}$ He has dealt with this difficult part of his life in a recent work entitled Sandy Bay (1998-1999) which will be discussed below.

It was at this Roman-Catholic-run residential school that Houle was exposed to Christian thought and ideology. Referring to his Roman Catholic upbringing, the artist states, "the Bible is the single most important cultural influence on my shamanistic heritage." ${ }^{.8}$ There is no doubt that Christianity left an indelible impression on him and together with his Saulteaux roots it is integral to his personal and artistic identity. Houle acknowledges the profound impact of Christianity on his outlook but he also appreciates

\footnotetext{
${ }^{5}$ Bonnie Devine, "Ways of telling: Sandy Bay," Winnipeg Art Gallery, Robert Houle: Sovereignty over Subjectivity, (Winnipeg, 1999), 46.

${ }^{6}$ One study on the effect of residential schools concluded that children suffered due to several factors including, "cultural discontinuities related to language, food, cultural barriers, strict adherence to rules and regulations of a regimented, militaristic approach." Linda R. Bull, "Indian Residential Schooling: The Native Perspective," Canadian Journal of Native Education, vol. 18, 1991, 58.

Houle spent grades 1 to 9 at The Oblates and Sisters of St. Joseph on the Sandy Bay Reserve. He attended high school in Winnipeg at the Oblates and Grey Nuns. Finally he spent one year in Jesuits College, at St. Paul's, the University of Manitoba. Gerald McMaster, "Persistence of Land Claims," in Winnipeg Art Gallery, Robert Houle: Indians from A to Z, (Winnipeg, 1990), 44, fn. 6.

${ }^{7}$ Deirdre Hanna, "Robert Houle's secret reserve," NOW Magazine, Toronto, ON, 20 Jan 2000.

${ }^{8}$ Robert Houle, quoted in Stedelijk Museum, Notion of Conflict: A Selection of Contemporary Canadian Art, (Amsterdam, 1995), 22.
} 
shamans he knew, including Larry Bear from the Sandy Bay Reservation, who would encourage him to go to church on Sunday, their reasoning being that it was the same God they were worshipping. Houle explained that whereas the shamans were inclusive, the Church was exclusive. It was only in his thirties that the artist realized that Roman Catholicism was an undeniable part of himself, and that he had been "weaned on it." $\mathrm{He}$ believes that he has a Christian tradition even if he is not practising it. However, he argues that the specifics of Christian theology are irrelevant to him. ${ }^{9}$

Although Houle sometimes feels torn between his native roots and the Christian tradition, in the end he realizes that both are very much part of his identity. His ideology is informed by the attitude of inclusiveness shown by shamans in his community. The artist accepts both his Saulteaux roots as well as the Christian tradition he was raised in. In fact the integration of both Native and Christian spiritual traditions is not uncommon among Native peoples. As the scholars Murray L. Wax and Rosalie H. Wax note,

Today, most Indians are Christians, at least nominally; but, in many cases, the Christianity is integrated with the native worldview, and the individual participated [sic] in a variety of both Christian and neotraditional rituals. ${ }^{10}$

\footnotetext{
${ }^{9}$ Interview with Robert Houle, Toronto, 25 Jan. 2000.

${ }^{10}$ Murray L. Wax and Rosalie H. Wax, "Religion Among the American Indians," The Annals of the American Academy of Political and Social Science, 1978, 436, Mar, 27. For personal stories on how some Native Christians of North America resolved this existential dilemma in their lives see James Treat ed.,
} 


\section{HOULE'S UNDERSTANDING OF SPIRITUALITY}

I am convinced that art has the capacity to raise the spirit. ${ }^{11}$

During a January 2000 interview, Houle was asked what he thought "spirituality" meant. He replied by saying, "Intuitively I don't know very much about it, but I have been attracted to it in poetry and art." He gave as examples both the poetry and illustrations of the English artist, poet and mystic William Blake, the Dutch abstract artist and Theosophist Piet Mondrian, the Canadian mystical artist and promoter of Theosophy Lawren Harris, and New York Abstract Expressionist Barnett Newman. ${ }^{12}$

Besides poetry and art, Houle also referred repeatedly to the spiritual significance of dreams during the interview. Dreams and visions hold a great spiritual significance in Ojibway traditions. It is during the so-called "vision quest" when youth at puberty fast and spend time in isolation in order to acquire power through a dream or vision. ${ }^{13}$ In particular Houle spoke about a recurring dream that he had which was most disturbing to him in which he saw friends and family as dead. He was frightened that his dream would become reality, as the world of dreams is closely related to real life. It was only when he was able to receive help from a shaman back home in Winnipeg that he was cured of his fears and no longer had such dreams. In an article entitled "The Great Dreamers" Houle

Native and Christian: Indigenous Voices on Religious Identity in the United States and Canada. (New York: Routledge, 1996).

${ }^{11}$ Robert Houle, "Sovereignty over Subjectivity," C Magazine, no. 30 (Summer, 1991), 35.

12 Interview with Robert Houle, Toronto, 25 Jan 2000.

${ }^{13}$ McMaster, "Persistence of Land Claims," 37. 
explains what dreams mean to him and links the activity of dreaming to creativity. He

writes,

Communion with the past through dreams has [a] long tradition among the Ojibway. The world of dreams has no past, present, or future; in other words the conception of time as a physical reality is absent. The experience in the dream is not a transfer from reality, but a separate world which has its own laws and dimensions. It is also the dimension of the dead....In dreams there is no true perception of time, only forms and shadows that make any experience an act of pure imagination. Dreaming is an act of pure imagination, attesting in all men a creative power, which, if it were available in waking would make every man a Dante, Shakespear[e], Michelangelo, or Morris[s]eau. ${ }^{14}$

The importance that Houle gives to his dreams and dreaming in general shows that he believes in spiritual worlds and conditions beyond this physical one and that dreams continue to be of significance to him as they were to his ancestors.

It is quite remarkable that Houle should be so deeply steeped in the spiritual traditions of the Saulteaux. In the 1960s, when Houle was in his early twenties, few Saulteaux overtly practised their Native spiritual traditions. ${ }^{15}$ According to historian Christopher Vecsey, ...most Ojibwa traditions have lost their power and meaning.... The structure of traditional Ojibwa religions has collapsed, leaving fragmented elements which Ojibwas have refashioned through new religious movements. Vestiges of the traditional religion remain but the religion as a whole does not... 16

${ }^{14}$ Robert Houle, "The Great Dreamers," undated (ca. 1970/71), artist's file, National Gallery of Canada, Ottawa. The Berens River Ojibway regarded dreams in a similar way. See Jennifer S. H. Brown, ed., A. Irving Hallowell, The Ojibwa of Berens River, Manitoba-Ethnography into History, (Fort Worth: Harcourt Brace Janovich Publishers 1992), 84-87.

${ }^{15}$ Steinbring, "Saulteaux of Lake Winnipeg," 253.

${ }^{16}$ Christopher Vecsey, Traditional Ojibwa Religion and Its Historical Changes, (Philadelphia: The American Philosophical Society, 1983), 57. 
Therefore, it required much determination and a conscious effort on the part of the artist to re-learn knowledge that was common among his ancestors. Part of this regaining of his Saulteaux identity has meant a concerted effort in re-learning his native Ojibway language and becoming well-versed in spiritual traditions. For example, he has studied the medicinal powers of herbs. ${ }^{17}$ Traditionally the Ojibway were known for their profound knowledge of the local flora, which enabled them to use wild plants for food and medicine. ${ }^{18}$ Another example of Houle's interest in his Native heritage is his participation in the Sun Dance which is one of the significant spiritual traditions still performed by Plains Indians, such as the Saulteaux. ${ }^{19}$ According to one scholar, the Sun Dance has been of particular importance since it has been instrumental in the revitalization and preservation of many traditional elements. It is an annual ceremony that revolves around renewal of the self as well as that of the world and is appropriately held during springtime or in early summer. ${ }^{20}$ During the summer of 2000 , Houle was planning to take part in his third Sun Dance when his nephew was planning to go on a "vision quest." ${ }^{21}$ Houle pays tribute to this ceremony in his sculpture Sun Dance Pole of $1981 . .^{22}$

\footnotetext{
${ }^{17}$ Interview with Robert Houle, Toronto, 25 Jan 2000.

${ }^{18}$ Christopher Vecsey, "American Indian Environmental Religions," in Vecsey \& Venables, Robert W. eds., American Indian Environments: Ecological Issues in Native American History. (New York: Syracuse University Press, 1980), 9.

${ }^{19}$ Interview with Robert Houle, Toronto, 25 Jan 2000.

${ }^{20}$ Joseph E. Brown, The Spiritual Legacy of the American Indian, (New York: Crossroad, 1988), 16, 41.

${ }^{21}$ Interview with Robert Houle, Toronto, 25 Jan. 2000.

${ }^{22}$ Wood, acrylic, ribbon, metal, sweet grass on wood, $(190.5 \times 30.5 \times 23.0 \mathrm{~cm})$, collection Canadian Museum of Civilization, Hull, Quebec.
} 
An exploration of some of the salient features of Saulteaux spiritual traditions is crucial to understanding Houle's work which expresses these cultural references to a point. Although the object of this discussion is to understand the spiritual character of the Saulteaux people, the scarcity of material on their heritage necessitates the use of more general sources such as those on the Ojibwa people of the Great Lakes area and the Plains Indians. In this case, even if from a western perspective there is a strong common ground that binds all Native spiritual traditions together, the rich diversity of each group should be acknowledged. Another important factor to consider when looking at Native spiritual traditions, or in fact any historical process, is the element of change. As Vecsey aptly explains, "Indian religions have both changed and persisted over the last five hundred years, as have the religions of the whites. ${ }^{23}$ Therefore, when reading about some of these beliefs and ideologies one should keep in mind that they are constantly evolving.

Spiritual traditions affected the everyday life of the Saulteaux people. For example, in times of difficulties the shaman's help was sought and people relied on his powers. Among their youth, as with those of other Native groups, it was common to go through a "vision quest," as noted above. The Saulteaux are also known for the Midewiwin, a society whose main purpose was to train in the medical arts. ${ }^{24}$ Although the last regional celebration of the Midewiwin occurred in $1926^{25}$ it seems to still influence the Saulteaux

\footnotetext{
${ }^{23}$ Vecsey, "American Indian Environmental Religions," 1.

${ }^{24}$ Steinbring, "Saulteaux of Lake Winnipeg," 250-251.

${ }^{25}$ Ibid., 252.
} 
people. Houle's training in medicinal herbs, as noted earlier, reflects its enduring influence.

For the Ojibway, as for most of the Native peoples of North America, spirituality was so closely interwoven into everyday life that it was not accorded a separate name. A scholar in this field of study, Joseph E. Brown, believes that this is still true in the life of contemporary Native cultures, even though it is hard to generalize and attitudes are always shifting. He explains this concept in the following way,

It has now become abundantly clear that it is a fundamental and universal characteristic of Native American cultures, as indeed of all primal or primitive cultures, that "religion"- there is no equivalent word for this in any American Indian language - is not a separate category of activity or experience that is divorced from culture or society. Rather, religion is pervasively present and is in complex interrelationships with all aspects of the peoples' life-ways. ${ }^{26}$

One idea that appears in the literature repeatedly is the all-pervasive character of spiritual principles in the everyday aspects of traditional Native life. The Ojibwa writer Basil Johnston is best known for his autobiographical writings on the residential boarding school experience. ${ }^{27}$ His more recent book, The Manitous: The Spiritual World of the Ojibway, draws heavily on Ojibwa mythology to elucidate the spiritual character of the life of the Ojibwa people. ${ }^{28}$ Johnston explains how for the Ojibwa a spiritual reality is omnipresent:

${ }^{26}$ Brown, The Spiritual Legacy of the American Indian, x. For this reason the term "religious" has been avoided when discussing Houle's work and has been substituted with "spiritual."

${ }^{27}$ Indian School Days, Toronto: Key Porter Books, 1988.

${ }^{28}$ Note that Johnston is writing specifically about the spiritual traditions of the Ojibwa of the Great Lakes area rather than of the Plains. 
It was long assumed that people who were preoccupied with material needs and wants would have little interest in matters of the spirit and the mind. On the contrary, it was this very mode of life, there were realities and presences in life, that awakened in man and woman a consciousness that manitou, the mystery, pre corporeal and the material. The spirit, the

Even if Houle no longer lives the traditional life that Johnston talks about, he nonetheless follows the idea that the spiritual world-like the dream world-is closely connected to the physical one.

\section{HOULE'S VIEW OF THE LAND}

One significant element in Native spirituality that has affected Houle's artistic practice is his attitude towards and understanding of the land and its spiritual significance. The close interconnectedness of spirituality and the land for Native peoples of the past and, in many cases, the present is well documented in scholarship on Native spirituality. An exploration of these beliefs will help facilitate a better understanding of Houle's artistic output.

Scholarship refers repeatedly to the solid interconnectedness between Native spirituality and the natural environment; this suggests that the Native holistic view of life did not allow them to distinguish absolutely between nature and divinity. They are usually synonymous. In fact, the natural world had such a profound impact on the Native peoples of North America that the geographic specifics of their physical environment had

\footnotetext{
${ }^{29}$ Basil Johnston. The Manitous: The Spiritual World of the Ojibway. (New York: Harper Collins, 1995), xviii.
} 
a defining influence on their spiritual outlook and shaped their religious practices. The Swedish scholar of comparative religion and ethnology, Åke Hultkrantz, an expert in Native spirituality, has observed that the natural environment and its use are of the utmost significance in the expression of spirituality. For example, there is a clear division between a "hunting religion" and an "agricultural religion." This division, for instance, had an impact on the tribes' respective views on the afterlife. For hunting tribes, the concept of a happy afterlife includes a land with plenty of game. For agriculturists on the other hand, belief in a subterranean world of the dead, where Mother Earth produces new vegetation, is predominant. ${ }^{30}$ Hence, "the outlook on religion as well as the structure of religion were dependent on the interaction between the natural environment and culture. ${ }^{31}$

Vecsey takes this argument further and has identified three types of integration between nature and religion among the Native peoples of North America. First there is "primary integration, in which the religious core is molded by environmental relations." This means that for example for hunting tribes, it is common to apologize to the animal that was killed, while among agricultural tribes, planting activities were combined with prayers. "Secondary integration" means that the social structure of Native peoples "was molded in part by environmental interactions, and the religious structure reflected the

${ }^{30}$ Åke Hultkrantz, Native Religions of North America: The Power of Visions and Fertility, (San Francisco: Harper \& Row, 1987), 1, 14, 34.

${ }^{31}$ Åke Hultkrantz, "Feelings for Nature among the North American Indians," in C. Vecsey, ed., Belief and Worship in Native North America, (New York: Syracuse University Press, 1981), 119. 
social structure. For example, hunting cultures were characterized by "atomistic shamanism" as "the individualism of hunting carried through to an individualism of religion." The third type of integration, known as "morphological" or symbolic integration, means that "religious symbols in words, designs, and motions reflected the surrounding environment." For example, myths made reference to natural phenomena or art objects celebrated and evoked nature. ${ }^{32}$

Although not a hunter himself, Houle as a Saulteaux belongs to the cultural group of the Plains Indian who subsisted until recently on hunting and fishing. Reflecting this heritage, he "place[d] tobacco around a young tree as an offering...to celebrate a communion with nature." ${ }^{\prime 33}$ This occurred during his residence as an artist at the McMichael Canadian Art Collection in Kleinburg, Ontario, where he worked in the former studio of Tom Thomson. With regard to the second integration, it has already been mentioned that shamans featured prominently in the life of the Saulteaux. Houle himself feels close to and consults with shamans in his home community in times of need. In Saulteaux mythology we find evidence of symbolic integration in the frequent references to beings with anthropomorphic endowments. In Houle's art this occurs when the artist evokes the land in his abstract paintings.

\footnotetext{
${ }^{32}$ Vecsey, “American Indian Environmental Religions," 10-11.

${ }^{33}$ Clara Hargittay, "Robert Houle His Creative and Spiritual Journey, 1980-1990," Winnipeg Art Gallery, Robert Houle: Indians from A to Z, (Winnipeg, 1990), 15.
} 
What all these scholars agree on is that nature is central to spiritual beliefs and to life itself for Native North Americans. The natural world is the place of worship, a place approached with much reverence, just as temples or churches are for the mainstream religions. Similarly, for Houle, encounters with the natural world, for example during his residencies in Winnipeg and Kleinburg, have had a profound effect on his artistic output and his choice of using the landscape.

Since Houle has also been exposed to Christian thought and ideology, a brief comment should also be made on the Judeo-Christian view toward the land. The Old Testament prominently contains several direct references to the land. Most discussions on this issue refer to Genesis 1:28, where it mentions that the earth should be "subdue[d]." Closely aligned to this idea is a concept that gained wide popularity in the Christian world which originated in the writings and philosophies of Aristotle and left its mark through the Middle Ages down to the late eighteenth century, namely that the universe is a "Great Chain of Being." According to Arthur Lovejoy, Aristotle proposed that all creatures should be ranked according to their degree, with human beings at the top of the scale. God was considered at the very apex of this scale and infinitely higher than any human being. ${ }^{34}$

\footnotetext{
${ }^{34}$ Arthur O. Lovejoy, The Great Chain of Being: A Study of the History of an Idea. (Cambridge, MA: Harvard University Press, 1957), 58-59. Beside Aristotle, Plotinus is also known for his theory on a hierarchy of degrees of being. Other sources that discuss the Christian view toward the land include Geoffrey R. Lilburne, A Sense of Place: A Christian Theology of the Land, (Nashville, Abingdon Press, 1989) and Ian G. Barbour, "Experiencing and Interpreting Nature in Science and Religion," Zygon: Journal of Religion and Science, vol. 29, no. 4, (Dec 1994), 457-487.
} 
This contrasts to the Ojibway point of view where, according to Johnston, "no one is granted primacy or dominion over the Earth or another species." ${ }^{35}$ This might or might not include the superiority of a Supreme Being. In the pre-contact period ${ }^{36}$, Ojibways supposedly believed that humans and animals were not very different from each other. After contact with Europeans, Ojibways were recorded by non-natives to believe that "animals of the lowest, as well as highest class in the chain of creation, are alike endowed with reasoning powers and faculties." Vecsey continues,

Twentieth century Ojibwas did not lose this belief in the personal, living quality of nature. Ojibwa linguistic categories which consider shells, stones, thunder, pipes, as well as plants and animals as animate, have persisted, and belief in metamorphosis from human to nonhuman form continues. Ojibwas still speak of bears and other animals as "relatives," "grandfathers," brothers," and the like. So much are the animals alive in the Ojibwa world view that they are said to have such religious habits as praying to the four directions. ${ }^{37}$

Presently the artist's understanding of the land seems to be primarily drawn from his Native roots rather than his Christian upbringing. And this should not only be attributed to the fact that he was born a Saulteaux, but more importantly to his conscious efforts to study the traditions of his ancestors which is a means of affirming his identity. These traditions place great importance on the land and hence landscape painting becomes a suitable vehicle to express his interest in spiritual themes.

\footnotetext{
${ }^{35}$ Johnston, The Manitous, 13.

${ }^{36}$ Contact here refers to the time when Europeans came into the lives of Native peoples.

${ }^{37}$ Vecsey, "American Indian Environmental Religions," 19-20.
} 
When asked in a recent interview, "What is your relationship to the land, especially considering that you live in the large urban environment of Toronto?" Houle explained that his perception of time and place is more a matter of individual rather than collective belief. He has no desire to go back to his ancestral lands. "You can bring that time and space with you, it is transportable and within you." Houle believes that the external world is only a small part of an interior one. He has travelled to many places in his dreamscape, what he terms his "inner landscape." ${ }^{38}$ As early as 1978 the artist expressed a similar relationship to nature:

My approach to nature is not one of awe. The belief that the Indian is very close to nature is a misconception that dates back to the days of the "noble savage"....We are not any closer to nature than the white man is. It's just that our approach is different.... The Indians don't idealize nature at all....[Nature] does not need to be appreciated by saying, "It is beautiful." ${ }^{39}$

Like most people of Native heritage, Houle is not unrealistic or sentimental in his views about the natural world. His ancestors were very much aware of the potential harshness of nature, the reality that only the fittest would survive and that taking a life or giving one's own was expected. "[T]here was no aesthetic indulgence in the beauty and drama of nature there was... an experience of nature as a realm of mystery. Nature revealed a reality of a higher order... ${ }^{{ }^{40}}$ Hultkrantz goes on to explain that the best example of the association between the spiritual and nature comes from the Plains Indians, the cultural group that Houle belongs to. For the Plains Indians, "the divinity

\footnotetext{
${ }^{38}$ Interview with Robert Houle, Toronto, 25 Jan. 2000.

${ }^{39}$ Marie-Jeanne Musiol, "Houle and the Ojibway leaves," (interview) The Native Perspective, vol. 2, no. $10,1978,23$.

${ }^{40}$ Hultkrantz, "Feelings for Nature among the North American Indians," 126.
} 
manifests its being through nature." And hence "it is man's duty to care for the wellbeing of nature." ${ }^{.41}$ Hultkrantz suggests that this intimate relationship with nature has been weakened over time. One reason for the waning in respect originally accorded to nature as a manifestation of the supernatural was the influence of the values of the white settlers. ${ }^{42}$

Although Houle has lived most of his adult life in an urban environment, the centrality of the land to his ideology can be discerned. His early views on the land have evolved and the artist seems to have a closer relationship to it now as reflected in his art and the increased references to the land and in the ideas he has expressed. For example, in 1992 the artist wrote, "a society based on a philosophy emphasizing technology worship, economic expansion, and commodity accumulation is doomed to failure, as it leaves out an understanding of and respect for the sacredness of nature and the limits to human endeavour. ${ }^{\$ 43}$

Houle appreciates and acknowledges the importance of the land for the spiritual and cultural well being not only for Native peoples, but for the whole world. He tries to make his audience aware of a sense of sacredness of the natural world. ${ }^{44} \mathrm{He}$ also tries to promote the idea, which is one of the core attitudes held by Amerindians of the northern

\footnotetext{
${ }^{41}$ Ibid., 126-127.

${ }^{42}$ Ibid., 131.

${ }^{43}$ Robert Houle, "The Spiritual Legacy of the Ancient Ones," Diana Nemiroff et.al., Land, Spirit, Power: First Nations at the National Gallery of Canada, (Ottawa: National Gallery of Canada, 1992), 48.

${ }^{44}$ See for example his essay "The Spiritual Legacy of the Ancient Ones," 45, 60.
} 
hunting cultures, that the land cannot be owned. ${ }^{45}$ For example, in his essay for the

National Gallery of Canada exhibition Land Spirit Power Houle states,

There is no word for "landscape" in any of the languages of the ancient ones still spoken. In Ojibwa, whenever the word uhke is pronounced, it is more an exaltation of humanness than a declaration of property. ${ }^{46}$

This statement echoes the idea that there is no word in the many different Native languages of North America to denote "religion" because the spiritual aspect of life was so interwoven into everyday concerns. Similarly, it could be deduced from Houle's words that landscape is so much part of the life and spiritual aspirations of the Ojibway that it is not accorded a separate term. This reinforces the idea that there is a relationship between spirituality and landscape in the worldview of Native peoples.

The loss of ancestral land, to Houle, does not only mean being deprived of the source of food and shelter, but also has spiritual consequences. It has been one of the causes of a grave identity crisis for generations of native North Americans. Houle has supported the restitution of ancestral land through his politically engaged works and statements made both as an artist and curator. His political and spiritual beliefs are closely associated. His political advocacy on the issue of land claims is given expression in the five mixed media paintings that constitute Premises for Self Rule (1994). The artist

${ }^{45}$ See Wayne Alfred Holst, "Aboriginal Spirituality and Environmental Respect: A Perspective on Traditional Amerindian Views of Nature with Special Reference to the Meaning of 'the Land' in Northern Cultures," Social Compass, vol. 44, no., 1997, 152.

${ }^{46}$ Houle, "The Spiritual Legacy of the Ancient Ones," 61. 
uses paragraphs drawn from historical Canadian legislation that has profoundly affected native Canadians, which are partly covered by a superimposed archival photograph of Native peoples and placed next to a colourfield painting. Premises for Self Rule Treaty No. 11871 [Fig. 7] is of particular significance to the artist as it specifically deals with the Saulteaux peoples and their homelands. ${ }^{47}$ The green colourfield painting here takes on a powerful metaphorical association with the land. According to writer and curator Clara Hargittay, what is at the heart of this work are the "inherent rights to selfdetermination" but it is the painting itself that embodies the spiritual aspect of this quest. $^{48}$

Thus far it has been established that a spiritual understanding of the land is of primary value for Houle and this has translated into works of art that are imbued with spiritual significance. His Saulteaux roots and his Christian residential school experience both find expression in his art. His efforts to re-learn or deepen his knowledge of his native spiritual traditions have made him further aware of the importance of the land for his and other people's well-being. This has translated into works where the abstracted landscape plays a significant role. More detailed analyses of some of his key works will make the powerful motivation of spirituality clearer.

\footnotetext{
${ }^{47}$ Ibid., 62.

${ }^{48}$ Clara Hargittay, "Robert Houle: Identity and Multiplicity," Real Fictions: Four Canadian Artists, exh.cat., (Sydney, Australia: Museum of Contemporary Art, 1996), 38.
} 


\section{THE SPIRITUAL SYMBOLOGY OF HOULE'S ART}

It is important to acknowledge the basic fact that the spiritual legacy of art from any one culture offers reassurance that the human species has some commonalities which are important to knowing who we are, where we are, and where we are going. ${ }^{49}$

Houle repeatedly makes reference in his works to ideas, events and objects that have iconographical value in Native traditions, Roman Catholic doctrine and liturgy, or both. This tendency is evident in his work since the mid-1970s. All of the works that will be discussed at length make reference in a direct or indirect manner to the land, or visually resemble an abstract landscape. Hence the land emerges as a symbol for spirituality in Houle's art. Houle acknowledges his use of aspects of his native Ojibway culture in his art. In fact, he believes that "to deny the legitimacy of this inspirational source would be like refusing the Renaissance its Greco-Roman heritage..." ${ }^{50}$ And in his essay for the Land, Spirit, Power catalogue, Houle strongly urges contemporary Native artists to "honour[...] their birthright" and reminds viewers that "no apologia is needed for any native aesthetics at work in the creative process of these artists;..." He regards contemporary Native artists as "the spiritual children of the ancient ones." Houle believes that the new aesthetic that contemporary artists of Native ancestry are formulating should draw inspiration from spiritual traditions by "involving the ritualistic and shamanistic art of the ancient ones." ${ }^{\text {51 }}$ These ideas and sentiments find expression in the artist's own work and in his view of himself as a shaman-artist.

\footnotetext{
${ }^{49}$ Houle, "The Spiritual Legacy of the Ancient Ones," 72.

${ }^{50}$ Robert Houle, "The Emergence of a New Aesthetic Tradition," New Work by a New Generation, 2.

${ }^{51}$ Houle, "The Spiritual Legacy of the Ancient Ones," 70-71, 53.
} 
Although most of the following discussion will focus on works produced by Houle from 1983 to 1999 , it is important to acknowledge that there are earlier works that also show the artist's interest in Native spirituality. Epigram: A Visual Statement (1980-83) ${ }^{52}$ is an early example where the artist has incorporated porcupine quills in a painting. The black acrylic canvas with a blue undercoat of Epigram is covered with porcupine quills that are laid out in groups, pointing to various directions. The porcupine quills' colour is no longer visible underneath the thick black acrylic paint, only their shape remains. Indirect references to quillwork go back to 1975 , when Houle began to employ "small taches and strokes to represent quillwork in his painting." ${ }^{53}$ They would remain a feature in his work until the 1990s.

The likely reason Houle chose porcupine quills is that quillwork has a spiritual significance for many Native peoples. This activity relates to Manitou Be-na-si-ka or "God making activity." 54 The repetitive nature of quillwork provided ample opportunity for the mind and soul to contemplate God. Houle refers to beadwork, which often replaced quillwork as trade with Euro-North Americans became more common, and believes that it signifies "the meticulous process of putting in order." 55 Quillwork

\footnotetext{
${ }^{52}$ Mixed media-acrylic and porcupine quills on canvas, $(76.4 \times 101.5 \mathrm{~cm})$, collection of the McMichael Canadian Art Collection, Kleinburg, Ontario.

${ }^{53}$ Curatorial File for Epigram: A Visual Statement, McMichael Canadian Art Collection, Kleinburg, Ontario.

${ }^{54}$ Ibid.

${ }^{55}$ Musiol, "Houle and the Ojibway leaves," 22.
} 
traditionally was (and in some instances still is) considered a sacred art form among some Native North American tribes. In fact it was held in such high esteem that those women who excelled at quillwork enjoyed a certain prestige in the community, equal to a successful male warrior. ${ }^{56}$ Before commencing quillwork, the Plains Indian women had to pray and fast and during the activity had to retain a contemplative attitude. The geometrical patterns that were created were equated with rays of the sun and hence held sacred..$^{57}$

Houle also employs these taches in a print entitled Diamond Composition (1980) in the collection of the Hamilton Art Gallery. ${ }^{58}$ Due to the nature of the medium, actual porcupine quills are not used here but are represented by small parallel strokes. Here the artist not only uses the small parallel lines but also employs another noteworthy featurea diamond-shape format with grids. These compositional choices of the diamond shape and the grids also hearken back to Mondrian's Composition, Bright Colour Planes with Grey Lines (1919) [Fig. 8]..$^{59}$ Victoria Henry observes that “...Houle has filled in his spaces with his four stroke motif in a way that has no integral relationship to the Mondrain [sic] concept of landscape and cityscape. Houle is overlaying his motifs on western art." ${ }^{{ }^{60}}$ The diamond-shaped canvas might also be inspired by works such as $L e$

\footnotetext{
${ }^{56}$ Janet C. Berlo and Ruth B. Phillips, Native North American Art, (Oxford: Oxford University Press, 1998), 114, 116.

${ }^{57}$ Brown, The Spiritual Legacy, 76-77.

${ }^{58}$ Screenprint on paper, $(81.2 \times 81.5 \mathrm{~cm})$.

${ }^{59}$ For another "Mondrianesque" work see Composition 2 (1979), collection Canadian Museum of Civilization, Hull, Quebec.

${ }^{60}$ Victoria Henry, "Robert Houle, March 13 1989," 6. Henry is the Director of the Canada Council Art Bank and was formerly Houle's art dealer.
} 
Cercle de Grande Reserve (1965) [Fig. 9] by the artist Yves Gaucher, whom he held in high regard. Houle also uses the diamond shape in a later work named after one of the extinct tribes, entitled Yamasee (1988) [Fig. 10], a highly abstract piece where quills are again employed.

The use of porcupine quills is also of philosophical interest to Houle. Houle had resigned from his position as a curator of contemporary Indian art at the Museum of Man, as a way of showing his outrage with the lack of recognition accorded to the work of contemporary Native artists. He believed that their art needed to be seen first and foremost in art galleries rather than in the context of anthropological or ethnographic artifacts, and recognized that contemporary Native art would never be recognized as contemporary art as long as it was displayed and presented as the artwork of an extinct or dying race. This does not mean that contemporary art produced by Native artists cannot employ time-honoured symbols of Native North American art. Since his resignation, Houle has been interested in "liberating" traditional Native artifacts such as parfleches, warrior staffs and shields. ${ }^{61}$ Therefore the use of porcupine quills makes reference to his strong conviction that as a contemporary Canadian artist of Native ancestry he has the right and privilege to refer to traditional cultural motifs in his art.

\footnotetext{
${ }^{61}$ Clara Hargittay and Robert Houle, "The Struggle Against Cultural Apartheid," Muse (autumn, 1988), 58-60.
} 


\section{Parfleches for the Last Supper}

The Old and New Testament are the Great Code of Art. ${ }^{62}$

Parfleches for the Last Supper (1983) [Fig. 11 a-m] demonstrates fully how Houle fuses his traditional Native values with his Christian religious beliefs, using contemporary art-making vocabulary. It is therefore a reflection of the spiritual makeup of the artist who created it. Spirituality is intrinsic to this work, which associates an Ojibway ritual meal with the Last Supper of the New Testament. Although it does not deal directly with the landscape, each parfleche is reminiscent of a flat prairie landscape due to the repeated use of both inherent and painted horizontal lines. ${ }^{63}$

The word 'parfleche' comes from the French term parer flèche (to turn away arrows) in reference to the impenetrable rawhide used ${ }^{64}$ In the life of the traditional Plains Indian, the folded rawhide was decorated and served as an envelope or pouch to carry ceremonial objects or valuable personal items. As Plains Indians led a nomadic life on the land, a pouch or parfleche was a necessary item to transport an individual's valuables. As such, the presence of the parfleche motif may be understood as an indirect reference to the land. Parfleches have been a recurring feature in Houle's oeuvre,

\footnotetext{
${ }^{62}$ William Blake, Aphorism on the Laocoön Group. Houle chose this quote to head his entry of this work in the exhibition catalogue by the Stedelijk Museum, Notion of Conflict, 22.

${ }^{63}$ The folded horizontal flap of the parfleche creates the illusion of a horizon line and hence the flat prairie landscape. In addition to the horizontally running flap, almost all of the thirteen panels have ritualistic lines running parallel to the line created by the flap, hence reinforcing the idea of a landscape. At times the horizontal lines are reminiscent of cloud formations and with the addition of oblique, parallel lines of the porcupine quills, like rain clouds (numbers 1 and 8 especially).

${ }^{64}$ Berlo \& Phillips, Native North American Art, 114.
} 
especially since his resignation from the Museum of Man in 1980, and he has explored their physical and spiritual qualities as recently as $1999 .{ }^{65}$ The artist's aim in using parfleches, warrior staffs, and shields in his work has been to revive and resurrect objects that are of spiritual consequence to Native peoples. This resurrection and revival is achieved in conjunction with centuries-old Christian themes or iconography.

In this work, Houle chose parfleches because they were an integral part of a personal spiritual experience - a naming ceremony of a sibling for which his mother had prepared a ritual meal. The artist remembers a shaman coming to their home to pronounce the secret name of his brother for the first time. Part of the ritual entailed carefully opening the flaps of a parfleche. Houle believes that the "ritual act of closing, folding and then opening and releasing" of a parfleche creates a spiritual aura. ${ }^{66} \mathrm{He}$ uses the idea of the ritual meal and links it to another meal of grave spiritual consequencethe Last Supper. The Last Supper is perhaps one of the best known events of the life of Jesus. It was the last Passover meal that Jesus shared with his disciples before he was crucified. During the evening Jesus distributed bread and wine and asked his disciples to partake of these as his body and blood and therewith inaugurated the Christian sacrament of Holy Communion. ${ }^{67}$

65 "New Parfleches" a series of six diptychs where the artist honours individuals that greatly influenced him, was exhibited in Toronto, Pari Nadimi Gallery, Oct 7-30, 1999. Other parfleches include, Mohawk Parfleche (1990) collection National Gallery of Canada, Parfleche (Grey and Green) (c 1987) and Everything You Wanted To Know About Indians From A to Z (1985) collection Winnipeg Art Gallery, and Parfleche II-C (1984) collection McMichael Canadian Art Collection.

${ }^{66}$ Interview with Robert Houle, Toronto, 25 Jan 2000.

${ }^{67}$ See for example Matthew 26:20-28. 
Houle explains that the parfleches for this work "were created out of the desire to unite in a single continuum, the effects of Christianity on traditional Saulteaux spirituality. ${ }^{968}$ Perhaps what Houle is attempting here is a reversal of history by appropriating Christian concepts, such as the Last Supper, to resurrect traditional Native ideology and artifacts. Historically it was the Christian missionaries who appropriated Native concepts and changed them in such a way that they would be in accord with Christian dogma but also more palatable to the concepts of the new converts.

This "dual state of being" has historical antecedents. In the past, even those Ojibway who professed to be Christians still interpreted and understood Jesus Christ through their own traditional religious patterns. For example, some regarded Jesus as another manito, one of the many powers. Others believed that Jesus would appear in their dreams and help them with the hunt. ${ }^{69}$ Similarly Houle has stated that for him Jesus is none other than a great shaman. ${ }^{70}$ Vecsey explains this simultaneous belief in both Christian dogma and Ojibway traditions:

...[s]ince their traditional religion admitted new revelation without nullifying the old, they were able to accept pieces of Christianity selectively without disposing of corresponding traditional pieces. In short, they were able to hold traditional and Christian beliefs, participate in traditional and Christian ceremonies, interpret the world through traditional and Christian theory, and relate to traditional manitos and the Christian God simultaneously. ${ }^{71}$

\footnotetext{
${ }^{68}$ Houle, quoted in Stedelijk Museum, Notion of Conflict, 22.

${ }^{69}$ Vecsey, Traditional Ojibwa Religion, 56.

${ }^{70}$ Interview with Robert Houle, Toronto, 25 Jan 2000.

${ }^{71}$ Vecsey, Traditional Ojibwa Religion, 56.
} 
Parfleches for the Last Supper was inspired by a modern interpretation of the Passion of Christ-Barnett Newman's Stations of the Cross (1958-1966) [Fig. 6 a \& b].

Newman's work gave Houle "the needed confidence and reassurance that religious work could be abstract; an idiom limitless in applicability." ${ }^{\text {72 }}$ But Houle greatly admires the Abstract Expressionists not only because of their formal language but also because of their interest in the spiritual. As art historians Janet Berlo and Ruth Phillips explain, Robert Houle... was attracted as a student to the formal language of abstraction, and particularly to the art of Barnett Newman and the New York Abstract Expressionists. Houle responded in particular to their use of abstraction as a means of exploring the spiritual... He was also returning a compliment; during the 1940s the Abstract Expressionists had studied and celebrated Native American art for the access it gave to the spiritual. ${ }^{73}$

Newman chose the traditional fourteen panels to depict the Passions of Christ. His highly abstract and austere interpretation of the Stations of the Cross is, according to one critic, not concerned with death but rather "Resurrection." "74 Houle's Parfleches for the Last Supper is made up of thirteen parfleches, representing the twelve Apostles and Christ.

Both Houle and Newman are committed to abstraction as their visual vocabulary. Neither is illustrating an idea or painting an allegory, yet each is able to capture the spiritual essence of these events. The adoption of an abstract mode of expression was not only an outcome of Houle's academic training, which introduced him to modernism.

\footnotetext{
${ }^{72}$ Houle, "Parfleches I.H.S." Toronto 1984, Victoria Henry papers.

${ }^{73}$ Berlo \& Phillips, Native North American Art, 233.

${ }^{74}$ Thomas Hess, Barnett Newman, (New York: Museum of Modern Art, 1971), 98, 103.
} 
There are also historical precedents in Native cultural traditions for avoiding pure representation. "Realization that he [the Native artist] could not draw a flower as perfectly as it was made by the Creator, led him to seek out the spirit, or essence, of the ...flower." ${ }^{\text {75 }}$ According to Houle, his Ojibway ancestors sought out the essence of the object and hence made a move from representation toward abstraction. Houle believes that just like traditional Native artists in the past, so today "[c]ontemporary Native artists often follow a similar course, seeking graphically to represent emotions, spiritual essence, or unseen forces hidden behind a subject's physical façade." ${ }^{976}$

In the area of colour, Houle's work is distinguished from that of Newman. Whereas Newman restricted his palette to raw canvas, various blacks and (in three of the Stations) white, Houle uses in most instances bold, primary colours. He uses a bright yellow cross for Jesus, a colour which also refers to the Sun Dance. Instead of the raw canvas that Newman employs, Houle uses handmade paper and porcupine quills as accents. These natural materials create a sharp contrast to the acrylic paint used. The choice of colour and materials, made up of natural and synthetic, symbolizes the "two seemingly irreconcilable polemics of the Sun dance and Catholicism," according to Houle. ${ }^{77}$

\footnotetext{
${ }^{75}$ Robert Houle, "Search for Identity," Tawow, vol. 2, no. 2, (summer 1971), 3.

${ }^{76}$ Ibid.

${ }^{77}$ Houle, quoted in Stedelijk Museum, Notion of Conflict, 22.
} 
Houle has selected passages from the Gospels to accompany each parfleche. He has specifically chosen those passages that describe the conversations that went on during the Last Supper. They are the answers that Christ gave to the questions of each apostle, re-creating the ambience of that Supper. For example for Parfleche \#1 Matthew he has chosen the following quotation: "In the world you will have trouble, but be brave: I have conquered the world." (John 17:33) ${ }^{78}$

A knowledge of Christian iconography enhances the appreciation of some of these highly abstract pieces. Houle explained that until he began working on this work, he had never actually read the Bible. But he wanted to do this work and he needed to read and find out about each of the Apostles. ${ }^{79}$ According to curator Shirley Madill, Houle studied the character of each Apostle and through the employment of "color theory and ritualistic manipulation of marks created an identity for each person." ${ }^{180}$ For example, the parfleche for Peter has a light brown square in the centre, a reminder of the following passage from the Gospels,

And I say also unto thee, That thou art Peter, and upon this rock I will build my church;"(Matthew, 16:18)

Parfleche \#5 Philip includes two crosses which allow for a dual, syncretic reading. These crosses could refer to the Christian Greek cross and simultaneously make reference

\footnotetext{
${ }^{78}$ See Appendix I for the passages for each parfleche.

${ }^{79}$ Interview with Robert Houle, Toronto, 25 Jan. 2000.

${ }^{80}$ Shirley Madill, "Robert Houle: A Dual State of Being," in Winnipeg Art Gallery, Robert Houle: Indians from A to Z, (Winnipeg, 1990), 26.
} 
to the four cardinal points held sacred by the Saulteaux. Hargittay claims that in Ojibway cosmology, the four cardinal directions signify the unity of creation. ${ }^{81}$ This cross, which we will see again in later works, has shafts equal in length, intersecting at their middles, with a point at the centre. For Plains Indians, this point is not only the centre of the circle, which is held sacred, but also unites within itself the four directions of the cross and represents a human being. ${ }^{82}$ This is why the concept of "centrality" can be found in many rituals such as the Sun Dance, a ceremony in which Houle takes part as often as he can. According to Houle, this cross is also symbolic of a natural phenomenon: Venus, the Morningstar, the first and last star in the sky. ${ }^{83}$

Parfleche \# 8 Thomas is executed in black with only two thin horizontal lines in red and white, as well as porcupine quills breaking out of the darkness. Houle appropriates the story of Thomas's doubting of Christ and recasts it as the "doubting of one's identity" or "the doubting of one's culture." $84 \mathrm{He}$ achieves this by contrasting the dark parfleche of Thomas with the bright yellow one of Jesus. As the colour yellow may refer to the Sun Dance, a Plains Indian who doubts his or her identity could be characterized by a dualistic, sharply contrasting colour scheme.

\footnotetext{
${ }^{81}$ Hargittay, "Identity and Multiplicity," 40, fn. 15.

${ }^{82}$ Brown, The Spiritual Legacy, 36.

${ }^{83}$ Conversation with Robert Houle, Toronto, 8 Oct. 1999.

${ }^{84}$ Conversation with Robert Houle, Toronto, 8 Oct. 1999.
} 
Although not all of his works try to convey a spiritual message according to the artist, Parfleches for the Last Supper is a spiritual work. ${ }^{85}$ It demonstrates his interest in his dual spiritual roots - his native Saulteaux traditions and his Roman Catholic upbringing. In it he successfully bridges the gap between the two so that it sometimes becomes difficult to distinguish between these two unique sources of inspiration. Through the use of the parfleche he has resurrected a spiritually significant Native article and has attempted to give it a place in the history of Christianity and hence Western society. He creates a work that is both spiritually meaningful to an Ojibway as well as a Christian.

The Place Where God Lives or Manitowapah You sense its place and meditative qualities. They become a religious group of paintings. ${ }^{86}$

This series of four paintings executed in 1989 [Fig. 12], directly inspired by the Parfleches for the Last Supper, deals both with the concept of the land as well as with a specific spiritual place that is closely related to Houle's Saulteaux heritage. Like Parfleches for the Last Supper, it is a bi-cultural work in which Houle's tribal beliefs and Christian upbringing meet.

This series was produced in response to the Manitoba environment, at a time when Houle was an artist-in-residence at the Winnipeg Art Gallery in 1989. Although Houle

${ }^{85}$ Interview with Robert Houle, Toronto, 25 Jan. 2000.

${ }^{86}$ McMaster, "Persistence of Land Claims," 42. 
states that he carries the land within him, nevertheless his experiences during his two residence programs show that the physical environment that surrounds him affects him and his art in a significant way. ${ }^{87}$ In 1989 , both his experiences as an artist-in-residence at the McMichael Canadian Collection in Kleinburg, Ontario, and at the Winnipeg Art Gallery, moved the artist to explore the subject of the land with a fresh outlook. The scholar of contemporary Native art, Gerald McMaster, explains how Houle realized he had no personal vocabulary for depicting the landscape during his time as an artist-inresidence at the McMichael. He immersed himself in his surrounding landscape and realized that "Place took on a new meaning. It takes you there, you don't take it away." The outcome of Houle's McMichael experience was Seven in Steel (1989) [Fig. 13]. This work commemorates seven extinct Native tribes in steel, a material purposefully chosen for its quality of permanence. Seven in Steel makes reference not only to art objects in the McMichael collection, such as a fragment of a totem pole and a traditional hunting scene by Inuit artist Parr, but also to the landscapes of the Group of Seven and Tom Thomson. ${ }^{89}$ Similarly, the Manitoba landscape had a great impact on Houle during this specific time in Winnipeg, which resulted in the production of his monumental work The Place Where God Lives. The example of these two large works seems to suggest that the actual physical landscapes surrounding Houle have had a significant effect on his artistic output and partly inspired him to explore the subject of the land.

${ }^{87}$ As stated in an interview in Toronto, 25 Jan 2000.

${ }^{88}$ McMaster, "Persistence of Land Claims," 43.

${ }^{89}$ Hargittay, "His Creative and Spiritual Journey," 16-17, and Carol Podedworny, "Trajectories of Meaning...the work of Isaac Applebaum and Robert Houle," Garnet Press Gallery, Toronto, Jan 1993. 
The inspiration for The Place Where God Lives, like Parfleches for the Last Supper, came again in part from Houle's Saulteaux roots. Drawing on Saulteaux mythology, Houle references an island in the Narrows of Lake Manitoba which is thought to be the dwelling place of God or Manitou. "The Place Where God Lives" or Manitowapah is the origin of the name of the province of Manitoba. It was a place of pilgrimage for Native people who lived in that area. Tobacco was often offered to the gods at that place. Strong winds would send waves crashing against the porous limestone on the shores of the lake, and the resulting sounds of wind and waves were regarded as the drumbeat or voice of the Manitou or Great Spirit. ${ }^{90}$

Although Houle has retained some of the themes found in Parfleches for the Last Supper, this later work differs in many ways. Most importantly, unlike the earlier work, it was directly inspired by his experience of the Winnipeg landscape, with which he is intimately familiar. This may explain why these panels have something so very personal about them.

The spiritual character of these large panels is enhanced through the choice of colours. According to McMaster, "to Houle colours are religious." entitled Divas, based on the music from three operas, Houle had stressed the emotional

${ }^{90}$ Historic Resources Branch, "The Origin of the Name Manitoba," ( Manitoba, n.d.), unpaginated ${ }^{91}$ McMaster, "Persistence of Land Claims," 38. 
association of colour. ${ }^{92}$ This idea reappears in The Place Where God Lives. The

canvases are brushed in the pigment traditionally associated with native artifacts:

Matthew is predominantly red, Philip green, Thomas ochre and Bartholomew blue. The distinctiveness of each panel is enhanced and given its own character through the use of gestural marks, including crosses as well as vertical, horizontal and oblique lines, the latter probably making reference to quillwork. What they hold in common is an allusion to the flat prairie landscape of Manitoba, as Houle repeatedly uses horizontal lines and brushstrokes, particularly in the upper half of the canvas. The ambiguity of the horizon line in the prairie landscape intrigues Houle. This ambiguity, he suggests, is mystical. For the artist, light is an important part of these panels, as it is light that renders the horizon line hazy and creates a mystical aura. "The mist from the Lake or the grayness of the snow or sky is hit by light... Snow has a multitude of colours..."93

Houle sought out a painterly way to appropriate the landscape. By using the format of the parfleche, with its horizontal emphasis in the centre of the canvas, he allows the panels to be read as landscapes. The artist explains his intentions with this work in these terms,

They do appear to refer to the land because of the ambivalent horizon line, but they are really an attempt to work through pure abstraction. I have always been an admirer of Barnett Newman. His work is the inspiration for Parfleche [sic] for the Last Supper, 1983 and continues through The Place Where God Lives. ${ }^{94}$

${ }_{92}$ Ufundi Gallery, Press Release: "Divas-Robert Houle," Ottawa, Oct 2-21, 1992, Artist's file, National Gallery of Canada, Ottawa.

${ }_{93}$ Conversation with Robert Houle, Toronto, 8 Oct. 1999.

${ }^{94}$ Extended label copy from "Prairietheism: Internalizing the Prairie Landscape," May 17-Sept 22, 1996, Winnipeg Art Gallery, Winnipeg Art Gallery files. 
Gerald McMaster agrees with Houle and states that, "The paintings make allusions to landscape, but are not landscape paintings. They are about a special place. They are landscapes for the mind." ${ }^{95}$ It seems reasonable to state that these four panels do not "represent" a landscape, nor do they depict the Narrows of Lake Manitoba. They act first and foremost as metaphors for a greater reality, as symbols of a spiritually powerful place. However, one could disagree with McMaster, instead terming them "landscapes of the soul" as they have a meditative quality conducive to meditation and contemplation. Their appeal is not so much intellectual, or structural, but operates through the use of colour and signs, emotion and symbol..$^{96}$

The four panels also refer to the parfleches for Matthew, Philip, Thomas and Bartholomew (sketches numbers 1, 5, 7, and 8). Why has Houle associated a significant Saulteaux sacred place with four Apostles from his Christian heritage? He may be associating a sacred Saulteaux place with a sacred Christian topic in order to bring it to the consciousness of his non-Native audience. In addition, the number four is significant in both traditions. Each panel represents one of the four directions, held sacred in Native spirituality, while also referring to the four Gospels in the New Testament. ${ }^{97}$ Typically, Houle successfully interweaves these seemingly contradictory sources.

\footnotetext{
${ }^{95}$ McMaster, "Persistence of Land Claims," 42.

${ }^{96}$ However, it needs to be pointed out that for Houle, issues concerning the land are never far from political assertions of self-determination and self-rule. Curators have, for example, discussed this work in terms of "reappropriating and reclaiming Manitoba." See McMaster, "Persistence of Land Claims," 42 and Susan Douglas, "Crossroads Visualism: Robert Houle," Parachute, no. 80, Oct-Dec 1995, 45.

${ }_{97}$ Conversation with Robert Houle, Toronto, 8 October 1999. Despite this reference to the four Gospels, the artist nowhere explains why he did not select Mark, Luke and John.
} 
Shirley Madill states that "the landscape, both physical and spiritual, is important to him as a means of understanding both one's past history [sic] and future path." ${ }^{.98}$ This notion of identity is a recurring theme in Houle's oeuvre and is a fundamentally spiritual activity. Without knowing oneself, it is difficult to realize one's place in the world. Lacking awareness of one's identity makes it impossible to positively contribute to society. The land continues to give Native peoples, like Houle, a source of identity and is wedded to their spiritual well-being.

The relationship toward the land, as experienced by people of Native background who have to live in a society that largely does not share their views, is a source of crisis and conflict with regards to identity. Art historian Gerhard Hoffmann has identified this issue as central to many works by contemporary Native artists. He writes,

In pictures and assemblages of Native American artists there is a tension between Indianness and nature on one side and Western civilization and its corruptions of nature on the other. Within this pattern there are endless variations possible with accentuation of the elemental/aboriginal/mythical or the defunct/alienated/clichéd. ${ }^{99}$

One of Houle's works that shows a "defunct" version of nature is Zero Hour (1988). Here the artist deals with the apocalypse of a technology-driven society, warning against a possible nuclear disaster through the depiction of an ominous "mushroom"

\footnotetext{
${ }^{98}$ Shirley Madill, "Coming Home," in Winnipeg Art Gallery, Robert Houle: Sovereignty over Subjectivity, (Winnipeg, 1999), 11.

${ }^{99}$ Gerhard Hoffmann, "Postmodern Culture and Indian Art," Canadian Museum of Civilization ed., In the Shadow of the Sun, (Hull, Quebec, 1993), 276.
} 
cloud. The Place where God Lives, in contrast, is a "mythical" or spiritual interpretation of nature.

What strikes us immediately about these four canvases is their physicality. Both in terms of physical scale and boldness of colour, they stand out. Scale is an integral part of the composition and is necessary if the artist wishes to elicit feelings of awe from his audience. Houle has fulfilled the requirements for depicting the sublime that Longinus set down in his book On the Sublime in the first century AD. He is able to create a sense of vastness which in turn inspires awe. ${ }^{100}$ To convey the idea that we are looking at the dwelling place of God, we need to be either overwhelmed, and taken over by the grandness of these panels (each $244.0 \times 182.4 \mathrm{~cm}$ ) or to sense that we are intimately embraced and immersed in a sea of colour. The Abstract Expressionists, upon whose work Houle has drawn repeatedly, accentuated scale. We need only remember the large atmospheric canvases of Mark Rothko or the immense austere panels of Barnett Newman. The latter believed that the sublime was "man's natural desire for the exalted."101 The German theologian Rudolf Otto proposes that the sublime is "the most effective means of representing the numinous." 102 This hearkens back to the ideas of the Northern Romantic artists who understood that scale was the perfect means to elicit

\footnotetext{
100 Jane Turner, ed. The Dictionary of Art, (New York: Grove's Dictionaries, 1996), Vol. 29 , 889.

${ }^{101}$ Quoted in Lawrence Alloway, Barnett Newman: The Stations of the Cross, (New York: Solomon R. Guggenheim Museum, 1966), 14. Newman himself wrote The Sublime is Now (1948).

${ }^{102}$ In The Idea of the Holy, Oxford, 1923, Chapter VII, quoted in Alloway, Barnett Newman, 14.
} 
feelings of awe. Instead of large canvases and multi-panel works, they used human figures or animals as staffages, to make the landscape appear grander.

\section{Sandy Bay}

No one can tell who has not healed. No one can heal who has not told. The process of telling contains the possibility of health and reconciliation. ${ }^{103}$

One of Houle's most recent and noteworthy works is Sandy Bay (1998-1999) [Fig. 14], a highly personal piece hearkening back to his residential-school years on the Sandy Bay Reservation. Sandy Bay can move the viewer in such a way that we feel both the loss and suffering of the artist and at the same time his victory and happiness in dealing with and overcoming a deep-seated pain. Curator Madill describes Sandy Bay as a "healing work" where "an inner state of tumult ...can be quelled but not cured."104

Although traditional Native iconographical motifs such as porcupine quills or the characteristic cross of the four directions appear here, they remain secondary to the main theme of the work, which once again addresses the dual identity of the artist. In this work, however, his school years at a mission-run residential school, where he was forcefully divorced from his Saulteaux culture, takes precedence. His reference to the landscape is crucial in understanding this emotionally charged painting.

${ }^{103}$ Devine, "Ways of telling," 47.

${ }^{104}$ Madill, "Coming Home," 15. 
Sandy Bay consists of five parts, which can be read from left to right. On the far left, we see two photographs drymounted on masonite, one depicting an Oblate priest in a garden, the other an image of the First Communion class, which includes the artist's sister. Next we move to a large, almost monochromatic panel rendered in grisaille, in which Houle has left aside abstraction, and depicted his old school on a winter day. The artist pointed out in conversation that the school building he had painted has no doors, only windows, signifying that no one could come in or go out of the school. ${ }^{105}$ Paint running down the lower half, toward the bottom of the canvas, strongly suggests streams of tears. Houle also employs text in this work, as he has in many others. He has included an Ojibway lullaby that his mother used to sing to him: ON SAM KI KISEWATIS ANA ANITOWIYAN ("Oh you are so kind and so treasured although you are god-like"). ${ }^{106}$ The lullaby may be a reminder that the speaking of Ojibway was strictly forbidden at the school. An act of defiance, it is written in capital letters in the same space as the residential school building, just to its lower left. It also reminds the viewer that children had to live far away from their parents and their mothers's lullabies. In this way they were not only removed from the loving care of their families, but also deprived of two important cultural transmitters: mother and language. A narrow panel of the same height follows in blue, a colour that spells spirituality for the artist. Looking carefully one can discern in the upper-half a semi-abstract landscape in blue-black representing the landscape of Sandy Bay. The last, purely abstract panel, is painted in a beautifully rich

${ }^{105}$ Conversation with Robert Houle, Toronto 8 Oct. 1999.

${ }^{106}$ Madill, "Coming Home," 15. 
red, with Houle's characteristic gestural lines and marks. Towards the lower centre of the panel one can see short, dark red, parallel lines, perhaps a reference to quillwork and towards the lower left the traditional Saulteaux cross is placed.

The use of white, blue and red may act as a reminder to the audience of the colours of the British and French conquerors whose manifold impact on the native population included the residential schools. ${ }^{107}$ Residential schools were to many a painful experience, particularly as many children were forced to live away from home and forbidden to speak their Native tongues or practise their culture. It is only since the 1969 White Paper that residential schools for Native students have been gradually phased out. ${ }^{108}$

Writing about his personal experience at the residential school in Sandy Bay, the artist states, "One dismal outcome of the residential school system is a self-image which varies from marginality or invisibility to one which is harshly oppressed or openly targeted." ${ }^{109}$ In a recent interview with Deirdre Hanna of NOW Magazine, Houle revealed that this work deals with abuse, including sexual abuse at his residential school. As the

${ }^{107}$ Similarly Houle uses these three colours to make reference to the colonizers of Canada in his work Kanata (1992) based on the work The Death of General Wolfe (1770) by Benjamin West. The influence of Newman's Voice of Fire, with its use of blue and red has also been commented upon. See curatorial file for Kanata, National Gallery of Canada, Ottawa.

${ }^{108}$ Scott Trevithick, "Native Residential Schooling in Canada: A Review of Literature," The Canadian Journal of Native Studies, vol. XVIII, 1 (1998), 50-51.

${ }^{109}$ Robert Houle, "Artist's Statement," in Amelia Trevelyan, Lost Tribes: Robert Houle, (Frederick, Maryland, 1991), 3. 
oldest child he felt responsible for protecting his younger siblings but instead he complied through his silence and felt guilty for doing so. ${ }^{110}$

One of the fonder memories Houle had at the Roman-Catholic-run residential school was when he was asked to meet with a high-ranking priest, who later became a Cardinal. He felt that he was accorded a special privilege since he was the only student asked to meet with the priest. Looking back, Houle wonders whether he was singled out to determine if he would make a good priest himself. Besides this one incident, he remembers resisting the priests and nuns at the school, partly because of the theology they professed and partly because he was too young. He saw them more as figures of authority than as "spiritual beacons." Houle remembers that around grade five or six he would go into the chapel looking for signs of Jesus. To his great disappointment, he did not find any. ${ }^{111}$

While working on Sandy Bay, Houle was very involved with his past and it created much anguish and many tears. But these tears he believes were part of a cleansing, healing process that he needed to go through. He feels that through this work, he has now dealt with his past in the residential school and overcome this burden. Artist and Native writer Bonnie Devine reiterates Houle's words when she explains that, in her

${ }^{110}$ Hanna, "Robert Houle's secret reserve."

${ }^{111}$ Interview with Robert Houle, Toronto, 25 Jan. 2000. 
culture, "the process of telling is sacred and honoured....[it] contains the possibility of health and reconciliation."112

The monochromatic photographs, together with the gray-blue-white depiction of the school building, represent Houle's past. As the faded colours suggest, these memories are fading and no longer haunting the artist. The blue canvas acts as a catalyst between past and present, between a cultural discontinuity and an assured identity. Particularly noteworthy is Houle's use of a semi-abstract landscape in this panel. The primacy of the land, as a source of identity and spiritual well-being, comes once again to the fore in this work. It seems plausible that this blue panel with its landscape is important not only for the unfolding of the work (or the story) but for coming to terms with his past. His association with and closeness to the land will give him the strength to accept this "dual state of being." It should also be noted that as the work moves from left to right, it becomes increasingly abstract, with the last panel being void of any kind of reference to the physical world. Hence the semi-abstract landscape, though acknowledging the spiritual importance of the land, is also the last reference to this material world. The last panel signals the arrival of the artist at his final destiny — he has found a balance between the seemingly contrary cultures he knows. He uses a rich red as his main colour, making reference to his Native roots. We also recognize the characteristic cross, referring to the

${ }^{112}$ Devine, "Ways of telling," 46-47. She is a member of the Serpent River Ojibway First Nation. 
four directions which are held sacred in Native mythology and the oblique lines referring to quillwork. Everything else is pure abstraction.

This work can also be read in another way. The photograph of the school children represents how non-Natives view people of Native heritage — as the other, people who need to be "civilized" in a European-style school system. The last panel, which is abstract, represents Houle's true identity, namely the way he sees himself. This syncretic identity consists of traditional Native, reconstructed Native culture and Christian ideology. Houle is stressing that what matters is not any physical or outwardly signs of being of Native heritage but rather the spiritual connection that is felt in the soul of an individual. And this deep-seated identification with Houle's Native culture is nowhere better represented than by his relationship to the land.

The use of the land, Mother Earth, is also significant because it equates in the traditions of the Ojibway with motherhood and womanhood. ${ }^{113}$ For example in the peace pipe smoking ceremony the second whiff of tobacco is offered to the land in thanksgiving with words such as these, "To you, Mother, we give thanks.... When I am hungry, you feed me; when I am cold and wet, you shelter me; when I am downcast, you comfort me. For this am I grateful, I am indebted to you."114 The mother figure not only stands for protection, nurture and spiritual well-being, but it is very much a symbol of

113 Johnston, The Manitous, 9.

114 Ibid. 
roots and identity. ${ }^{115}$ This further strengthens the argument that the land, and its translation into a landscape in Houle's art, are crucial to the artist's identity.

Hoffman observes that the reference to the land in the work of contemporary

Native artists is significant and is an affirmation of their native roots. He writes,

...the Native artist is confronted with the fact that, like it or not, Indianness still defines his or her mentality and creativity and gives the artwork its specific identity. The Indian artist may even find that the aesthetic use of nature/myth as an alternative form of reference entails an unforeseen existential reidentification with the Native tradition and thus a necessary separation from modalities of perception and thought that the mainstream artist embraces. ${ }^{116}$

Vecsey concurs that, "We cannot deny that today American Indians do express an intense association with the environment that identifies them as Indians." 117

Although a highly personal work of a cathartic nature, Sandy Bay contains a universal message: a personal spiritual renaissance is possible through the understanding of one's spiritual traditions, in this case through close identification with the land, in order to overcome past sufferings. For Native peoples who in early childhood were removed from their homes to be brought up in an environment that was totally unfamiliar and where any mention of one's spiritual and cultural heritage was forbidden, a great deal

${ }^{115}$ Although even Ojibways themselves, such as Johnston, have often used the term "mother" synonymously with the earth, some scholars believe that this idea did not originate in the world view of the Native North American. For example Maureen Korp states, "The claim of a traditional earth-centered reverence is, I believe a valid one, but the earth metaphor of mother may not necessarily be a traditional one." In her book she goes on to explain why "the metaphor is problematic for several reason." (65) See Sacred Art of the Earth: Ancient and Contemporary Earthworks, (New York: Continuum, 1997), 64-68.

${ }^{116}$ Gerhard Hoffmann, "Postmodern Culture and Indian Art," 281.

${ }^{117}$ Vecsey, "American Indian Environmental Religions," 7. 
of effort is required to once again feel close to that culture. Perhaps the first step in that spiritual revival is an appreciation of the spiritual importance of the land to the Native worldview.

Houle's interest in the spiritual and its expression in his art are clearly central to his work. The artist is able to weave elements of both Saulteaux and Christian spiritual iconography into his works of art. His more recent immersion into his native culture has meant a closer identification with the land and a greater understanding of its spiritual significance. This new understanding, together with his experiences as artist-inresidence, have led Houle to explore the subject of the land in an innovative and meaningful way. His references to the land have alluded to the once nomadic life-style of the Plains Indians, as in Parfleches for the Last Supper. In The Place Where God Lives, Houle uses the image of the land to refer to a place held sacred in Saulteaux mythology. And in Sandy Bay the landscape acts as a reminder that the land is significant for the spiritual happiness of Native peoples and that it helps them gain a better understanding of their own identities. Using the formal language of contemporary art, Houle introduces elements of his two spiritual traditions, which to an untrained eye could easily go unnoticed. Abstraction becomes a suitable vehicle to express cultural ideas in all of these three major works discussed. 


\section{CHAPTER III}

\section{OTTO ROGERS}

Like Robert Houle, Otto Donald Rogers demonstrates an interest in expressing spiritual aspirations. The sources of their spiritual beliefs might be different, but both artists strive to express in their work something beyond a mere concern with the physical or material aspects of life. They also share the fact of their upbringing on the Canadian prairies; its influence is manifest in their repeated use of the landscape motif. The most characteristic feature of the prairie landscape - the horizon line-is prominent in their paintings, collages and installations and offers a most suitable metaphor to express their spiritual aspirations. ${ }^{1}$

\section{THE ARTIST}

I'm trying to create objects of contemplation to stand as bridges between the spiritual and the ordinary world. ${ }^{2}$

Although predominantly known for his landscape paintings, Otto Rogers has also produced a number of still lifes, portraits, collages and sculptures over the course of his long career, which spans forty years. His works have been widely exhibited in all parts of Canada, as well as in Europe and the United States. He taught art at the University of Saskatchewan for thirty years (1959-1988) and acted as head of that department for

\footnotetext{
${ }^{1}$ It should be noted that other artists have used the vertical to express their spiritual aspirations, such as Mondrian and Newman.

${ }^{2}$ Rogers in Laurie Savage, "Rogers featured in Sask. Series," The Commentator, 26 Sept. 1982, 8.
} 
several years. He has participated in and later coordinated several programs at the celebrated Emma Lake workshops held in Saskatchewan. ${ }^{3}$

It was Rogers's art instructor at teachers' college in Saskatoon, Wynona Mulcaster, who introduced him to the works of such twentieth-century masters as Georges Braque, Pablo Picasso, Henri Matisse and Paul Klee through illustrations in books. Rogers was immediately drawn to their works. Mulcaster encouraged him to study fine arts and he left for Wisconsin, where he received a Bachelors degree in art education and a Masters degree in fine art. Upon the completion of his degrees, Rogers returned home to Saskatchewan where he started his career in the academic world and as an artist. Although the Emma Lake workshops, closely connected to the New York School of colour field abstractionists, were influential for many painters of his generation, Rogers claims to feel more affinity to the European masters than to those artists generationally closer to him such as the Abstract Expressionists. However he does admire Pollock, Rothko, Still, Gottlieb, Johns, and Rauschenberg and learned from their example "the abandonment, or large-scale, what Greenberg would call 'Big Attack' approach..."4 Rogers's work is influenced by "the totality of the image, the idea of continuous space that you have in Pollock; also the simplicity of the image..."

\footnotetext{
${ }^{3}$ For an account of the Emma Lake Workshops, see Mendel Art Gallery, The Flat Side of the Landscape: The Emma Lake Artists' Workshop, ed. John O'Brian (Saskatoon, 1989).

${ }^{4}$ Rogers in an interview with Lynne Bell, "Otto Rogers - A Message of Celebration and Supplication," Arts West, Vol. 3 (Nov/Dec 1978), 18.

${ }^{5}$ Ibid.
} 
From 1988 to 1998 Rogers lived abroad and accordingly has been somewhat less visible in the art scene in Canada. Until 1998 he was serving in a senior administrative role at the Bahá'í World Centre in Haifa, Israel. As there are no clergy in this religion, Bahá'ís from all over the world either volunteer to serve or are elected or appointed to international institutions at its World Centre. During his residency in Haifa, Rogers had time to paint only on weekends but still managed to have one exhibition per year in Canada. He has now settled back in Canada and lives and works in Ontario.

\section{ROGERS'S UNDERSTANDING OF SPIRITUALITY}

Rogers has been described by one critic as a "self-consciously religious painter... whose art is dedicated to the worship of God as manifest in the Persian Prophet, Bahá'u'lláh." It is in this light, rather than from a purely formal standpoint, that Rogers's work needs to be addressed. The artist's search for spiritual meaning was present long before he heard of the Bahá'í Faith. In his childhood, contemplation of the natural world led him to feel that there was something more important than this physical world. As he states, "All things were moving and I knew that my motion had a Mover. I saw in this environment a part of the creation and without hesitation I loved its Creator."

Rogers explained in a phone conversation on 26 June 2000 from his home in Ontario, that his parents did not belong to any particular church, although they were God-

\footnotetext{
${ }^{6}$ Ross Woodman, A Celebration of the Human Spirit: Five Canadian Artists, exh. cat. (London, Ont.: McIntosh Gallery, 1988), [unpaginated].

${ }^{7}$ Otto D. Rogers, in "Reflections on the Spiritual Quest of the Artist," Southern Alberta Art Gallery, Otto Rogers: New Paintings and Sculpture 1977-78, (Lethbridge, Alta., 1978), unpaginated.
} 
fearing and pious people. He grew up in a home where he was taught not to have any prejudices and saw how his parents treated everyone equally, regardless of their ethnic background. His father, particularly, embraced anything that was new and progressive. For example, he would always use the latest farming implements on his farm. He believed that everything that was progressive and not destructive was good. Rogers attributes this openness of mind, lack of prejudice and lack of ties to any particular organized religion as important elements in his upbringing that encouraged him to more freely and independently investigate a new religion. ${ }^{8}$

Living on a vast farm in the prairies and being the youngest child in the family, Rogers was often left alone with nature, whose immensity impressed him. He had close association and therefore developed an affinity with nature. Rogers feels that there is a definite link between his enthusiasm about God, his love for nature and his search for something new that ultimately has found expression in his religious beliefs and his art.

One of the spiritually significant moments in his life occurred when Rogers was only fourteen. His mother bought the first book the family ever owned-a copy of the Bible. He read it with much enthusiasm and was especially struck by the following passage:

Ask, and it shall be given you; seek, and ye shall find; knock, and it shall be opened unto you:

\footnotetext{
${ }^{8}$ Phone interview with Otto Rogers, 26 June 2000.
} 
For every one that asketh receiveth; and he that seekth findeth; and to him that knocked it shall be opened. (Matthew, 7:7-8) ${ }^{9}$

Next to his experience with nature, this verse fanned his interest in his quest for spiritual truth. Although Rogers did not know what "truth" might be, he felt the inclination toward some greater purpose or idea in his life. This search came to a momentary end when Rogers discovered his love for the arts in teachers college. However, he soon came to believe that art is but a reflection of the truth. Not long after, while studying for his Master's degree in Wisconsin, he met Barbara Nelson, his future wife, who introduced him to the Bahá'í Faith. ${ }^{10}$ At this point Rogers did not ask many questions about this young religion or its validity, even after having a Bahá'í wedding ceremony. Rogers explained that as soon as he heard the words of Bahá'u'lláh, he felt that they came from the same source as the Lord's prayer. He did not distinguish between Christianity and the Bahá'i Faith. He felt that they were essentially one, but because the latter was more recent, it was more progressive and suited his purpose better. He compared his decision to embrace the Bahá'í Faith to his father's approach of always buying the latest equipment for the farm. ${ }^{11}$ In 1960 while living in Saskatoon, Rogers officially joined the Bahá'í Faith. At this point, he felt that he had found the truth he had been searching for. He has on numerous occasions stated that the Bahá'í Faith has been an important source of inspiration not only for his life but also for his art.

\footnotetext{
${ }^{9}$ Conversation with Otto Rogers, Haifa, Israel, 25 Dec. 1997.

${ }^{10}$ Ibid.

${ }^{11}$ Phone conversation with Rogers, 26 June 2000.
} 
Unlike Native spiritual beliefs, the Bahá'i Faith is relatively new in terms of religious history - less than 200 years old — and hence there is ample documentary material and original scripture available for study. The Bahá'í Faith is characterized by an inter-related and clearly stated set of core beliefs. It is an independent religion that originated in Persia (now Iran) in 1844 and, according to the 1992 Encyclopaedia Britannica Book of the Year, is one of the most geographically wide-spread religious movements in the world. It was founded by Bahá'u'lláh (1817-1892) who detailed its laws and teachings in over 100 volumes. A monotheistic religion, it teaches that all religions come from the same divine source and essentially promote the same spiritual truths. It postulates that humankind is fundamentally one, regardless of race, nationality, sex or class.

The principle of the oneness of humankind, as defined by Bahá'is, is central to Rogers's artistic practice; he repeatedly refers to the concept of unity and more specifically, "unity through diversity" when discussing his art. According to the Bahá'í teachings, unity is of pivotal importance. ${ }^{12}$ It is the ultimate goal, be it at the level of the family, the nation or the planet. ${ }^{13}$ The Bahá'í writings stipulate, however, that unity is not to be understood as uniformity; rather, it is seen as "unity in diversity." These writings also claim that unity does not imply a suppression of the diversity of race, culture or

\footnotetext{
${ }^{12}$ Some of the passages where Bahá'u'lláh talks about unity can be found in Gleanings from the Writings of Bahá 'u'lláh, (London: Bahá'í Publishing Trust, 1978), 215, 218, 286.

${ }^{13}$ For example see, 'Abdu'l-Bahá, Selections from the Writings of 'Abdu'l-Bahá, trans. Committee at the Bahá'í World Centre and Marzieh Gail (Haifa, Israel: Bahá'í World Centre, 1978), I 221, 279.
} 
nationality. ${ }^{14}$ Rogers embraced the idea of unity in diversity early on in his life and found confirmation of these ideas in his discovery of the Bahá'í Faith. He believes that the principle of unity through diversity can be used as a metaphor in art. He often uses the following passage from the Bahá'í writings on diversity to explain his compositions: "diversity is the essence of perfection....difference reinforceth harmony, diversity strengtheneth love, and multiplicity is the greatest factor for co-ordination."15 His use of "diversity," "difference" and "multiplicity" as tools for achieving harmony will be explored in greater detail in relation to individual works. In 1996, Rogers explained why he believes this concept should be applied to art,

\begin{abstract}
All these things, in a very real way, are definitions, as I understand it, of a metaphor that would apply to a work of art, because in a work of art, you seek to include as much diversity as possible, knowing that if you can create harmony out of that diversity, you will have something that is more perfect; something that attracts a condition of love, and that the multiplicity within that will be its greatest factor for coordination. Often simple designs, things that are interesting as designs, but not necessarily interesting as art, only use one or two ingredients, and they make simple repetitions of very similar qualities. Whereas great paintings usually employ a great multiplicity of things. And of course the more elements you have, the greater degree of difficulty there is in creating harmony and unity out of it. ${ }^{16}$
\end{abstract}

His aim is to create harmony and unity out of multiplicity. Writer and critic Ann Boyles

further elucidates this point in a 1998 exhibition catalogue on Rogers's art when she states,

The painter's task is to clearly express the elements - to show how each is beautiful and profound in its own right but also to provide the framework by means of which, in the blink of an eye, you see how all these make one indivisible entity. To achieve this effect, he must distance himself

\footnotetext{
${ }^{14}$ Shoghi Effendi, The World Order of Bahá'u'lláh-Selected Letters, (Wilmette, IL: Bahá'í Publsihing Trust, 1991), 41-42. Shoghi Effendi (1897-1957) is the great-grandson of Bahá'u'lláh and was appointed Guardian of the Bahá'í Faith by his grandfather 'Abdu'l-Bahá.

15 'Abdu'l-Bahá, Selections from the Writings, ๆ 166, 291.

16 "Divine Influence and Human Response," transcript of a talk given at the Bahá'i World Centre, Haifa, Israel, 30 Aug 1996, [unpaginated, 4-5].
} 
enough so that he can, in a sudden moment, co-ordinate it all - in effect, to create a visual symphony without the individual movements losing their identity. ${ }^{17}$

The concept of unity in diversity is heavily stressed and often repeated by Bahá'u'lláh and in other books written about aspects of the Bahá'í Faith. Rogers is strongly influenced by his religion and is eager to attribute his approach and themes to the influence of his religious beliefs. Therefore it is perhaps not surprising that he is able to place many of his works in the context of religious scripture. For example, Rogers uses his painting El Greco Fervor (1986) [Fig. 15] to explain this concept. ${ }^{18}$ It is one of his many abstract bi-partite compositions where the canvas is divided horizontally, as in this case, or vertically. Light colours such as whites, yellows and light blues characterize the upper half of the painting. The paint is applied in such a way that it creates a swirling motion. The lower half of the canvas is executed in a dark pink-tone with a texture reminiscent of stucco. Geometric blocks in browns and blacks are placed along the edges of the canvas. In terms of colour, texture and movement the two halves are very different and yet they are unified. The artist explains:

The desire for transcendence creates in my artistic struggle discontent with a minimum response, with ordering known arrangements. I am led to a juxtaposition of diverse elements which one might not expect to be together, such as the static opaque geometric blocks and the moving transparent space of the sky. These diverse elements are held together in one drama which aspires to a unity through diversity. ${ }^{19}$

${ }^{17}$ Ann Boyles, "Attracting a Condition of Love: The Art of Otto Rogers," Buschlen Mowatt Gallery, Otto Donald Rogers, (Vancouver, 1998), 15.

${ }^{18}$ Rogers named this work after El Greco, because he feels that he was also interested in creating a unified picture out of diverse elements. The upper zone reminds one of El Greco's View of Toledo (1608).

${ }^{19}$ Rogers in Joan Murray, The Best Contemporary Canadian Art, (Edmonton, AB: Hurtig Publishers, 1987), 148. 
It is through the use of metaphors that Rogers applies principles such as unity in diversity to his art. He states, "this is precisely what an artist is doing. This is what metaphors are made of: bringing contrasting elements together and creating harmony." ${ }^{20}$ Rogers's repeated use of metaphors is an important aspect of his art and worthy of further exploration. The specific metaphors he employs are often from the Bahá'í sacred writings which contain many such analogies. In literature, both secular and religious, metaphors are used to facilitate the understanding of spiritual concepts and difficult subjects. In the Bahá'i sacred scriptures it is common to see examples taken from the natural world to explain spiritual principles. ${ }^{21}$ This is because in the Bahá'í cosmology the physical world is a means of gaining access to the spiritual world in the same way that a mirror is a vehicle by which light is conveyed..$^{22}$

The writings of the Bahá'i Faith further reinforce the idea that the use of physical metaphors is useful in explaining spiritual aspirations by suggesting that human knowledge is of two different kinds. The first kind of knowledge is about things that are perceived through the senses and are based on physical objects or phenomena. The second kind of knowledge, which includes ideas of the spirit and spirituality, is

\footnotetext{
${ }^{20}$ Rogers in a interview with Paula Gustafson, "Interview - Otto Donald Rogers," Artichoke, Summer 1996, 28.

${ }^{21}$ For example, to explain the essential oneness of all the Manifestations of God such as Buddha, Christ, Muhammad and Bahá'u'lláh, the metaphor of the sun is used. The sun rises and sets daily, it is the same sun and yet it is also a new day and a different sun, identified with a different day of the week. Or the analogy of the bird is used to explain the principle of the equality of the sexes. Humanity is likened unto a bird. One wing represents males, the other females. Not until both wings are equally strong can the bird fly - not until both sexes are equally developed can humanity advance.

${ }^{22}$ John S. Hatcher, The Purpose of Physical Reality: The Kingdom of Names, (Wilmette, IL: Bahá'í Publishing Trust, 1987), 76. Rogers use Hatcher's discussion of metaphors in his explanations of this concept.
} 
intellectual in nature and not based on things perceptible to the senses. These are

formulated or derived within the mind and are more difficult to express to others.

Therefore, a Bahá'í belief system proposes that in order to convey spiritual matters it is useful to resort to physical analogies or explanations in order to facilitate understanding. ${ }^{23}$

For example, using the metaphor of the natural world, the principle of unity in

diversity is elaborated upon in the Bahá'i writings in the following way by 'Abdu'l-Bahá:

Let us look rather at the beauty in diversity, the beauty of harmony, and learn a lesson from the vegetable creation. If you beheld a garden in which all the plants were the same as to form, colour and perfume, it would not seem beautiful to you at all, but, rather, monotonous and dull. The garden which is pleasing to the eye and which makes the heart glad, is the garden in which are growing side by side flowers of every hue, form and perfume, and the joyous contrast of colour is what makes for charm and beauty.

Thus should it be among the children of men! The diversity in the human family should be the cause of love and harmony, as it is in music where many different notes blend together in the making of a perfect chord. ${ }^{24}$

This principle manifests itself in Rogers's paintings, which have been described as "static dynamism," where "the manipulation of forms, colour and textures...create[s] a sense of balanced tension between opposing forces." ${ }^{25}$ The landscape is a suitable metaphor of this principle as it contains diverse elements, textures, and colours, and is yet transcended by an overall unity.

23 'Abdu'l-Bahá, "Outward forms and symbols must be used to convey intellectual conceptions," Some Answered Questions, collected and trans. Laura Clifford Barney, (Wilmette, IL: Bahá'í Publishing Trust, 1984), 83-84.

24 'Abdu'l-Bahá, Paris Talks: Addresses given by 'Abdu'l-Bahá in 1911, (London: The Bahá'í Publishing Trust, 1995), 44-45. 'Abdu'l-Bahá (1844-1921) was the eldest son of Bahá'u'lláh and his appointed successor.

${ }^{25}$ Peter Millard, “Otto Rogers: Mira Godard Gallery, May 7-28,” Toronto, 1977. 
This interest in creating unity from diversity manifests itself in his working method and use of tools as well. If in the beginning of his career Rogers employed only one medium, since the 1970 s he has predominantly been producing multi-media works perhaps in an effort to demonstrate the principle of unity through diversity. For example, he has made numerous collages, and paintings are executed no longer just with a paintbrush but also with a spray gun and at times include charcoal and modelling paste. Other techniques include rubbing colours with a rag, blotting colours with paper towels, and using rollers, and scrapers. ${ }^{26}$ In one work he combines the use of very thick paint with very diluted paint or even water. Although there is complexity due to the various techniques and materials in a work, nevertheless the artist's ultimate goal is to attain a simplified image. ${ }^{27}$

The Bahá'í sacred texts on the importance of the arts are also relevant to this discussion of the influence of the Bahá'í Faith on Rogers's oeuvre. The arts are regarded highly within this religion and together with sciences and crafts are seen to be necessary

${ }^{26}$ L. Bell, "A Message of Celebration and Supplication," 22.

${ }^{27}$ The concept of unity through diversity also is evident in a series of experiments with collage work that Rogers made during the mid- to late 1970s. He wanted to do something that bridged sculpture and painting. This resulted in a series of "fabrications on plywood," each of which contain a physical element such as a piece of rope, his leather belt, corrugated cardboard and strips of canvas. Among these is Silver Field of 1976, which is reminiscent of a prairie winter scene. The artist has applied acrylic paint as well as charcoal to two pieces of raw canvas, which in turn are affixed to a board of partly exposed plywood. Despite - or as Rogers would argue, because of - the diversity in terms of physicality and visual effect of the materials employed, the viewer faces a coherent and unified picture; Other examples include Power of Renewal, which incorporates the artist's leather belt and New Sun-Eternal Balance, both 1979, both collection of the Canada Council Art Bank. 
for the progress of the world. Every Bahá'í is asked to acquire and become proficient in one of these branches of knowledge. ${ }^{28}$ Talking about the arts, the Bahá'í writings state:

\begin{abstract}
All Art is a gift of the Holy Spirit. When this light shines through the mind of a musician, it manifests itself in beautiful harmonies. Again, shining though the mind of a poet, it is seen in fine poetry and poetic prose. When the Light of the Sun of Truth inspires the mind of a painter, he produces marvellous pictures. These gifts are fulfilling their highest purpose, when showing forth the praise of God. ${ }^{29}$
\end{abstract}

The Bahá'í writings do not impose a specific faith-based iconographical program on artists and Bahá'ís "are [not] trying to develop a Bahá'í school of painting or writing." At the same time as Bahá'í artists are "free to paint, write and compose as their talents guide them, ${ }^{\prime 30}$ they are encouraged to "exercise a leadership role in restoring to a materialistic society an appreciation of reverence as a vital element in the achievement of true liberty and abiding happiness." ${ }^{\text {31 }}$ The Bahá'í Faith proposes that the Prophets of God do not so much teach the arts, but provide a tremendous cultural impetus which eventually and gradually leads to the creation of new art. The Bahá'í writings further explain that Christianity, Islam, Buddhism and other religions have each in their turn produced different styles and movements of architecture and painting. ${ }^{32}$

${ }^{28}$ Bahá'u'lláh, Tablets of Bahá 'u'lláh revealed after the Kitáb-i-Aqdas, (Haifa, Israel: Bahá'í World Centre, 1978), 51.

${ }^{29}$ As quoted in Lady Blomfield, The Chosen Highway, (Wilmette, IL: Bahá'í Publishing Trust, 1954), 167.

${ }^{30}$ From a letter written on behalf of Shoghi Effendi, 20 July 1946, in Research Department of the Universal House of Justice, The Importance of the Arts in promoting the Faith - A Compilation, (Thornhill, Ontario:Bahá'í Canada Publications, 1999), ๆ 38.

${ }^{31}$ From a letter written on behalf of the Universal House of Justice, 30 June 1988, The Importance of the Arts, $₫ 60$.

${ }^{32}$ From a letter written on behalf of Shoghi Effendi, 3 February 1952, The Importance of the Arts, 141. 
The Bahá'í Faith's promotion of the arts might partly explain the attraction and later adherence of a number of artists to the Bahá'i Faith. ${ }^{33}$ In the West, one of the best known artists who was a follower of the Bahá'í Faith was the American painter Mark Tobey (1890-1976), as noted in Chapter I. As there is no "Bahá'í school of painting," it becomes clear why there is no necessary artistic continuity between earlier Bahá'í artists such as Tobey, and younger artists such as Rogers. The very concept of unity in diversity and other aspects of the Faith may make the emergence of a single "style" ideologically inconsistent. These concepts seem to call for and encourage a diversity of artistic expression rather than a uniform and formulaic approach to art.

However, Tobey and Rogers have a significant commonality: their shared attitude toward spiritual principles and their choice of abstraction as a formal language. Their use of an increasingly non-objective mode of painting might reflect their interest in moving away and showing detachment from the physical world, which is symbolic of their quest to make the viewer aware of a greater reality. Tobey also had a more direct influence on some of Rogers's early works. Some still-life paintings the young artist executed in the early 1960s such as Untitled (Still Life) [Fig. 16] (1961), now in the collection of the Winnipeg Art Gallery, have Tobey's characteristic "white writing" style. White writing

${ }^{33}$ A portrait painter named Juliet Thompson introduced Mark Tobey to this religious movement in 1918. In Europe the potter, and father of the studio pottery movement, Bernard Leach (1887-1979) became an adherent. It was Tobey who introduced both Leach and the latter's college friend, the South African artist Reginald Turvey (1882-1968) to the teachings of Bahá'u'lláh. The three artists formed a close bond of friendship based on shared spiritual beliefs and their commitment to excellence in their respective artistic fields. See Arthur L. Dahl et.al., Mark Tobey-Art and Belief. (Oxford: George Ronald, 1984). L. Johnson, Reginald Turvey -Life and Art. (Oxford: George Ronald, 1986). R. Weinberg, ed., Spinning the Clay into Stars: Bernard Leach and the Bahá'i Faith. (Oxford: George Ronald, 1999), 30. 
was the culmination of Tobey's years of interest and study of various Eastern calligraphic styles. It is characterized by innumerable lines, often in white, swirling and crisscrossing the canvas. One such work that epitomizes this style is Meditative Series VIII (1954) [Fig. 17]. Rogers acknowledges the influence of Tobey in his own work of the early sixties. His use of gouache, a medium that the more senior artist frequently employed, also reflects Tobey's influence. ${ }^{34}$ Both artists appear to be striving to incorporate spiritual principles in their attitude towards both the process and the product of their art. They are also among those artists who see spiritual content as a paramount aspect of their abstract work.

Rogers repeatedly equates the creation of art with the worship of God..$^{35}$ In fact, the Bahá'i writings indicate that any work performed in the spirit of service and to the best of one's ability is regarded as worship. Rogers echoes these ideas and states, “...paintings to me are a form of prayer, as I believe that work is worship. When I work I believe that I am worshipping. The paintings are a form of prayer or supplication." ${ }^{n 36}$ Therefore Rogers not only attempts to apply broader spiritual ideas to the formal composition of his paintings, but in trying to live as a Bahá'í, believes that his endeavours will ultimately lead to art that has a spiritual purpose akin to prayer.

\footnotetext{
${ }^{34}$ Curatorial file, Winnipeg Art Gallery. See Rogers comment with regards to Tobey's influence in L. Bell, "A Message of Celebration and Supplication," 19

${ }^{35}$ See 'Abdu'l-Bahá, in The Importance of the Arts, ๆ 12.

${ }^{36}$ Rogers in L. Bell, "A Message of Celebration and Supplication," 22.
} 
Rogers explains that for him the spirit and the intellect are intertwined. Similarly he likens the creation of art to the acquisition of knowledge. He bases this argument on the Bahá'í writings that explain that there are four ways to acquire knowledge: through the world of the senses, through the faculty of the rational mind, through tradition that has been passed down, and lastly through the spirit. ${ }^{37}$ This explains why, for Rogers, art, spirituality and intelligence are all interrelated.

In a talk given in 1996, Rogers explained that the knowledge an artist wants to convey in a painting is intellectual in nature, meaning that it does not have an outward form. However, even though it is intellectual in nature, it is conveyed in a sensate way, for example, through colour, texture and form. The other way that this spiritual or intellectual knowledge is conveyed, according to the artist, is through the use of metaphors. Rogers warns that metaphors, as some might think, are not entirely based on the senses. ${ }^{38}$ Rogers supports his argument for art as an intellectual activity by drawing on the work of Hegel as well as the Bahá'í writings. The German philosopher wrote, "Insofar as works of art are produced by mind, they are essentially spiritual," while a Bahá'í document states, "The endowments which distinguish the human race from all other forms of life are summed up in what is known as the human spirit; the mind is its

\footnotetext{
37 'Abdu'l-Bahá, "The four methods of acquiring knowledge," Some Answered Questions, 297-299.

${ }^{38}$ Rogers, "Divine Influence and Human Response," [unpaginated, 5] and "A Short Essay in Nine Parts," in Canadian Art Galleries, New Paintings and an Essay by Otto Donald Rogers, (Calgary, AB, 1991), ch. 5, [unpaginated, 5].
} 
essential quality. ${ }^{.39}$ The sources he draws on equate the spirit and the mind, and Rogers also sees no contradiction between spirit and intellect, art and knowledge.

Rogers believes, and openly acknowledges, that the writings and teachings of the Bahá'í Faith have influenced to a significant degree not only his life but also his art. The artist also thinks that in turn, his art allows him to gain insights into some spiritual concepts of the Bahá'í Faith. ${ }^{40}$ In this way he views his religious beliefs, his life and his art as an interconnected and interdependent cycle of activity. The repeated references to landscape elements in his art are significant and need to be explored further. In view of his emphasis on spiritual concepts, it is important to consider whether the artist sees a strong connection between landscape and spirituality.

\section{ROGERS'S VIEW OF THE LAND}

From the earliest years until now, my paintings have been engaged with this most perfect of metaphors-the landscape. ${ }^{41}$

The imagery of "nature" or the "land" features prominently in the works of Rogers and it has two sources: first, the Bahá'í concept of nature and second, his experience growing up in the Prairies. Although his art has become increasingly more abstract since the late 1960s, the artist himself professes that it still "hinges on landscape" and "is rooted in landscape. ${ }^{942}$

\footnotetext{
${ }^{39}$ Hegel as quoted by Rogers, "Divine influence and human response," and The Universal House of Justice, The Promise of World Peace, as quoted by Rogers in Murray, The Best Contemporary Canadian Art, 148.

${ }^{40}$ Rogers, "Divine Influence and Human Response," [unpaginated, 1].

${ }^{41}$ Rogers, "A Short Essay in Nine Parts," ch. 7, [unpaginated].

${ }^{42}$ Rogers, "Divine Influence and Human Response," [upaginated, 8].
} 
Bahá'u'lláh's writings, as well as more recent Bahá'í scholarship specifically concerning the conservation of the earth's resources, provide a useful guide to understanding the Bahá'í point of view toward the land. In their cosmology, Bahá'ís respect the physical world for several reasons: because it was created by God and is a reflection of the spiritual; because the spirit or the attributes of God are present in all created things; and, because the soul of human beings comes into being at the time of the body's conception and spends the initial phase of its life in the physical world. Inspired by these teachings Rogers writes,

That this world so physical and so prescribed, should be so infused with another world devoid of time and place will forever remain a mystery. Perhaps the key to that mystery is the realization that the physical and spiritual domains are entirely interdependent. The contradictions we imagine between these two worlds exist only because of our limited view of creation and of the reality of the worlds of God. Reality is a single point. ${ }^{43}$

An environmental writer, Paul Hanley, has identified three principles that are paramount when considering the Bahá'í attitude of human beings to nature: unity, detachment and humility. Unity indicates that all created things, whether animate or inanimate, are essentially interconnected. Human beings and the natural world are therefore closely tied together and interdependent. Hanley acknowledges that it might be difficult for some to acknowledge the sacredness of nature, and that it is perhaps more easy to accept its interconnectedness. Secondly, and firmly related to the principle of unity, is the principle of detachment from the natural world. Detachment in this context

${ }^{43}$ Rogers, "A Short Essay in Nine Parts," ch. 7, [unpaginated]. 
implies that "the development of human consciousness remains limited if it is oriented only to the material reality... The physical world is problematic only if it is seen as an end in itself. Thus detachment from the physical world is a means of gaining conscious access to the spiritual realities that lie behind and beyond the physical. Paradoxically, this detachment allows us to see that the physical world perfectly and fully reflects the spiritual world."44 Finally, there is the attitude of humility, which Bahá'u'lláh states is best exemplified by the earth. He reminds the reader that the source of our prosperity and wealth is the very earth that we tread upon and he believes that anyone who is aware of this condition will be characterized by an attitude of humility ${ }^{45}$

Based on the above concepts, the Bahá'í teachings propose that as humanity evolves and matures, it should neither be totally dependent on nature, nor should it be completely removed and seek to dominate it. The middle ground should be sought. "Thus the centre of existence is neither humanity nor Nature (neither anthropocentrism nor biocentrism). It is God through his Manifestation..."46

Rogers readily applies the principle of "detachment" from the natural world to his art. He has stated that he wants to move away from landscape features in his work, and

\footnotetext{
${ }^{44}$ Paul Hanley, "Agriculture: A Fundamental Principle," The Journal of Bahá'i Studies, Vol. 3, no. 1, (1990-1991), 1-17 as quoted in Robert A. White, Spiritual Foundations for an Ecologically Sustainable Society. (New York: Bahá'í International Community, 1989), 7.

${ }^{45}$ See Bahá'u'lláh, Epistle to the Son of Wolf, (Wilmette, IL: Bahá'i Publishing Trust, 1988), 44, and Gleanings from the Writings of Bahá'u'lláh, ๆ V, 7-8.

${ }^{46}$ White, Spiritual Foundations, 10.
} 
toward more non-objective art. However, he has found it difficult to detach himself entirely from landscape elements. In fact, the total loss of any kind of reference to the natural world would probably undermine Rogers's work, as it acts as a perfect metaphor for a spiritual reality in the Bahá'í world view.

In addition to the Bahá'í sacred writings, the other important influence on Rogers's outlook toward the land is his close relationship to the topography of the prairies. It was in his formative years on his parents' wheat farm near Kerrobert, Saskatchewan that the artist began to feel a great affinity for nature and the prairie landscape. Rogers describes how he took obligatory walks every day - to and from a single-room school during the day and to gather the animals in the evening. He states that those "daily trips were as much a journey into the mind as they were over the prairie earth. ${ }^{947}$

It was upon his return to Saskatchewan from his studies in the United States that the landscape motif became increasingly important in his work. As Rogers succinctly states, "landscape found me." " In the 1960s and 1970s, for example, the artist used a tree motif repeatedly and heavenly bodies such as clouds, stars, sun and moon were also common. We see this for example, in Cloud Rotation [Fig. 18] of 1970, where clouds and stars hover over the land, conveying a great sense of space. ${ }^{49}$ But in his later works

\footnotetext{
${ }^{47}$ Rogers, in "Reflections on the Spiritual Quest of the Artist," [unpaginated].

${ }^{48}$ Keith Bell, "Otto Donald Rogers," Five from Saskatchewan, (Saskatchewan: Saskatchewan Arts Board, 1983), [unpaginated].

${ }^{49}$ Collection Canada Council Art Bank, Ottawa, Ontario.
} 
these natural motifs almost disappear completely. The only reference to the land in his highly abstracted paintings is a horizontal line, usually in the centre of the canvas, "where earth meets sky and matter meets nothingness." ${ }^{\text {50 }}$ Dots, triangles and lines replace the more naturalistic rendering of nature. Yet even here, Rogers maintains the importance of the landscape reference:

From the earliest years until now, my paintings have been engaged with this most perfect of metaphors - the landscape. My use of the landscape was always indirect, first establishing the most obvious features, commonly understood, and then quickly moving to a philosophic engagement with light and with the horizon line, the symbolic demarcation which separates what can be seen from what can only be imagined. ${ }^{51}$

This statement underscores that Rogers's view of nature is symbolic, which allows him to work in a highly abstract manner. It also echoes the idea introduced earlier, namely that Rogers tries to convey spiritual or intellectual knowledge through his art. This can also be linked to the Bahá'í view which proposes detachment from the transitory aspects of the physical world.

Rogers's choice of landscape elements in his art stems from his close association with the prairie landscape in his childhood as well as the Bahá'í writings which consider the natural world as a reflection of divine attributes and as the perfect metaphor for spiritual concepts. It is therefore easy to understand why the landscape motif is such an integral part of his artistic vocabulary. The following discussion will explore in more

${ }^{50}$ George Moppett, "Otto Rogers: Paintings, Collages and Assemblages 1973-1982," Mendel Art Gallery, Otto Rogers: A Survey 1973-1982, (Saskatoon, SK, 1982)," 4.

${ }^{51}$ Rogers, "A Short Essay in Nine Parts," ch. 7, [unpaginated]. 
depth Rogers's use of symbolism and metaphor in works that aspire to convey a spiritual content.

\section{THE SPIRITUAL SYMBOLOGY OF ROGERS'S ART}

I think of my paintings as prayers, supplications, ... a finite thing reaching out to the infinite. ${ }^{52}$

Rogers's paintings are replete with spiritual symbolism inspired by the teachings of the Bahá'í Faith. The artist has repeatedly stated the importance of his religion to his life and work, while also acknowledging that his upbringing on a farm in the prairies had a significant impact on his artistic output. One realizes that he is not so much trying to portray the teachings of the Bahá'í Faith or to illustrate its history, but is making an effort to apply some of its broad principles to his art. The works that will be discussed either make reference to the land or depict a horizon line, the demarcation point between earth and heaven. The majority of these works are abstract-a visual language chosen by Rogers because of its philosophical and symbolic possibilities rather than for purely formal considerations. Like many twentieth-century artists such as Kandinsky and Harris before him, he found abstraction an appropriate means by which to convey spiritual concepts. Critic and curator Nancy Tousley explains how "Rogers's goals have always been different from other abstractionists working in the prairies.... Although Rogers has cleaved to the modernist tenets of keeping the painting flat and its surface in tension, his equal loyalty to content determined that he was never a member of the formalist camp. ${ }^{.53}$

\footnotetext{
${ }^{52}$ Rogers as quoted in Sheila Robertson, "Otto Rogers invites scrutiny of paintings," Star-Phoenix, 2 Oct 1982 [page unknown].

${ }^{53}$ Nancy Tousley. "Spiriting the Seen and the Imagined," Border Crossings, Vol. 18, no. 2 (May 1999), 52.
} 
Most of the works that will be discussed were created in the 1970s and 1980s. However, these concerns also appear occasionally in his earlier productions. For example, his more figurative serigraph print, Reaching for the Sun of 1958, depicts a field of flowers that are yearningly reaching towards the sun. ${ }^{54}$

\section{Sunset Stillness}

In the 1960s Rogers's landscapes were more representational with recognizable depictions of trees, hills, suns and stars. He became particularly well known for his "lollipop-" or "mushroom-" shaped trees. This tree motif appeared repeatedly in his works of those years and appears to represent for him a deeper spiritual significance. One example is his oil-painting Sunset Stillness of 1966 [Fig. 19] where a single tree with a setting sun exudes a sense of calm and quietness. ${ }^{55}$ Like a halo above a head, the sun hovers just above the crown of the tree. Bands of green and blue surround the edges of the canvas. The tree and the frame are painted in dark colours with the sun and background in luminous beige. The sun and the background of the painting seem to radiate independently without the need of an external light source. The painting also seems to vibrate and emit warmth.

The tree motif was highly significant to Rogers. The shape of these trees is a reference to Rogers's childhood experiences with "puffballs on the farm which when

${ }^{54}$ Serigraph on paper, $65.8 \times 86.4 \mathrm{~cm}$, collection Mendel Art Gallery, Saskatoon.

${ }^{55}$ Other examples from the series include Summer Noon Storm (1966) collection Hamilton Art Gallery, White Tree (1966) and Point of Attraction (1972) both collection Canada Council Art Bank. 
kicked, produced a cloud of black dust-images which were to recur (via Klee) in the "lollipop" tree series..." 956 Although the shape of the tree was inspired by an encounter with nature, the choice of the tree motif has a deeper significance for the artist. In an interview, Rogers acknowledges that to him the tree is "a symbol of prayer and human growth. Our roots are in the earth but our aspiration is toward heaven. A world of art itself starts with materials from the ground but its fruit is elevated above the matter and toward the world of the spirit!"57 And in another instance, while commenting directly on Sunset Stillness, Rogers writes, "The tree, associated with human growth, appears bathed in the divine light of knowledge and understanding. Symbolically the tree is also equated with a prophet — an intermediary between us and God." ${ }^{158}$

Attributing human feelings to non-human subjects, especially using landscape elements such as trees, is, according to art historian Robert Rosenblum, very common among certain artists. He explains that this tradition was not only practised among the artists of the Romantic movement, but also among later artists such as Van Gogh and the early Mondrian who inherited its traditions. In their works trees often acted as protagonists, or like a human presence. In Canada, Harris's trees have been also interpreted to represent human beings such as those depicted in Lake Superior (c. 1924) [Fig. 20]. Rosenblum also comments on the recurrent use of the image of the sun by

\footnotetext{
${ }^{56}$ Keith Bell, “Otto Rogers,” Otto Rogers, exh. cat. Norman Mackenzie Art Gallery, (Regina, Sask., 1977), unpaginated.

${ }^{57}$ Rogers as quoted in Sarnia Public Library and Art Gallery, "Trees for your thoughts" artist's questionnaire, (1980), artist's file Mendel Art Gallery, Saskatoon.

${ }^{58}$ Rogers as quoted in Moppett, "Otto Rogers," 8.
} 
artists who are part of the Northern Romantic tradition. Kandinsky's use of a blazing sun as a symbol of divinity or revelation toward which human beings and nature aspire is one example. ${ }^{59}$ This parallels an idea found in the Bahá'í writings, where the sun is often used as a metaphor for the Manifestations of God or as a symbol for God. ${ }^{60}$ It is a useful metaphor as it illustrates that just as the physical sun ensures the life of all things on earth, likewise the divine is a source of life for the spirit.

In his essay for the exhibition catalogue The Spiritual in Art: Abstract Painting 1890-1985, Maurice Tuchman identifies five structures that he claims are based on modes of thought. These "five underlying impulses within the spiritual-abstract nexus" have been translated by artists interested in the spiritual into non-figurative visual forms. They are cosmic imagery, vibration, synaesthesia, duality and sacred geometry ${ }^{61}$ Referring to the artist's oeuvre Tousley states that, “[a]ll five impulses are present in Rogers's work." ${ }^{\prime 62}$ A brief exploration of how some of these "impulses" appear in Rogers's work is worthwhile.

Cosmic imagery, according to Tuchman, suggests the mystical concept that the universe is a single living substance. This has lead to a search for "the underlying life-

\footnotetext{
${ }^{59}$ Robert Rosenblum, Modern Painting and the Northern Romantic Tradition: From Friedrich to Rothko, (New York: Harper \& Row, 1975), 36-39, 90, 147.

${ }^{60}$ Bahá'u'lláh, Kitáb-i-Íqán-The Book of Certitude, trans. Shoghi Effendi, (Wilmette, IL: Bahá'í Publishing Trust, 1983), 34. See also footnote 21.

${ }^{61}$ Maurice Tuchman, "The Spiritual in Art: Hidden Meanings in Abstract Art," Tuchman et.al., The Spiritual in Art: Abstract Painting 1890-1985. (New York: Abbeville Press, 1986), 32.

${ }^{62}$ Tousley, "Spiriting the Seen and the Imagined," 52.
} 
form, the Ur-form, the thyrsus, the spiral, the double ellipse." ${ }^{63}$ Rogers's "lollipop trees" in works such as Sunset Stillness, are reminiscent of this concept of the spiral and the lemniscate, especially as the latter has the sun hovering over the tree. ${ }^{64}$ The choice of the spiral is also significant in light of Rogers's agreement with philosopher Rudolf Arnheim's discussion of the perceptual basis of the importance of a centre and a circular movement along a spiral in a composition. Arnheim shows that there is an interrelationship between compositional organizing principles and movement from a centre. He explains that the concept of the Cartesian grid - as a means of creating a sense of order-as well as the inclusion of a centre create power and movement. Arnheim explains,

The interaction between the two spatial systems generates formality and complexity-it represents, symbolically, the relation between the cosmic perfection of which any thing or creature possesses a little and the struggle between downward pull and upward striving that marks the drama of our earthly behaviour. ${ }^{65}$

After reading Arnheim, Rogers realized that many of his favourite paintings combined the spiral arrangement with the grid system. ${ }^{6}$

Sunset Stillness might also serve as an example of what Tuchman terms "duality" or paired opposites, in this case represented by stillness and motion. This means that the

${ }^{63}$ Tuchman, "Hidden Meanings in Abstract Art," 31-32.

${ }^{64}$ This work is also reminiscent of Adolph Gottlieb's work whom Rogers admires.

${ }^{65}$ Rudolf Arnheim, "Introduction," The Power of the Center: A Study of Composition in the Visual Arts (London: University of California Press, 1982), as quoted in Rogers, "A Short Essay in Nine Parts," ch. 9, [unpaginated].

${ }^{66}$ Rogers, "Divine Influence and Human Response." 
painting is both still and calm and yet the viewer's eye is in constant motion along the spiral shape of the tree and sun. Other sources of movement, this time outward, are the bands of colour around the edges which create a sense of "vibration," representing another one of the impulses identified by Tuchman. For Rogers to be satisfied with his paintings, they "have to be absolutely still and absolutely full of motion simultaneously..." ${ }^{67}$ And in another instance he explains why these are such important elements in his work: "Motion and stillness are key players in the aesthetic drama, which stands as a sign for man's struggle in this life." ${ }^{168}$

Both deep space and light are associated with evoking a spiritual dimension. In Sunset Stillness Rogers seems to be particularly concerned with light in favour of deep space for creating a spiritual atmosphere. For example, he has in a characteristic manner framed the rectangular canvas with borders in dark green and a luminous blue-green colour. At the bottom of the tree he has used a band of bright blue colour. All these formal devices create a frame within a frame and help to reaffirm the integrity of the picture plane or, more significantly, could suggest its opening up. ${ }^{69}$ But Rogers reaffirms that those bands on the edges of his canvas do not serve purely formal reasons. As he explains,

When people saw bands of color on the canvass [sic] they thought I was painting windows. But that was not the idea at all. It was when the tree became filled with energy. These vibrations on

\footnotetext{
${ }^{67}$ Otto Rogers, taped interview June 1973, Mendel Art Gallery archives.

${ }^{68}$ Rogers in Murray, The Best Contemporary Canadian Art, 148.

${ }^{69}$ Moppett, "Otto Rogers: Paintings, Collages and Assemblages 1973-1982," 8.
} 
the edge of the canvass were a kind of after image. So in a sense the tree was supplicating to a power outside itself, and when it did that it attracted that power to itself... ${ }^{70}$

Even if the bands do have the effect of defying deep recession into space - one of the main elements necessary in creating a spiritually-oriented landscape - the other element, light, is able to shine even more brightly and thereby exudes a spiritual atmosphere.

The importance of light as an expressive element in the paintings of Rogers and many other artists interested in the spiritual is noteworthy. Light is not just employed in paintings for its formal effect but acts as a means of expressing the spiritual. Literary critic Northrop Frye identifies three phases in the myth of light: the first beginning with "God," the second with "man" and the third with "nature." He reminds us that in the Bible the myth of creation begins with "God said, Let there be light." He also sees light as "the central symbol of all knowledge and understanding." Light is also used to remind us of the struggle with darkness. ${ }^{71}$ It has been suggested that Paul Klee inspired Rogers to use light in this particular fashion. ${ }^{72}$ As Rogers is a great admirer of Klee's work, this is quite possible.

Rogers's use of light is reminiscent of works by abstract-luminists, whose work "emerges...from a kind of theo-aesthetic that regards the pursuit of the Sublime as a

\footnotetext{
${ }^{70}$ Rogers, in I.M. "Otto Rogers-artist-sculptor-New Head University of Saskatchewan Art Department," Folio, (Sep 1973), 11.

${ }^{71}$ Northrop Frye, "The myth of light," Artscanada, Vol. 25, no. 5 (Dec 1968), 8.

${ }^{72}$ Tousley, "Spiriting the Seen," 52.
} 
means of directing art away from merely sensual concerns towards more metaphysical goals." The "transcendentalist wing" of Abstract Expressionism, Rothko, Newman and later Agnes Martin are regarded as proponents of abstract-luminism. Their works are characterized by a strong sense of inner light, often otherworldly in character. ${ }^{74}$ Like Rothko in particular, Rogers succeeds in this work in creating a sense of luminosity using striking contrasts of tone and hue. Through the manipulation of formal aspects of Sunset Stillness work he creates a distinctly emotional or intellectual impression on the mind which has a spiritual effect on the viewer.

Light is fundamental to Rogers's art, as is the ever-recurring theme of unity. Through the study of the Bahá'í Faith, he has come to believe that unity itself is light. He explains,

I came to the conclusion that obviously the most important element was light, and the most important principle unity. Without light you have nothing, no colour, no texture, no definition, no form. And without unity the thing just dissolves, there's no order....[U]ntil I discovered what Bahá'u'lláh,... said about it, I had never put the two things together. He wrote, "So powerful is the light of unity that it can illuminate the whole earth." 75

When it comes to spirituality in art Rogers equates the importance of the element of light with the principle of unity. In Sunset Stillness he focuses on the element of light and not so much on directly conveying the concept of unity. While some of his other works also focus primarily on light, increasingly he has shown more interest in conveying or

\footnotetext{
${ }^{73}$ Simon Morley, "Light as Surface," Contemporary Visual Arts, no. 15, 1997, 30-31

${ }^{74}$ Ibid., 31-32. See also Max Kozloff, "Light as Surface," Artforum (Feb 1968), 26-30.

${ }^{75}$ Rogers in Gustafson, "Interview: Otto Donald Rogers," 29.
} 
applying the concept of unity directly, leading him to greater abstraction in his use of light, as well as more generally in his art.

\section{Cloud Rotation}

I think primarily, that the whole creative act, if you want to call it that, exists somewhere between what you know and what you don't know-it's that desperate reach between the poles of the known and the unknown - that tantalizing mystery of life that keeps us going... ${ }^{7}$

If light was the primary means of creating a sense of the spiritual in Sunset Stillness, deep space is the most important element in other works. Rogers's landscape Cloud Rotation (1970) [Fig. 18] conveys a sense of a vast space. The painting has horizontal bands of colour at the bottom of the canvas representing the land. The rest of the canvas represents the sky. The sky is filled with numerous well-defined, rock-like cloud formations and $\mathrm{x}$-shaped stars. The top-most cloud is executed in blue, whereas the rest are in green or black. One feels the expanse of the prairies created through the use of a very low horizon line, where a vast sky dominates a narrow band of land. The number and "weight" (achieved through the use of impasto) of the clouds increases toward the top half of the painting, drawing the eye from the deep space of the lower half of the painting to the surface of the canvas. This push and pull between deep space and the surface of the canvas creates a sense of movement or "rotation" in an otherwise calm painting.

${ }^{76}$ Rogers as quoted in I.M. "Otto Rogers-artist-sculptor," 11. 
The use of vast space as a metaphor for spirituality is reminiscent of Friedrich's "dwarfing infinities of nature" $"$ discussed in Chapter I, or Harris's infinite spaces that came to the fore in his Lake Superior canvases painted after 1922. For Harris, a vast space was a metaphor for a developing consciousness. ${ }^{78}$ The creation of a vast and endless space in Rogers's paintings hearkens back to the immense prairie landscape but also evokes the spiritual worlds that he as a Bahá'í believes to exist, even though they are not visible to the eyes. He is not so much implying that his paintings are those spiritual worlds, but is trying to make his audience aware of a greater reality beyond this physical world.

Space and depth in a painting are created by providing the viewer with two reference points: one near and one far. Friedrich's paintings achieve a sense of deep space through the placement of a human figure or a tree in the fore- or middle ground. Harris's North Shore, Lake Superior $(1926)^{79}$ places the tree stump in the foreground of the canvas and contrasts it with the vastness of the lake and sky. Rogers partly achieves depth and space in Cloud Rotation through the use of a low horizon line and partly by a contrasting surface of impastoed colour used for clouds in the upper half of the canvas against more diluted colour for those closer to the horizon line. The sheer scale of the

\footnotetext{
${ }^{77}$ Rosenblum, Modern Painting and the Northern Romantic Tradition, 14.

${ }^{78}$ Jeremy Adamson, Lawren S. Harris: Urban Scenes and Wilderness Landscapes 1906-1930, (Toronto: Art Gallery of Ontario, 1978), 142.

${ }^{79}$ Oil on canvas, $(101.6 \times 127 \mathrm{~cm})$, collection National Gallery of Canada, Ottawa.
} 
canvas $(152.5 \times 213.5 \mathrm{~cm})$ also contributes in a significant way to creating a sense of space which extends beyond human dimensions.

Rogers has stated that he wants his work to become less figurative by reducing or excluding references to the land, clouds, water and sky. ${ }^{80}$ Cloud Rotation is indeed more abstract than for example, Sunset Stillness, or other works from his "tree series." Yet, he seems unable to leave all references to the landscape behind and in fact acknowledges that he feels uncomfortable without it. For example, with regards to his repeated use of the horizon line in his paintings the artist states, "It's a point of reference-a structural tool that I hang the rest of the painting on." ${ }^{91}$ Even if the artist hopes to move toward pure abstraction, the continued use of landscape elements in his works seems to demonstrate that these are in fact important elements in his vocabulary and that they are integral to conveying spiritual ideas in his art.

Writers and critics agree that the horizon line in Rogers's work is much more than a "structural tool." For the critic Lora Burke, for example, Rogers's iconographic use of the horizon line does not simply represent a division between earth and sky. Rather it is "a transition point between the corporeal and the ethereal, between the limitations of the physical body and the limitless freedom of the mind. ${ }^{{ }^{82}}$ For art critic and professor of

\footnotetext{
${ }^{80}$ Taped interview with Otto Rogers, June 1982, Mendel Art Gallery archives.

${ }^{81}$ Gary M. Dault, "Otto Rogers goes behind the surface," [Globe \& Mail?, 1977?], artist's file, Robert McLaughlin Gallery, Oshawa, Ontario.

${ }^{82}$ Lora Burke, "Two exhibitions displayed," The Leader-Post, Regina, 9 March 1977.
} 
English literature Ross Woodman, the horizon line is one of Rogers's chief compositional devices. He believes that the horizon line stands as a metaphor for God. He explains that in the Bahá'í writings God is considered to be unknowable in His essence and cannot be reached. In the same way the horizon line is always visible to the viewer but any attempt to reach it is futile as it recedes further the closer the viewer draws. ${ }^{83}$

In a statement made in 1991 Rogers confirms the importance of the horizon line beyond its compositional function:

My use of the landscape was always indirect, first establishing the most obvious features, commonly understood, and then quickly moving to a philosophic engagement with light and with the horizon line, the symbolic demarcation which separates what can be seen from what can only be imagined. ${ }^{84}$

It appears that the repeated use of the horizon line in Rogers's oeuvre is not only a formal device but creates spiritually significant iconography on several levels. In paintings where he employs a low horizon line, the artist is able to create a space that is spiritually charged, evoking other realms. The inclusion of a horizon line-a common feature of his work in the 1980s —often facilitates the creation of space, but more importantly, it acts on a metaphorical level as the dividing line between heaven and earth, the spiritual and the material realms.

${ }^{83}$ Film Crew Production, Approach to a Sacred Place: The Art of Otto Donald Rogers, Director, Davidson, Tom. Producer, Donnelly, Clark. [Videocassette, 57:50], Regina, Sask., 1992.

${ }^{84}$ Rogers, "A Short Essay in Nine Parts," ch. 7, [unpaginated]. 


\section{Movement of Light through Darkness}

... any movement animated by love moveth from the periphery to the centre..85

Movement of Light through Darkness (1981) [Fig. 21] was executed a decade after Cloud Rotation, and shows Rogers's interest in moving closer to non-objective art. A rectangle and several dark blobs of paint, squeezed directly out of the tube, replace landscape elements. Yet the horizon line, which divides the canvas horizontally into equal halves, creates an automatic reference to the landscape.

This painting is very dark and it is only after careful observation that a narrow area of light becomes discernible. As the title suggests, it indeed represents a movement, or a struggle, of a small area of light through darkness. The source of light is a thinly spraypainted area on raw canvas at the bottom and in the lower left corner of the canvas, creating an L-shape. The dark brown tones in the upper half of the canvas make the surface seem impenetrable, which is further suggested by its visible horizontally-running brushstrokes. Yet despite all of these factors, one gets the impression that should the light reach this dark area, the darkness will give way to the struggling light as suggested by the matte light reflected off the acrylic surface. In addition to black, the lower half is executed in tones of somewhat higher value such as dark red and dark brown. This seems to suggest that the area closest to the light is better able to reflect light and therefore also has relatively more colours.

85 'Abdu'l-Bahá, Selections from the Writings, đ| 166, 197. 
Because of the abstract nature of the painting, a literal interpretation of the work is futile. However, it is helpful to know what the artist has to say about Movement of Light through Darkness. He states, "Because there's a lot of absence of light in the world, we have to struggle to increase the light.... For evil to exist at all is proof there is light. It's a confirmation." ${ }^{" 86}$ His comment is based on the Bahá'i philosophy which explains that as darkness is the absence of light, so evil is the absence of good. ${ }^{87}$ This is in contrast to the Christian tradition where evil is thought to have a real presence.

The painting may be an attempt to represent the concept that since darkness is the absence of light, therefore light is more powerful. This is supported by the fact that only a small area of light is able to penetrate and potentially illuminate a vast area of darkness. The dark parts closest to the light are already affected by the light and are taking on the characteristics of light. Thus the overall effect of the painting illustrates Rogers's belief that we must struggle to increase light.

Since 1972 the artist has repeatedly used the dot motif in his paintings, as in Movement of Light through Darkness. These often dark dots have functioned both as a formal device by reaffirming the picture plane but also as "a focal point, as though for

\footnotetext{
${ }^{86}$ Rogers as quoted in Robertson, "Otto Rogers invites scrutiny of paintings," [page unknown].

87 “Abdu'l-Bahá, "The Nonexistence of Evil," Some Answered Questions, 264.
} 
meditation." ${ }^{188}$ According to Rogers, these dots are symbolic of the soul's yearning to be free from a rigid set of grids. ${ }^{89}$ The points also signify powerful centres of attraction. He writes,

Attraction then can be considered in relationship to a powerful centre. For the past decade or more the paintings I have worked on seem to require powerful points positioned in the space which hold in suspension all other elements. These points sometimes suggest stars, celestial disks, or even a kind of omnipresent eye. When there is more than one, they measure the space while your eye convinces the mind that the distance is immeasurable. ${ }^{90}$

Movement of Light through Darkness is one of the many paintings where Rogers employs Arnheim's two spatial systems, described earlier. The horizontal line dividing the canvas in two creates "order, ... discipline, and calculation." ${ }^{\text {"91 }}$ A glob of paint or modelling paste in the centre of that line draws our eyes to the centre of the canvas, then our eyes jump to the other dots which are seemingly randomly scattered on both halves of the canvas. In the end our eyes seem to always come back to the centre dot, creating a continuous up- and downward or spiral movement. As already noted in the discussion on Sunset Stillness, Tuchman has identified the spiral as one of the five elements found in the work of abstract artists interested in the spiritual. For example, the Swedish painter Hilma af Klint (1862-1944) who was interested in spiritualism and later became a follower of Rudolf Steiner, uses the spiral motif repeatedly in her work. Her "painting Group 6, No. 15 from the Series W.U.S./ Pleiad (1908) [Fig. 22] deals with evolution; the

88 [Elizabeth] Liz Wylie, “Otto Rogers' Mementos,” Vie des Arts 28, no. 3 (Summer 1983), 78.

${ }^{89}$ Rogers, "Divine Influence and Human Response."

${ }^{90}$ Rogers, "A Short Essay in Nine Parts," ch 9, [unpaginated].

${ }^{91}$ Ibid. 
spiral in the center reflects a Blavatsky diagram depicting evolution." ${ }^{22}$ Rogers's use of the spiral motif is more complex in that he attempts to direct the reaction of the viewer to create the spiral motion. This involvement of the viewer seems to be in accord with the artist's desire to engage the mind of the viewer.

\section{Ascending Landscape}

The collage Ascending Landscape (1980) [Fig. 23] is made of several different coloured, layered pieces of paper as well as acrylic paint and charcoal. Rogers's characteristic horizon line is prominently placed in the lower half of the collage, creating all at once the sensation of a landscape. At the top of the white paper is a bleeding black charcoal line that swings upward. Just below it, Rogers has placed a square piece of beige paper with two small holes on the upper right and lower left of the paper and through which a charcoal dot is visible. Below the square is a rectangular piece of dark beige paper that has been mostly covered in jade green paint, with a small dot or sun placed in the top centre. An obliquely placed, light cream-coloured rectangle runs through the green, the dark beige and down to the supporting white paper. Its shape is mirrored in the upper half by the charcoal line. Through the mirroring of these two elements the artist has introduced an unexpected twist to the composition. The collaged paper rectangle creates a sense of upward movement that leads the eye to the dots and the charcoal line above, and back down again. Suddenly this work which is composed of

\footnotetext{
${ }^{92}$ Sixten Ringbom, "Transcending the Visible: The Generation of the Abstract Pioneers," in Tuchman et.al., The Spiritual in Art: Abstract Painting 1890-1985, (New York: Abbeville Press, 1986), 150.
} 
materials of low colour value, becomes enlivened through the creation of a continuous movement — a characteristic important to the artist.

Like many other artists interested in the spiritual, Rogers has adopted the language of abstraction as his career has evolved. Ascending Landscape is a good example of an utterly abstracted landscape, especially as compared to his tree series or Cloud Rotation. His use of abstracted forms and his involvement with the Emma Lake workshops might mislead some to believe that his concerns are purely formal. In fact the choices he makes in his art are primarily dictated by spiritual concerns.

Rogers justifies his use of abstraction by pointing out that an earlier religion has encouraged it. He explained in a conversation how the prohibition of the depiction of human forms in the Islamic tradition has resulted in a rich history of using geometric motifs - a highly abstracted art form. In his view Islamic art does not necessarily depict the Qur'án but tries to convey its spirit. He argues further that all art is abstract as it is derived through arranging form, colour, and texture. Art is also abstract because it is not reality. Even a photograph mediates visual experience as it captures only a fraction of a second. For Rogers, the language of abstraction is most suitable to express the idea that the physical world is a reflection of the spiritual one. He looked at Modernists such as Matisse and realized that with his landscape paintings or landscape elements he could be creating bridges to the unknown. For Rogers, expression is rooted in experience and 
therefore it is reasonable to start with an experience everyone is familiar with such as hills, water and the like. As an artist he tries to create a dialogue between these two worlds, which he believes occurs partly on a conscious level and partly on an unconscious one. ${ }^{93}$ Rogers explains his use of the landscape motif in his work in relation to abstraction,

Over time the degree of abstraction has increased, and yet the images have become more familiar; even the obvious elements such as trees and hills have given way to geometric shapes which act in the drama of light and dark while providing a pictorial device to anchor the flow of undefined energy. ${ }^{94}$

Whereas some maintain that Rogers is a landscape painter, others, like the art critic Peter Millard, see him first and foremost as an abstract painter. Although Millard states that Rogers has successfully met the real challenge of the prairies, namely to depict its space and light, yet he believes that "it has happened almost inadvertently while he was pursuing artistic concerns that might seem to have little to do with prairie landscape." Sometimes the landscape element is intentional but at others it just emerges. ${ }^{95}$ This is an accurate observation with regard to Rogers, as it is clear by now that his primary interest is the philosophical or religious intention behind the work.

Ross Woodman offers an explanation for Rogers's choice of abstraction as his formal language. According to Woodman, an abstract mode of painting employing

\footnotetext{
${ }^{93}$ Personal conversation with Rogers, Haifa, Israel, 25 Dec. 1997.

${ }^{94}$ Rogers, "A Short Essay in Nine Parts," ch. 7 [unpaginated].

${ }^{95}$ Millard, "Otto Rogers," [unpaginated].
} 
Rogers's distinctive visual vocabulary enables the creation of a universal language that transcends any national and racial barriers. He affirms that Rogers's use of abstraction coupled with his interest in the spiritual takes back abstraction to its original intent. As Woodman further explains:

While influenced by Clement Greenberg and the Emma Lake School...it is clear that the purely painterly qualities of formalism have in his case (as indeed in the case of many other abstract painters) served a larger purpose. That larger purpose resides in making manifest, without attempting to incarnate, an unknown, invisible reality that ultimately transcends the understanding, though it is the very nature of the understanding to make it manifest. Otto Rogers, it may be argued, carries the impulse to abstraction back to a spiritual origin in the unknowable nature of God, an origin that transcends the purely aesthetic concern to isolate and work within the limits imposed by the application of paint to a two dimensional surface. ${ }^{96}$

Rogers's choice of abstraction, like that of Tobey, Harris and Kandinsky before him, seems to largely stem from its suitability to express spiritual ideas. Abstraction is the language or tool he has chosen as the vehicle for conveying metaphors. Again, the content for Rogers revolves around ideas of an unknowable divinity, the vastness of the unknown, and a life beyond the physical.

\section{Approaching the Shore of the Sea of Grandeur}

A work of art needs both light and fire so that we can learn to distinguish between them; it needs separation expressed so that reunion might be recognized. To concentrate on the one without the other would undermine the force of both. In a sense, the drama of human existence consists of the interplay between remoteness from and nearness to Beauty, Wisdom, Order and Love, and art derives its power from the tension and contrast in this interplay. ${ }^{97}$

Rogers has generally divided his square canvases along a horizontal central axis,

but in 1981 he started also to divide it vertically [Fig. 24]. This for some was a move to a

${ }^{96}$ Woodman, A Celebration of the Human Spirit, [unpaginated].

${ }^{97}$ Bahíyyih Nakhjavání, "Artist, Seeker and Seer: A vocabulary and a perspective for the appreciation and creation of art inspired by the Bahá'í Writings," Bahá'í Studies, no. 10, 1982, 11. 
higher degree of abstraction and a break away from the landscape motif thus far so prevalent in his oeuvre. However, according to long-time friend, colleague and art dealer Robert Christie, it was still the same prairie landscape just turned by 90 degrees. ${ }^{98}$ His idea can be supported by the fact that Rogers has sometimes flipped these vertical compositions by 90 degrees, establishing thereby the characteristic horizon line, and has continued work on them in that way. ${ }^{99}$ For some people who are familiar with Rogers's earlier work, even the vertically-divided canvases seem to be rooted in the land even if they emerged on a subconscious and unintentional level.

Writer Sheila Robertson believes that Rogers's challenge in these vertical compositions "is to reconcile the separate halves, without creating mirror images." 100 For example, the left side of the canvas is covered in dark browns and reds. The paint is applied in such a manner that one senses movement. In contrast to that, the right half of the unprimed canvas is left almost intact, save for a fine bleeding of colour from the other half, a thin layer of spray paint and some lines and dots. The right half has a sense of calm and stillness due to the even texture of the canvas which is only disrupted in a few instances by lines and dots. Yet the painting has also a quality of tension to it, created through the presence of the light and dark halves and the polarities of movement and stillness. According to art critic Elizabeth Wylie, both the vertical and horizontal

\footnotetext{
${ }^{98}$ Telephone conversation with Robert Christie, Saskatoon 14 Aug 1999.

${ }^{99}$ Wylie, "Otto Rogers' Mementos," 78.

${ }^{100}$ Robertson, "Otto Rogers invites scrutiny of paintings," [page unknown].
} 
divisions in his paintings, although a formal device, "can be interpreted as spiritual iconography."101 For example it could represent the concept of unity through diversitywhere the two halves despite their differences provide a unified composition. ${ }^{102}$ For the artist this "parallels the struggle...between the inner and outer nature."103

As mentioned earlier, Rogers does not try to illustrate passages directly from the Bahá'í scriptures in his art. However, he often titles a work after it is completed and after he has tried to understand the dynamics behind the painting. He then tries to find a relevant concept or passage from the Bahá'í writings based on which he selects a title. Although the titles of his paintings are not always a key to understanding them, yet in this instance it is helpful to know more about the passage that gave this work its title. The words "the Sea of Grandeur" are found in a book by Bahá'u'lláh, entitled The Four Valleys, which in mystical language explains the path or valleys that a seeker of God must pass through in order to attain to the goal of his or her quest. In the first of the four valleys, Bahá'u'lláh tells the story of a mystic and a grammarian who in their travels, in search of the knowledge of God, come upon the "Sea of Grandeur." The mystic, immediately throws himself into the sea, having recognized it as the object of his quest. The learned grammarian, however, hesitates because he is too preoccupied with trying to understand whether he has reached his goal through the use of logic and reasoning. The

${ }^{101}$ Wylie, "Otto Rogers' Mementos," 78.

${ }^{102}$ Robertson, "Otto Rogers invites scrutiny of paintings," [page unknown].

${ }^{103}$ Rogers as quoted in Robertson, "Otto Rogers invites scrutiny of paintings," [page unknown]. 
mystic urges him to forget his worldly knowledge and to fling himself wholeheartedly into the sea.

The bi-partite canvas acts as a metaphor on several levels in order to convey the essence of the above story. The dark area could reflect doubt or ignorance, whereas the light half of the canvas could act as a symbol for knowledge and certitude. The divided canvas could also be interpreted as the grammarian's dilemma: metaphorically speaking he might be hovering between the vertical line that divides darkness from light. And finally, the divided canvas could act as a symbol that represents human ignorance of the spiritual worlds, despite one's closeness to them. The dots on both halves of the canvas might suggest the interconnectedness of these two realities. The same function of establishing a connection is fulfilled by the dark line that runs intermittently between the two parts, from the top right half to the middle of the left one. ${ }^{104}$

This interpretation seems to agree with the concept of "reunion and separation" as discussed by Bahá'í author Bahíyyih Nakhjavání. She proposes that this concept is necessary for any artwork that wants to reflect the spirit of the Bahá'i teachings. She writes,

I would like to suggest that the concept of reunion and separation, then, is one of the central aesthetic principles for any work that presumes to reflect the spirit of the Bahá'i Revelation. This principle, characteristic of all high-striving-art, combines the full force of extremes - of terror and

\footnotetext{
${ }^{104}$ Some might be tempted to interpret this painting as representing the two principles in Chinese philosophy yin and yang. However, since Rogers is not engaged with those Asian cultural traditions, I believe this a purely visual coincidence.
} 
anger, tenderness and love - within a framework vulnerable enough to reflect and be affected by what it contains, achieving thereby a seemingly miraculous balance, without which both life and art could not possess the imagination with awe or bring the soul toward certitude. ${ }^{105}$

According to the philosopher Jean-François Lyotard, who shares a similar view,

"contradictory feelings" facilitate the expression of the spiritual. He explains that the

"contradictory feeling [of] pleasure and pain, joy and anxiety, exaltation and

depression..." is what constitutes the "sublime" whose "fundamental task ... [is that] of bearing pictorial or otherwise expressive witness to the inexpressible."106

Approaching the Shore of the Sea of Grandeur is one of many which evoke "duality," another one of the five impulses of the spiritual-abstract nexus identified by

Tuchman. By duality, Tuchman means that "the universe is conceived as being comprised of paired opposites (male-female, light-dark, vertical-horizontal), and [that] all things evolve in dialectical opposition." ${ }^{107}$ Rogers's paintings that have been divided either horizontally or vertically, are examples of this category. Approaching the Shore of the Sea of Grandeur is a particularly good example as it demonstrates both verticality but also light and darkness, as half of the canvas is left almost in its original state.

\footnotetext{
${ }^{105}$ Nakhjavání, "Artist, Seeker and Seer," 11. It should be noted that Bahá'u'lláh himself refers to this concept when he praises someone's poetry and states, "Its [the poetry's] perusal hath truly proved impressive, for it was indicative of both the light of reunion and the fire of separation." "Lawh-i-Maqsúd" (Tablet of Maqsúd), published in Tablets, 176.

${ }^{106}$ Jean-Francois Lyotard, "The Sublime and the Avant-Garde," Artforum, Vol. 22, (April 1984), 37.

${ }^{107}$ Tuchman, "Hidden Meanings in Abstract Art," 29, 32.
} 
Despite the polarities of light and dark, movement and stillness, the painting feels balanced and the two halves seem harmonious. This might reflect the Bahá'í concept of moderation, where everything that is taken to excess is seen as harmful. Nakhjavání believes that "balance" and "moderation" do not equate to blandness or sameness. In fact opposing elements are required to arrive at a complete whole. She explains,

...for a work of art to attain "moderation" in Bahá'í terms does not require that it should be preserved from "fire" and "snow" and present a bland temperature of "normality" to the reader [or viewer]. It is the precarious ambivalence between epiphany and betrayal that keeps our attentive spirits attuned to a work of art. In Aristotelian terms, this ambivalence resides in the combination of pity and terror; in the Christian tradition, it lies in the tension between innocence and corruption; in the imagery of the mystics of Islám, it can be found in the perpetual search for and loss of the beloved. Anything less than a structure capable of containing this ambivalence would be artificiality and not art. Balance requires that the "drowning" is commensurate with the "burning" in a work of art, or that the element of "vehement longing" expressing anguish at separation, counteracts the element of rhapsody celebrating reunion. The artist faces the challenge of achieving this balance, but he will fail if he attempts it by diminishing intensity. ${ }^{108}$

The final impulse identified in the spiritual-abstract nexus by Tuchman is synaesthesia. Synaesthesia is the condition where an overlap occurs between the senses.

For example, colours may evoke musical tones or vice versa or tastes may suggest colours. Synaesthesia was one of the hallmarks of the Symbolist artists, but it also interested artists like Kandinsky and Brooker. For example, Brooker's abstract painting Sounds Assembling (1928) [Fig. 25] might be the visual interpretation of the music of Johann Sebastian Bach. ${ }^{109}$ Rogers's In Celebration of the Nightingale's Song (1981) [Fig. 26], could perhaps be seen as an example of his use of synaesthesia. However, the

\footnotetext{
${ }^{108}$ Nakhjavání, "Artist, Seeker and Seer," 12.

109 Joyce Zemans, "The art and Weltanschauung of Bertram Brooker," Artscanada (Feb/Mar 1973), 66; and "First Fruit: The World and the Spirit Paintings," Provincial Essays, Vol. 7, 1989, 17-37; see also Ann Davis, The Logic of Ecstasy, 150-155; for synesthesia and Kandinsky see Tuchman, "Hidden Meanings in Abstract Art," 27, 32.
} 
"nightingale's song" is not a piece of music. In fact Bahá'u'lláh in his own writings, often refers to himself and to his message in the symbolic form of the nightingale and its song. Rogers is not so much translating a passage from the Bahá'í writings into visual form, but rather is paying homage to the revelation of Bahá'u'lláh in paint, as he would in a prayer.

Rogers's paintings and his writings demonstrate the centrality of spirituality in his work. The source of these concepts are the teachings of the Bahá'i Faith. Although he has been trying to move away from direct references to the landscape, yet it remains an important element in his art. While his repeated use of landscape motifs can be attributed to his upbringing on a farm in the Canadian Prairies, his metaphorical use of natural elements shows the profound influence of the writings of the Bahá'í Faith and its attitude toward the natural world. 


\section{CONCLUSION}

Most literary critics and writers on aesthetics contrive to pretend that no moral or religious issues should enter the realm of art; but it is not until we examine the implications of art in the sphere of moral value that we understand why art proceeds upon a knife-edge....

Donald Kuspit in his essay "Concerning the Spiritual in Contemporary Art," states that "Today art does not seem so mighty an element in spiritual life, and spiritual life does not seem so evident in art or in general."2 In contrast, this thesis has proposed that spirituality is indeed relevant to some contemporary artists and that art can be a vehicle for spiritual insights. In fact Robert Houle and Otto Rogers make us aware that physical existence in a materialistic society cannot be the purpose of life, but that there has to be a more important and enduring spiritual aspect to it.

Kuspit's comment is only partially true, since there are a number of artists who are interested in exploring spirituality in their art. Thus far the majority of scholars and critics have to a large extent neglected the spiritual in contemporary art. A few exceptions were introduced in the review of literature that include the spiritual aspirations of artists in the study of contemporary art in Canada. This thesis is a step in introducing the work of two artists primarily from the standpoint of their spiritual ideology and how this finds expression in their art. Both Houle and Rogers, have shown a repeated interest

\footnotetext{
${ }^{1}$ George Whalley, Poetic Process (Cleveland, 1967), p. xxx as quoted in Nakhjavání, "Artist, Seeker and Seer," 4.

${ }^{2}$ Donald Kuspit, " Concerning the Spiritual in Contemporary Art,"in Tuchman et.al., The Spiritual in Art: Abstract Painting 1890-1985, (New York: Abbeville Press, 1985), 313.
} 
in conveying a sense of spirituality through their abstract works. The thesis clearly shows that in order to get a more complete understanding of their work a mode of inquiry is necessary in which spiritual considerations complement formal analysis.

As was demonstrated, the landscape motif forms a central part of Houle's and Rogers's "spiritual" vocabulary in their art. Each uses a physical landscape to symbolize the immaterial and ethereal. Their choice of landscape as a metaphor for their respective spiritual outlook places them within a definite tradition of Western artists, starting in the mid-1700s, who have employed the same means. In more recent times Canadian scholars have shed light on some of the Group of Seven members and their contemporaries, who were influenced not only by their Christian backgrounds but also by their interest in specific spiritual movements that had become popular then, such as Transcendentalism and Theosophy. However, in contemporary Canadian art there have only been a few studies that have looked at spirituality and there is still much art that needs to be discussed with a view to the spiritual aspirations of the artists.

To date the discussion of both Houle's and Rogers's work has only tangentially discussed the spiritual aspect of their work. Although curators and critics have to some extent discussed the sources that inform Houle's spiritual sensibilities, they have leaned far more heavily toward an understanding of the political context of his work, even though the artist has explicitly stated that some of his works are spiritual rather than 
political in nature. In the light of the increased activism with regard to land claims and battles over the use of natural resources on the part of Native peoples in Canada, it is understandable that there is a tendency to interpret Houle's works solely from a political viewpoint. For instance, Houle has once again produced a work to raise the issue of the Oka crisis, the Mohawk stand-off of 1990 near Montreal. On the occasion of its tenth anniversary, he has created Kanehsatake $X^{3}$ It is obvious that Houle is making reference here to a significant political issue. However, as already stated in chapter II, issues of the land are closely related to spiritual wellness for many Native peoples. Hence, when discussing Houle's work the spiritual significance of the land cannot be ignored. A clear link should be made between the land and his search for a renewed sense of his own identity. Artist-in-residence programs both in Manitoba and in Ontario, where he dealt directly with the land, fortified his sense of identity and led Houle to use the subject of the land more frequently in his art.

Another issue that needs to be considered when discussing the spiritual aspect of Houle's work is his upbringing in both Native and Christian beliefs and his endeavours as an adult to re-learn Native traditions. Many of his works demonstrate the influence of these two spiritual traditions on his life and art. He has demonstrated a continued determination to re-learn his native spiritual traditions and the Ojibway language. These

\footnotetext{
${ }^{3}$ The original Kanehsatake was made between 1990-93, collection Art Gallery of Hamilton.
} 
have manifested themselves in different ways in his work such as, for example, his use of porcupine quills and references to the four directions held sacred in Ojibway spiritual traditions.

Similarly, discussions of Rogers's work have primarily focussed on formal concerns rather than spiritual ones. His use of the landscape motif is usually related to his upbringing on the Canadian Prairies, while its spiritual motivation is neglected. Yet, Rogers has unequivocally stated that his art is indebted to a large extent to the teachings of the Bahá'í Faith. As stated in chapter III, Rogers is not interested in illustrating these teachings but rather tries to incorporate them in his attitude toward his art-making and through the use of metaphors in his art. His engagement with the landscape is on a philosophical level and he believes it to be a perfect metaphor to express his spiritual aspirations. Bahá'í writings that use examples from the natural world to explain spiritual concepts and propose that it is necessary to explain spiritual or intellectual knowledge through references to the physical world have been influential for him. For Rogers spiritual content is conveyed through the employment of the principle of "unity through diversity," as well as the creation of vast space and a sense of luminousness. Rogers firmly believes that spirituality and religion have a place in the contemporary visual arts. He states,

The influence of religion on contemporary art is, however, discounted by many, and those artists who speak of such a connection may be greeted with marked suspicion. This is curious considering that the very study of the history of art itself is organized in relationship to the religions which evolved from the teachings of their prophet founders.... One can understand the reason for religion being discredited as the source of art today when the very definition of words 
associated with religion has been eclipsed by obscure man-made theology, ritual, dogma and division. $^{4}$

To give form to the link between spirituality and landscape, Houle and Rogers both turned to abstraction as their language of expression. This choice is not random. As was discussed in the second chapter, Houle's choice of abstraction has several reasons. First, he pays tribute to the Abstract Expressionists who were in search for a new spiritual vocabulary and who paid tribute to the spirituality found in Native art. Second, it was the language he learnt during his academic training. Finally, like his spiritual ancestors he seeks out the essence of the object and therefore prefers non-objective art. Since Rogers's use of the landscape is symbolic, it is appropriate for him to work in an abstract manner as well. His choice also reflects his desire to move further and further away from the landscape motif in his art, symbolizing the Bahá'í attitude of detachment from the physical world.

This thesis has shown that a discussion of Rogers's and Houle's art is not sufficiently served by a purely formal analysis but needs to be augmented by an exploration of their respective spiritual aspirations. While Kandinsky says that abstract art came about to express spirituality, Kuspit claims that art is no longer spiritual in

\footnotetext{
${ }^{4}$ Rogers, "A Short Essay in Nine Parts," ch. 2, [unpaginated].
} 
nature, as Kandinsky intended, but has in fact become materialistic. ${ }^{5}$ In this thesis it has been shown that there are some artists whose works provide an exception.

Further studies are necessary to establish the validity of this argument, using the works of other contemporary Canadian artists. We should explore whether spirituality has always been an integral part of art. We should consider whether spirituality is present in some art but is not made explicit. Perhaps artists have incorporated spiritual themes in their art even without being aware of it. Have some artists perhaps unconsciously incorporated spirituality into their works? Has spirituality always been there or was there a period when it was downplayed or ignored? And if so, was it ignored by the artists or the critics? There is a significant number of Canadian artists interested in spirituality, ${ }^{6}$ yet the past few decades have paid little attention to this aspect of art. These are just some of the open questions which still need to be explored.

There are some new lines of inquiry that were beyond the scope of this thesis and yet need to be explored. For example, an investigation of the use of the sublime by artists interested in the spiritual is necessary. Recent art-historical scholarship has established once again a link between the sublime and the spiritual, extending earlier studies on the effects of the sublime by Longinus, Edmund Burke, Immanuel Kant, Newman, and

\footnotetext{
${ }^{5}$ Kuspit, "Concerning the Spiritual in Contemporary Art," 313.

${ }^{6}$ See Korp's Ph.D. dissertation "Earthworks," where 120 artists took part in a study that was concerned with questions regarding spirituality and the land.
} 
Lyotard. More recently several British art critics and writers have argued that the sublime, as manifested for example in the works of Caspar David Friedrich, allows contemporary artists to tackle once again the subject of transcendental reality. ${ }^{7}$ There is a need to inquire into how this applies to the work of Canadian artists today.

It is hoped that this thesis has made a contribution, however small, to elucidating the link between landscape and spirituality in the abstracted works of two contemporary Canadian artists. It is recognized that this is one of the first steps in this direction and it is the author's hope that others continue this line of investigation and that the scholarship in this area is expanded.

${ }^{7}$ Clare Lewis, "Sublime Spaces: being and nothingness in contemporary installation," 20-25; Simon Morley, "The Friedrich factor: the German romantic's legacy," 26-33; and Roy Exley, "Tending the Abyss: the sublime edge in recent art," 34-39 all three articles in Contemporary Visual Arts (Focus on the sublime), issue $19,(1998)$. 


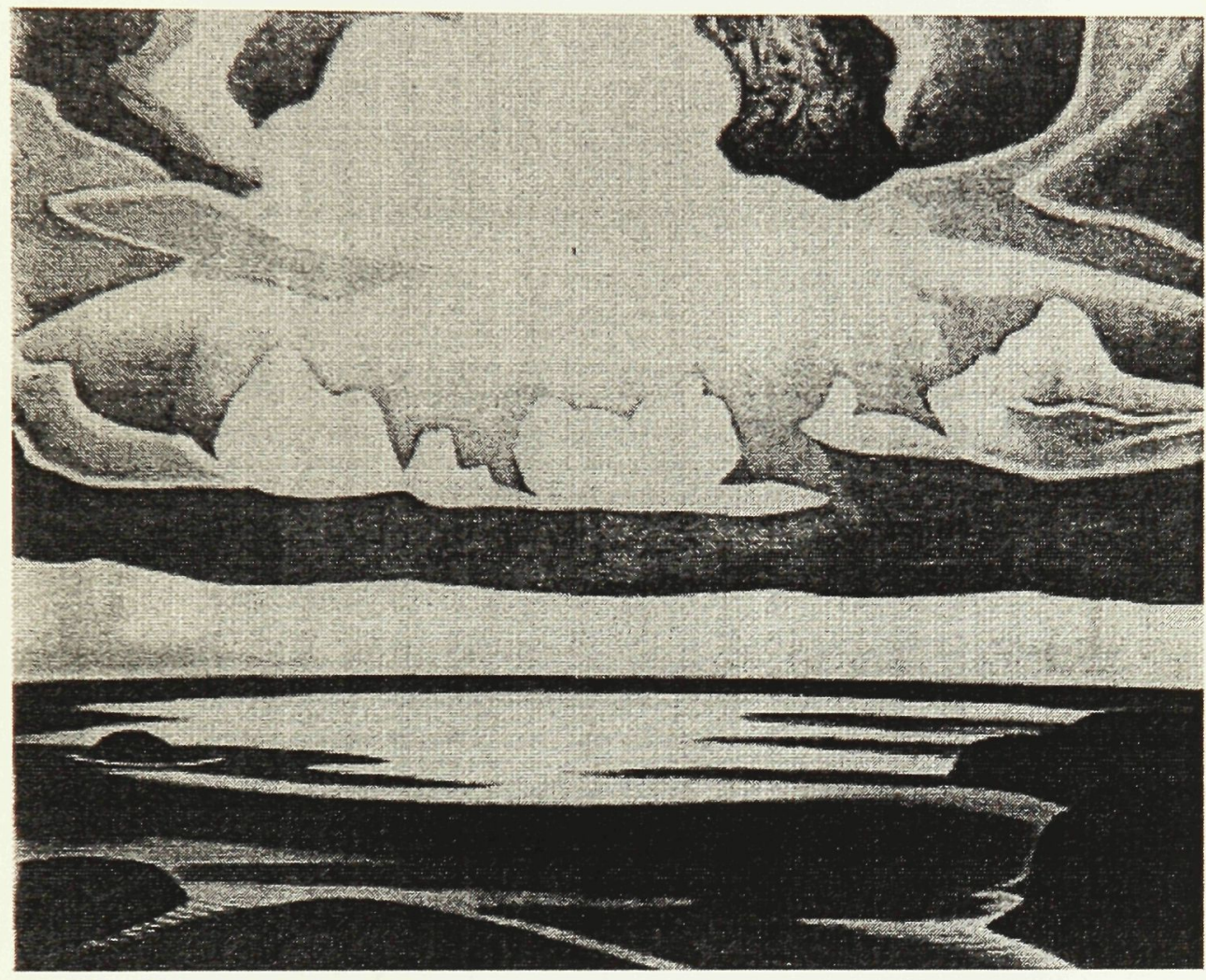

Fig. 1 


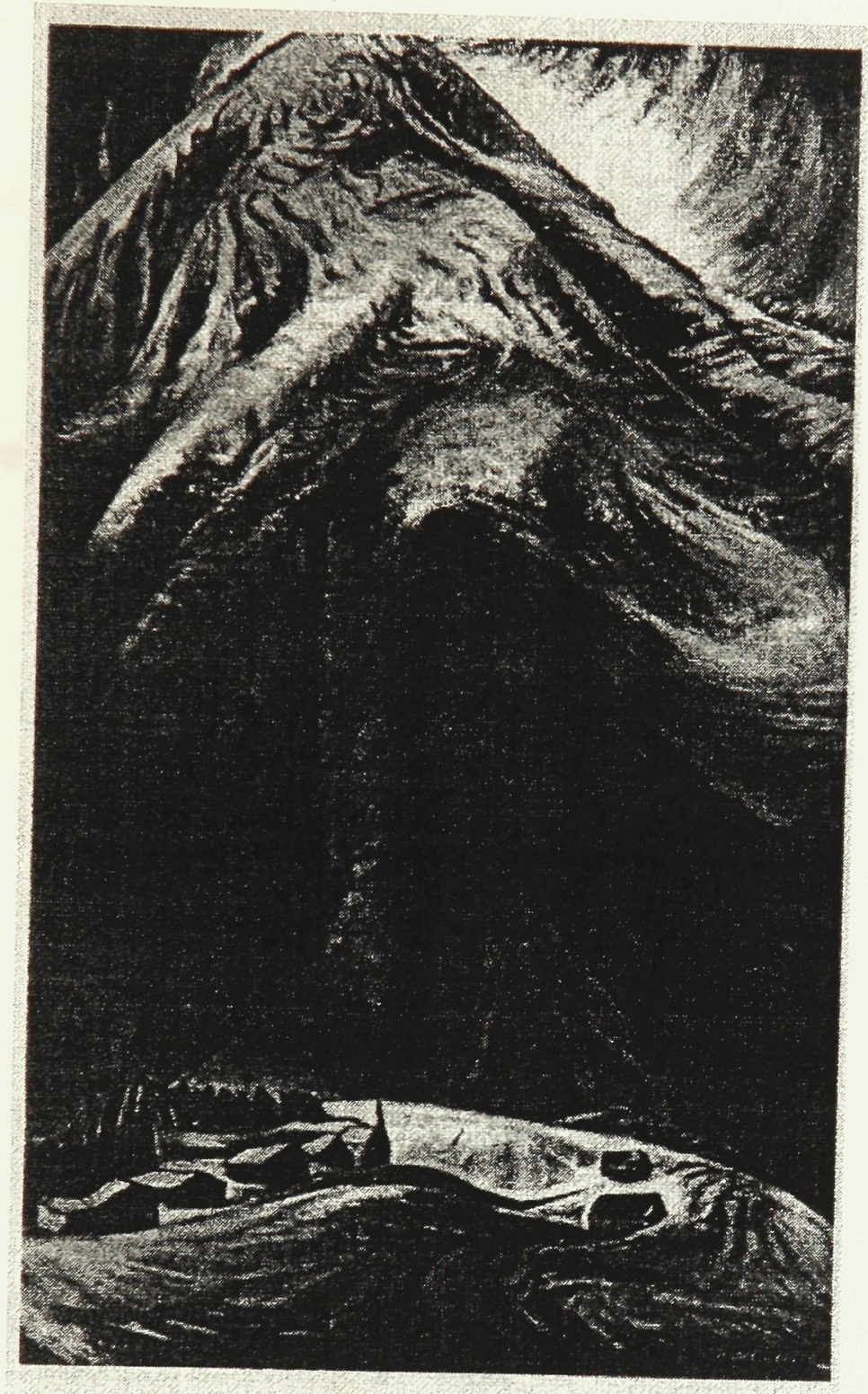

Fig. 2 


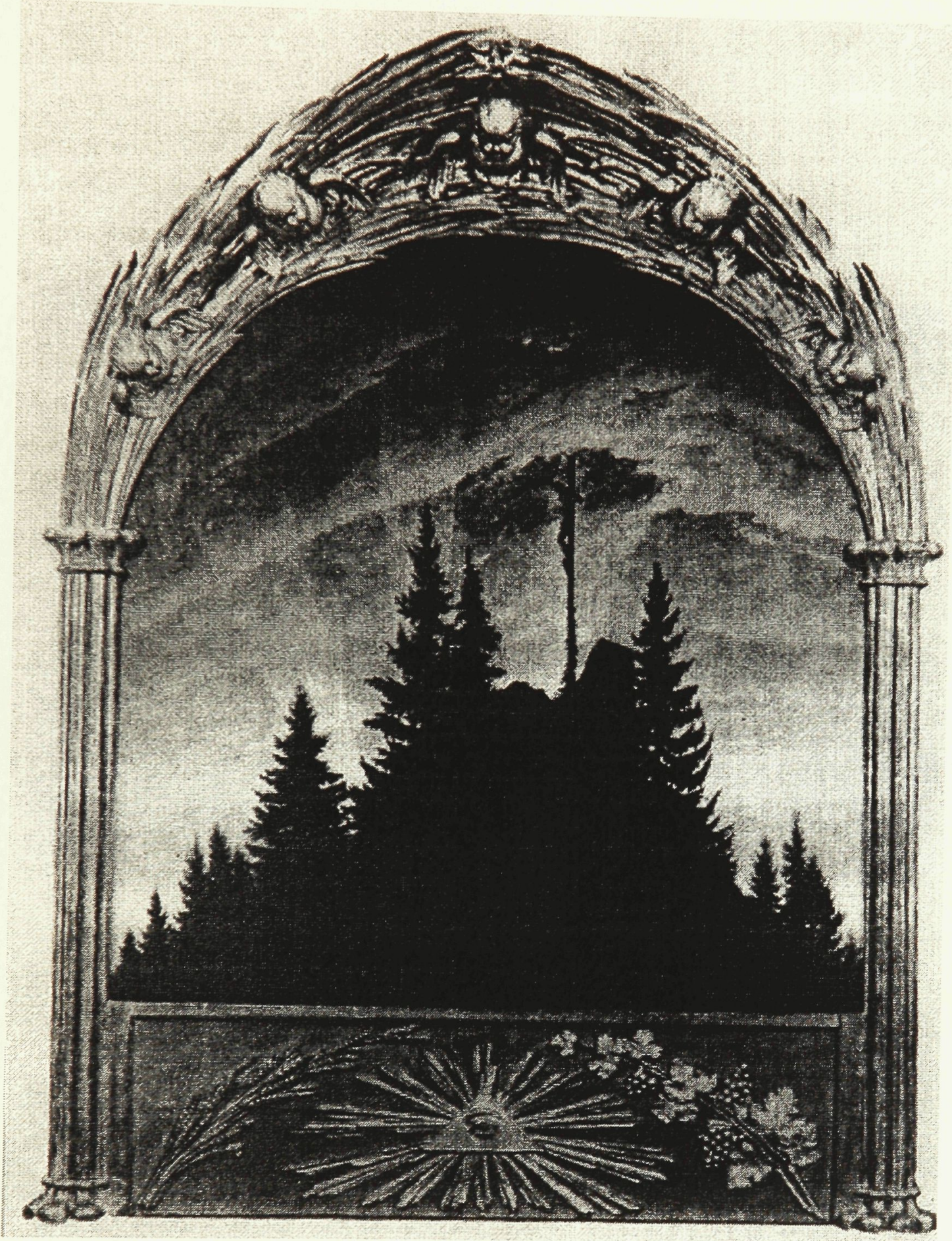

Fig. 3 


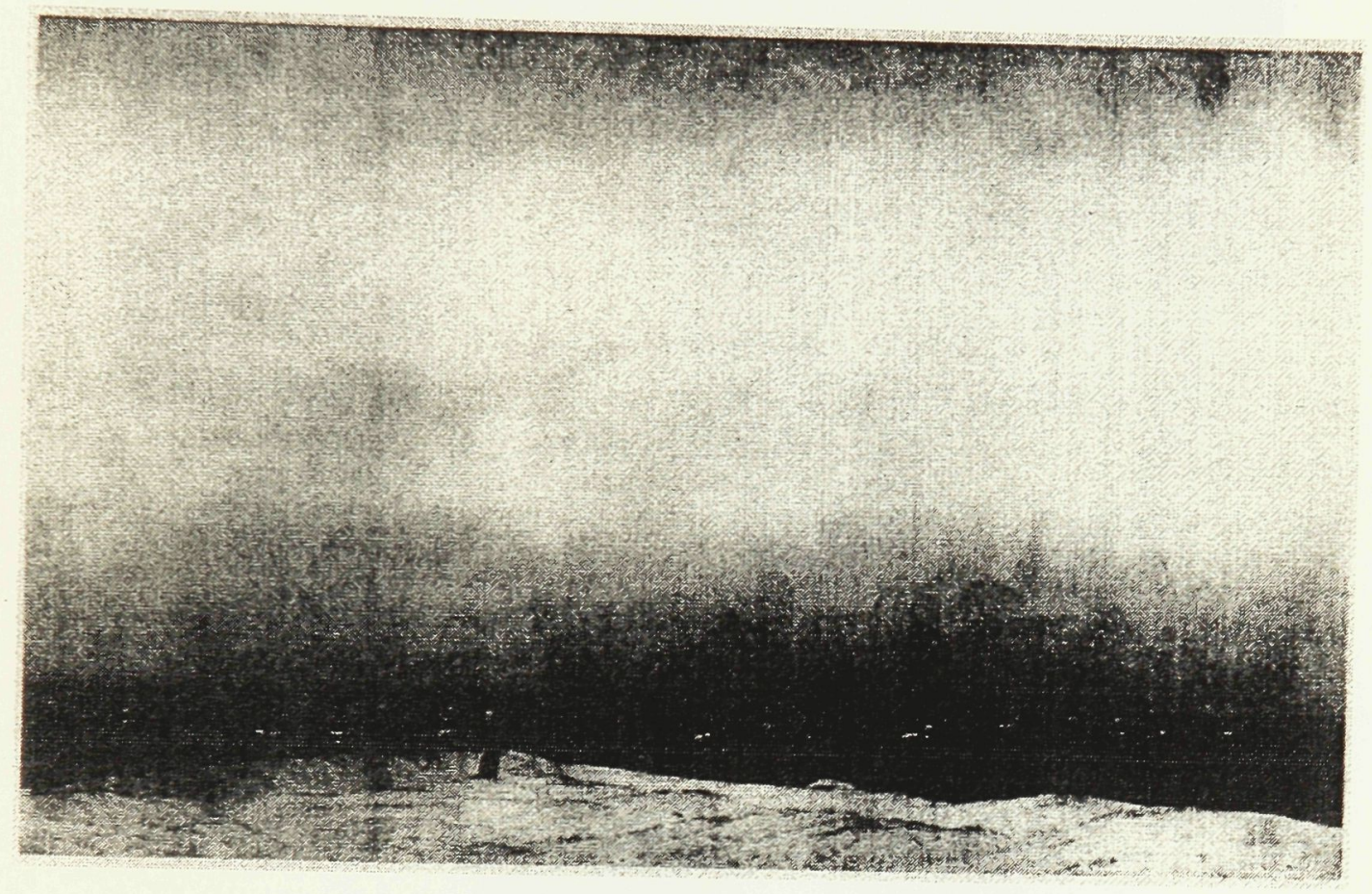

Fig. 4 


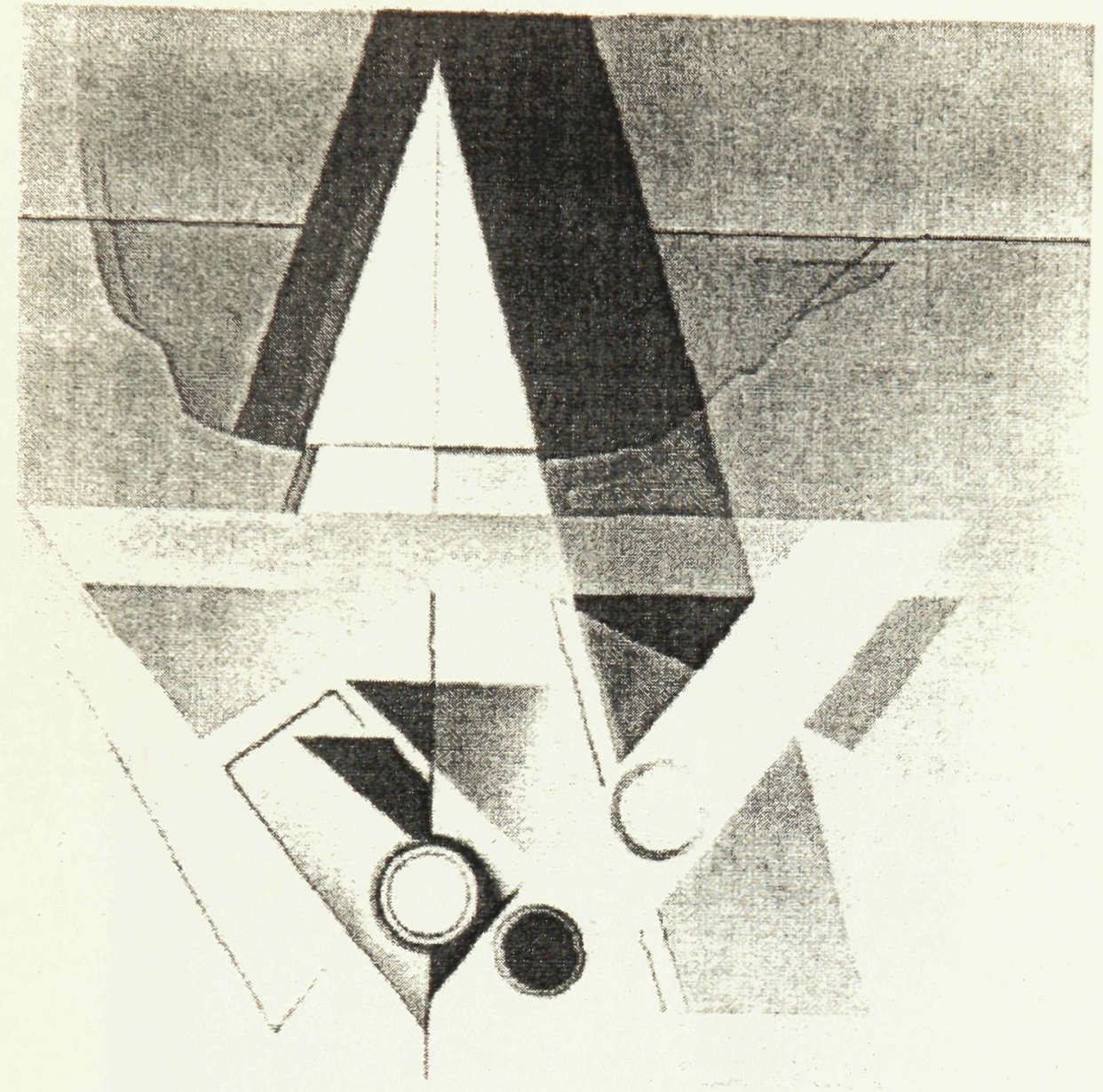

Fig. 5 


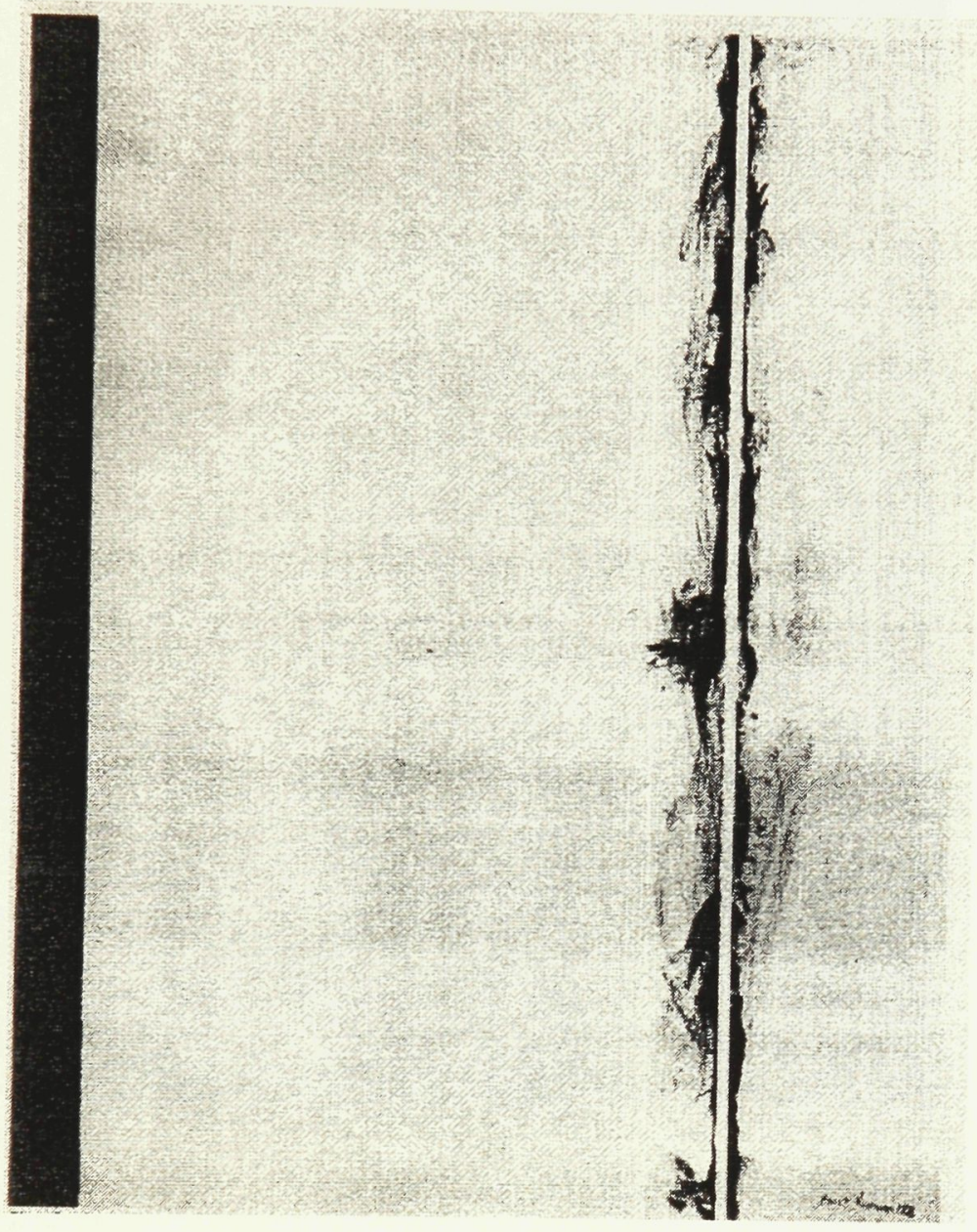

Fig. 6 a 


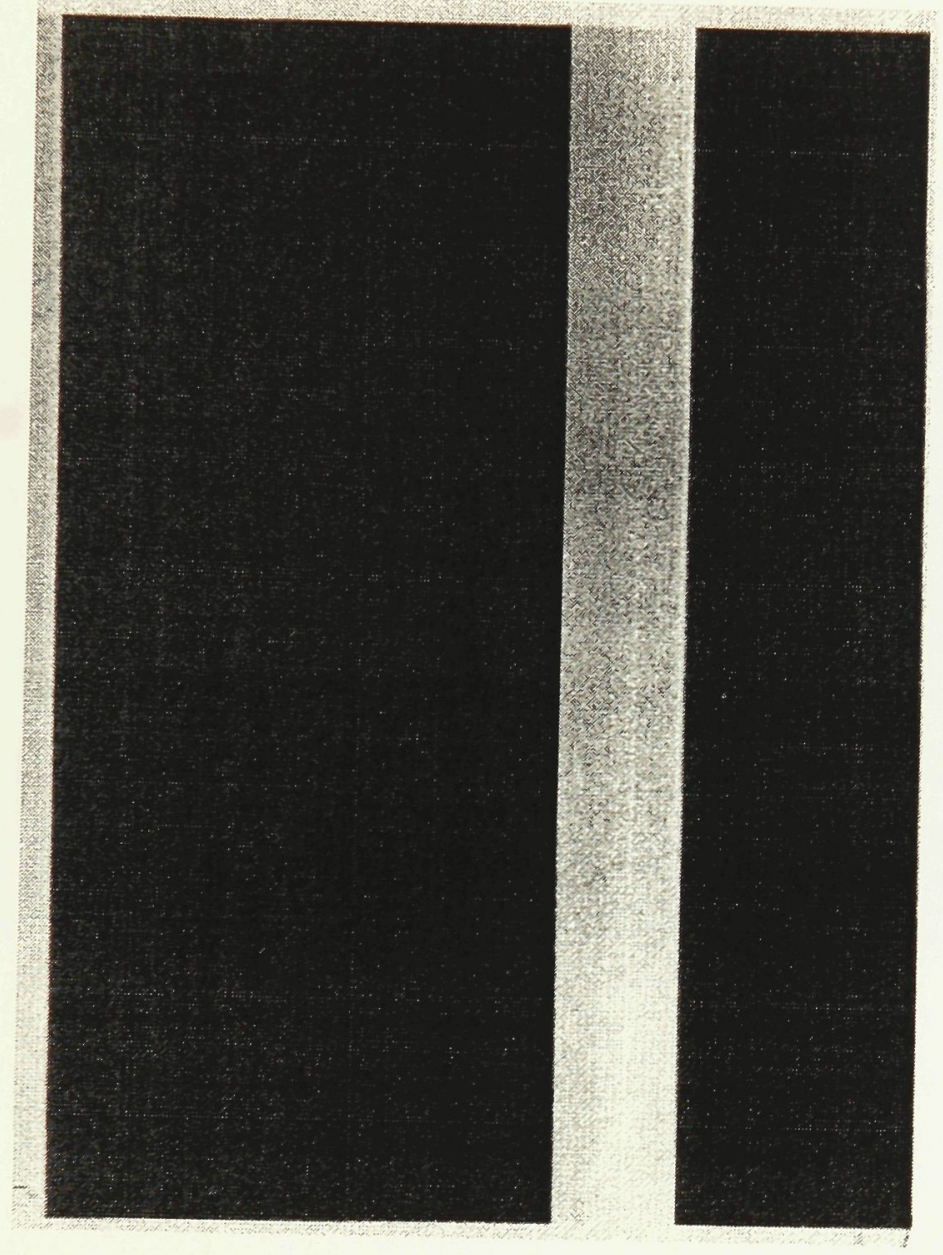

Fig. $6 \mathrm{~b}$ 


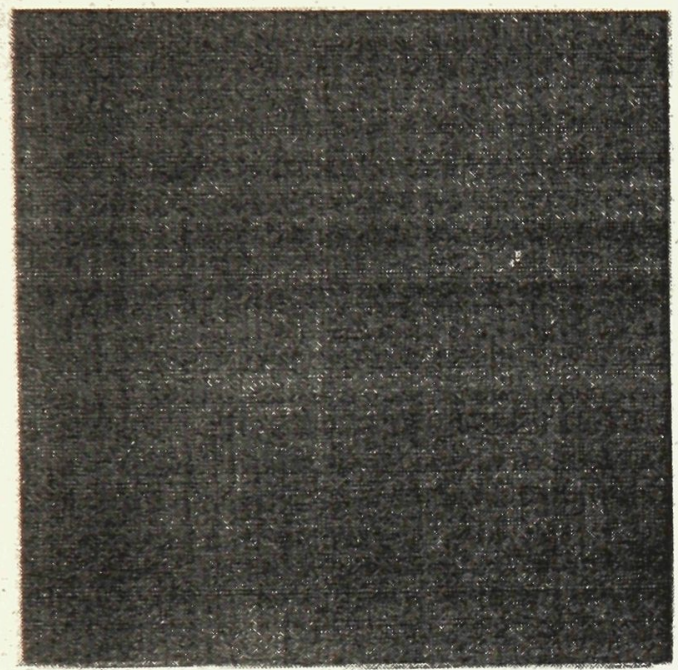

Twaty Na 1. AXTLLES OF A TAERTY mac: and

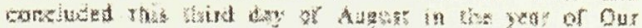

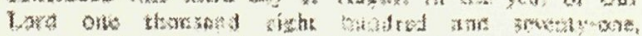

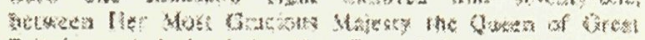

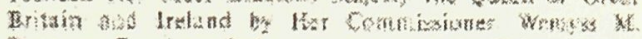

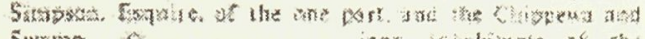

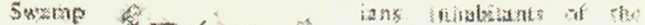

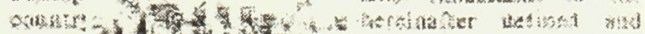

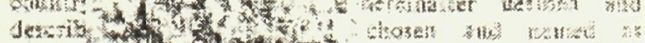

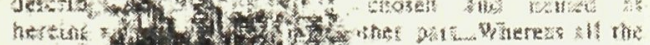
โn a a

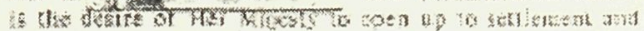

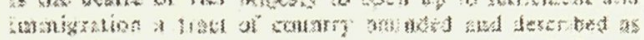

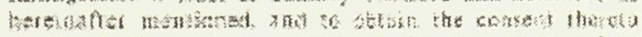

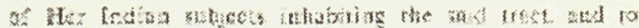

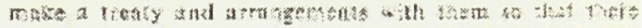

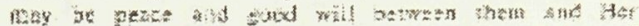

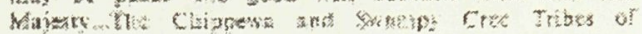

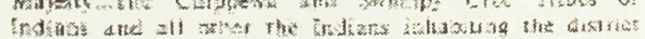

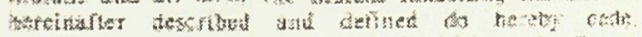

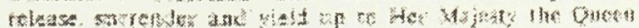

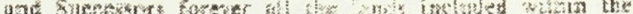

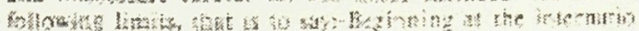

Fig. 7 


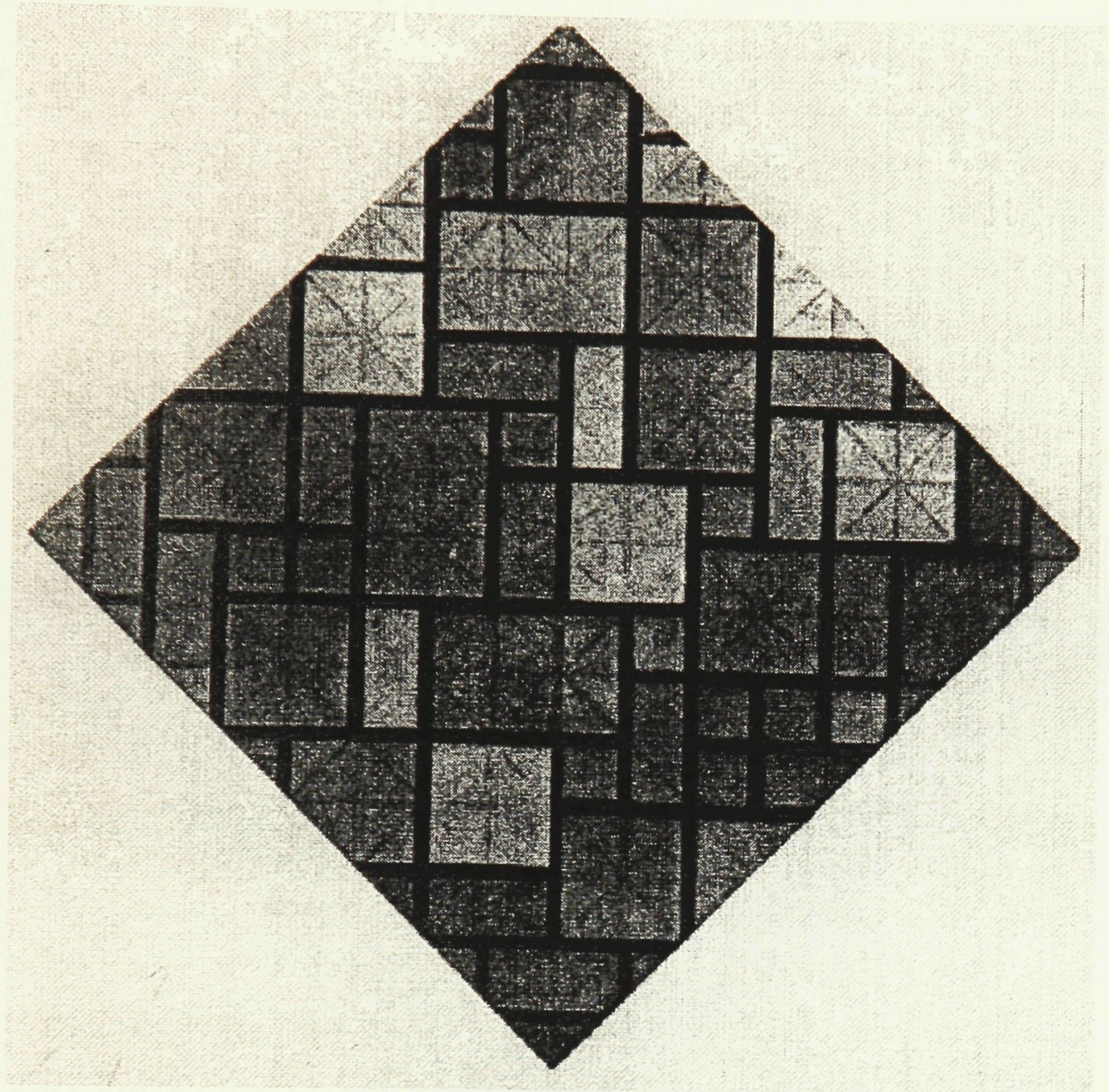

Fig. 8 


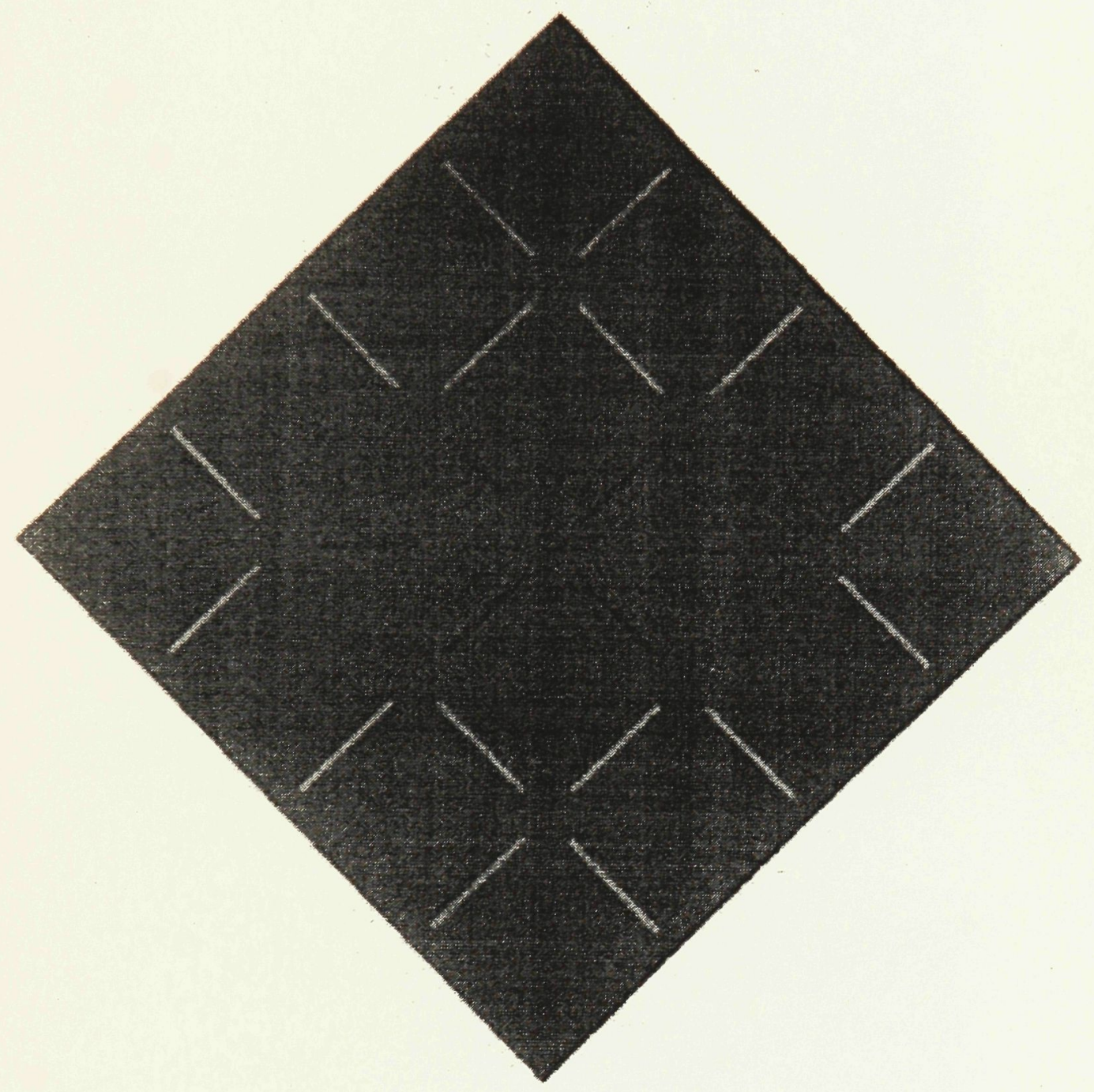

Fig. 9 


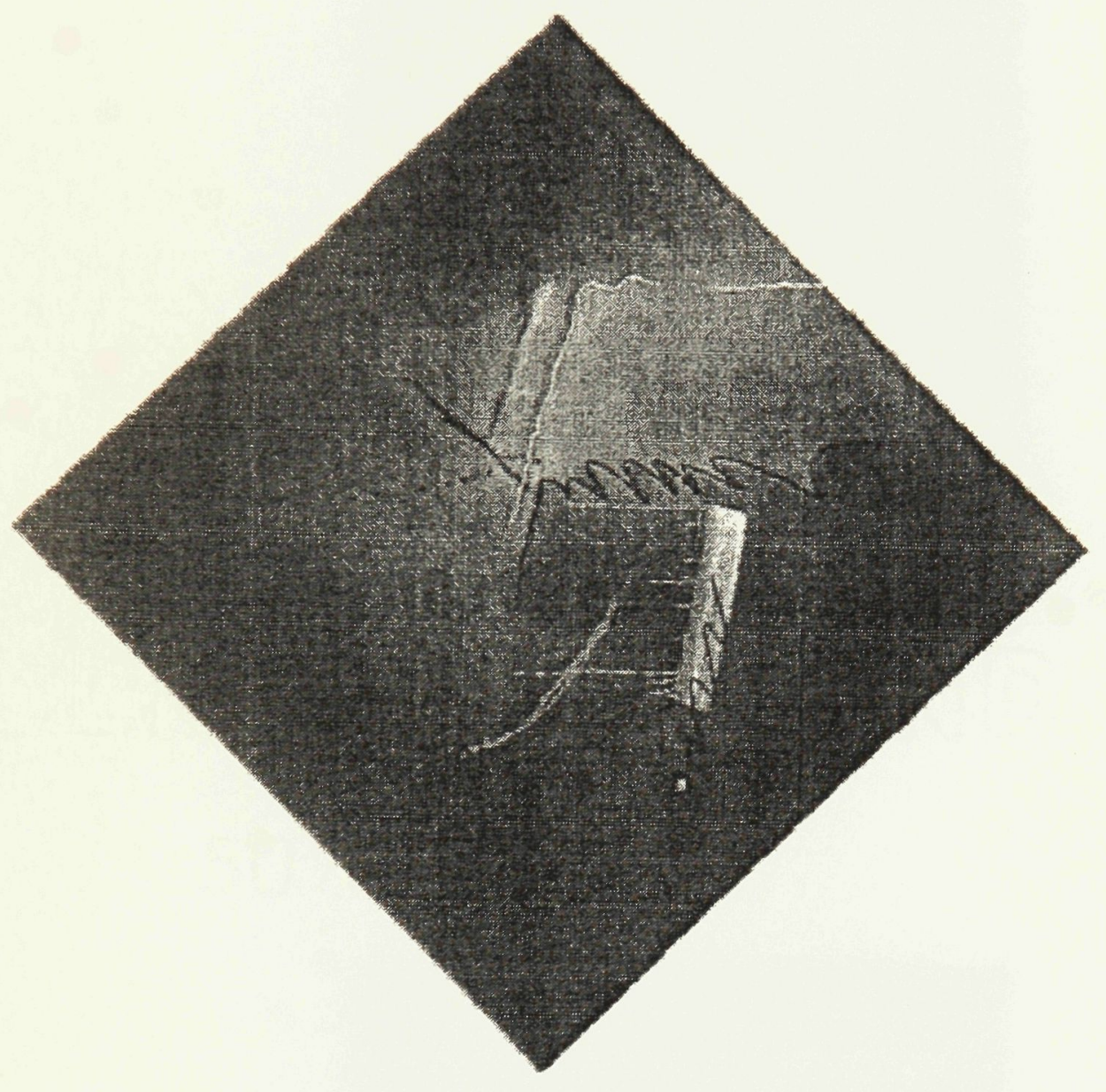

Fig. 10 

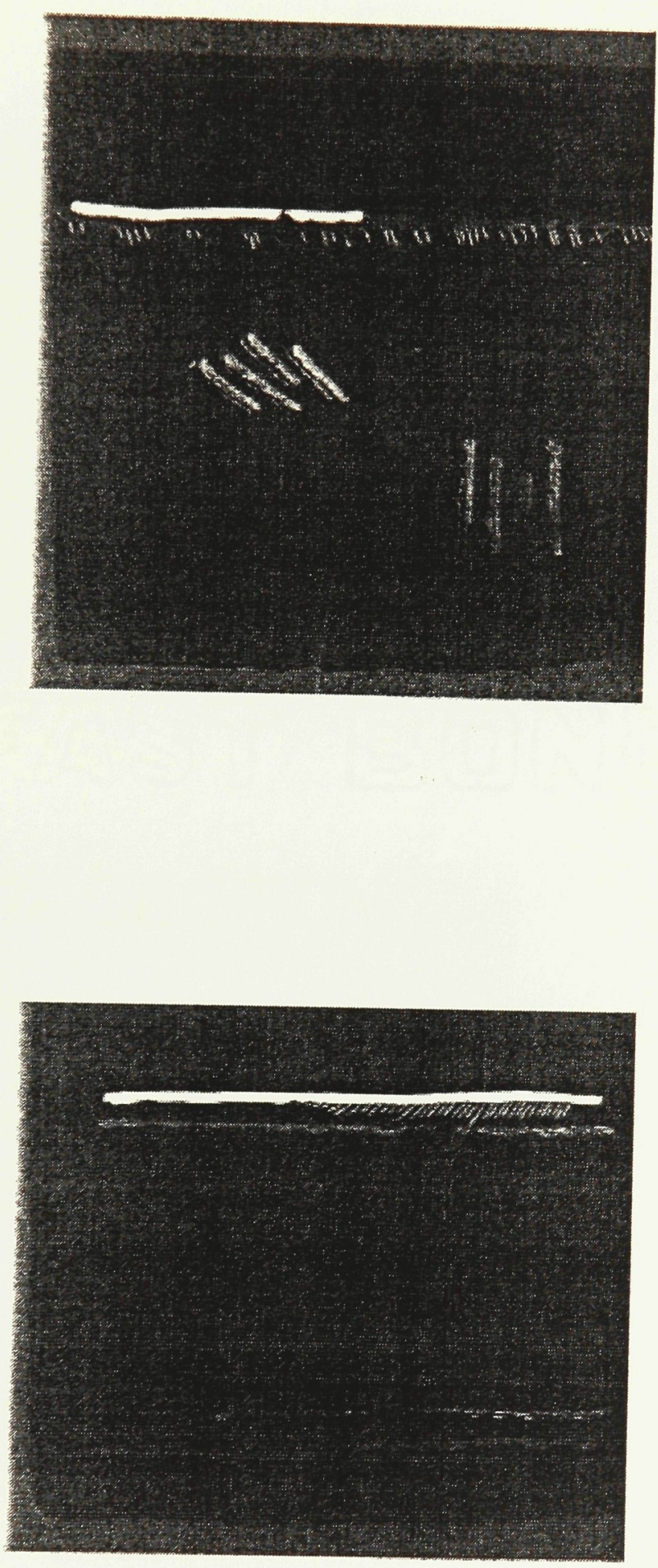

Fig. $11 \mathrm{a} \& \mathrm{~b}$ 

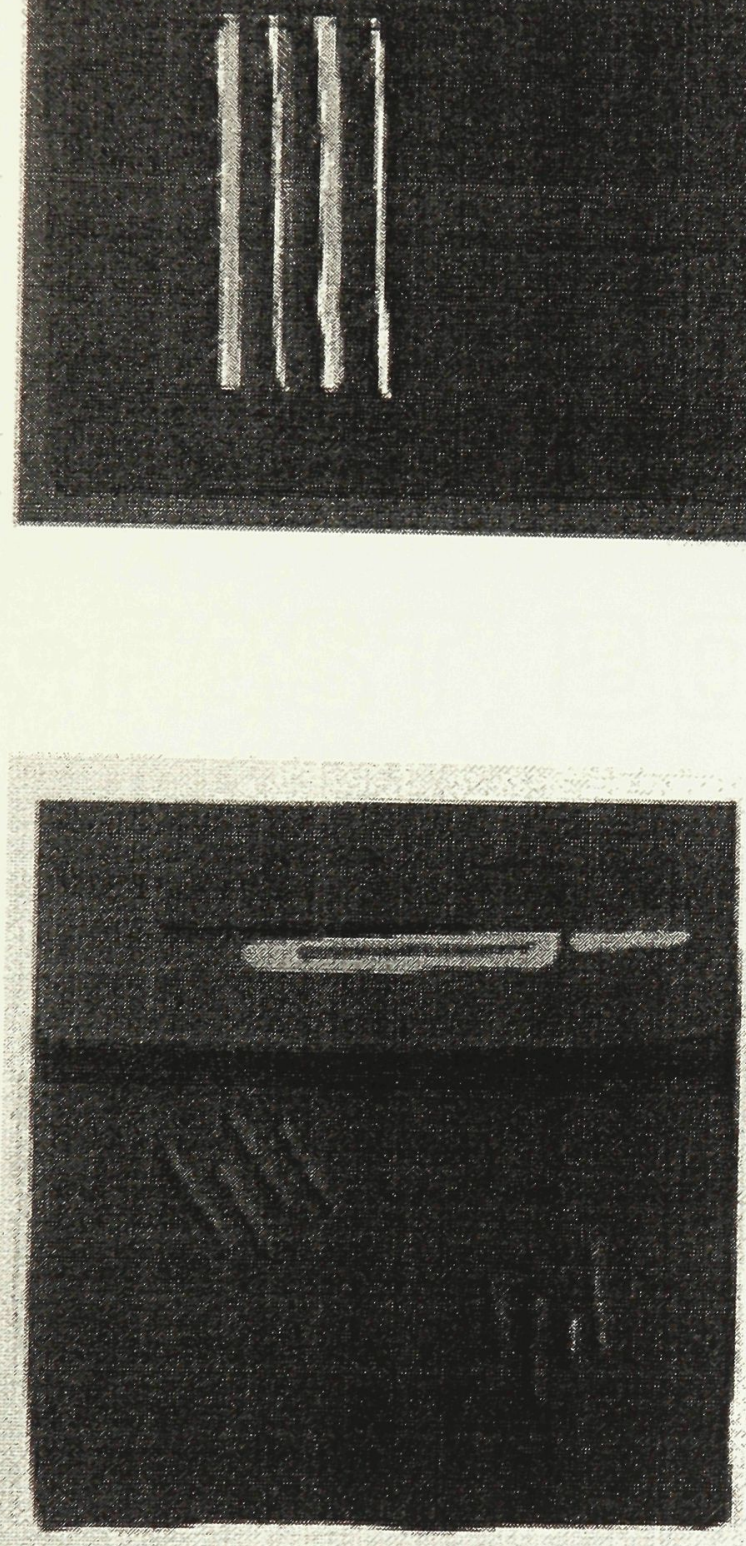

Fig. $11 \mathrm{c} \& d$ 

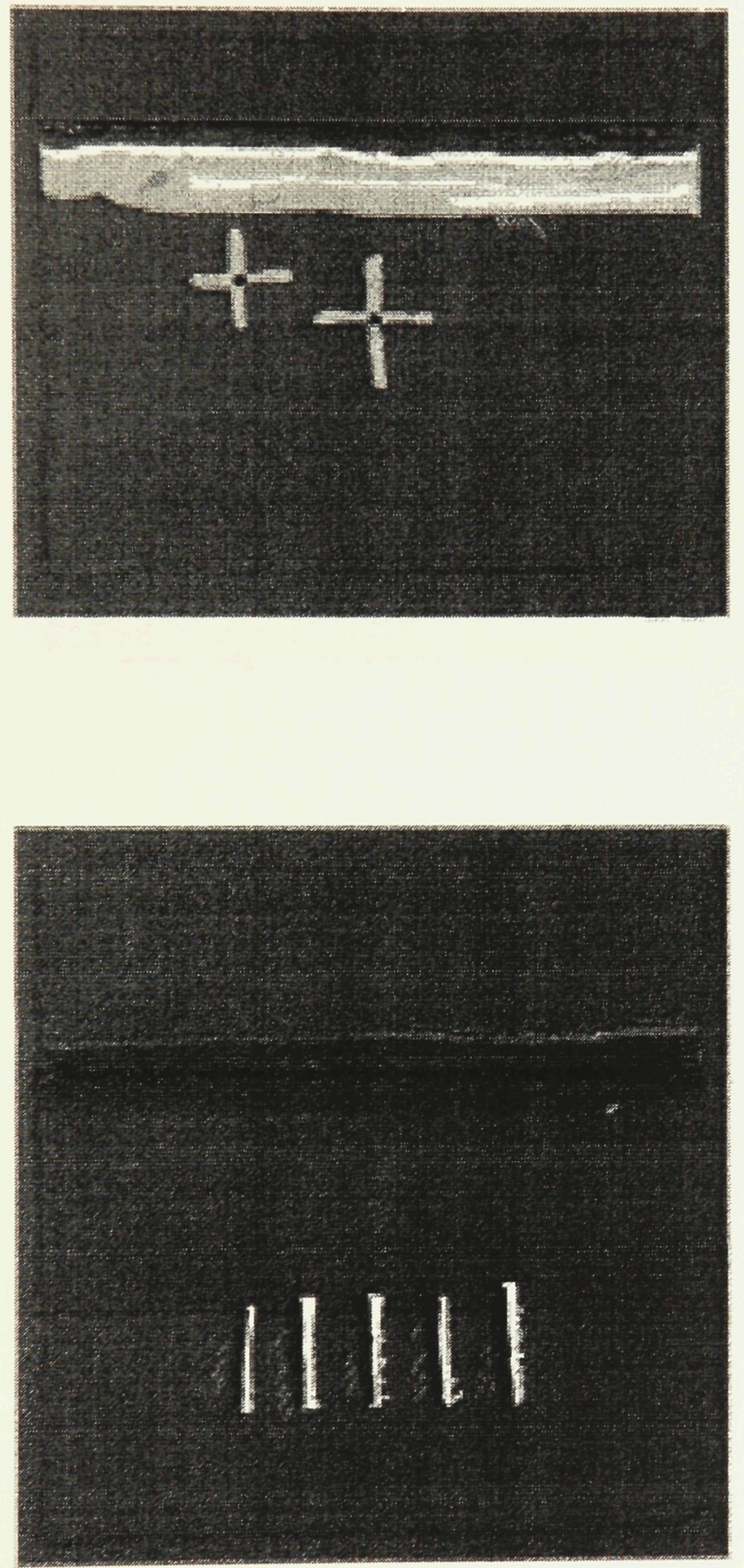

Fig. 11 e \& f 

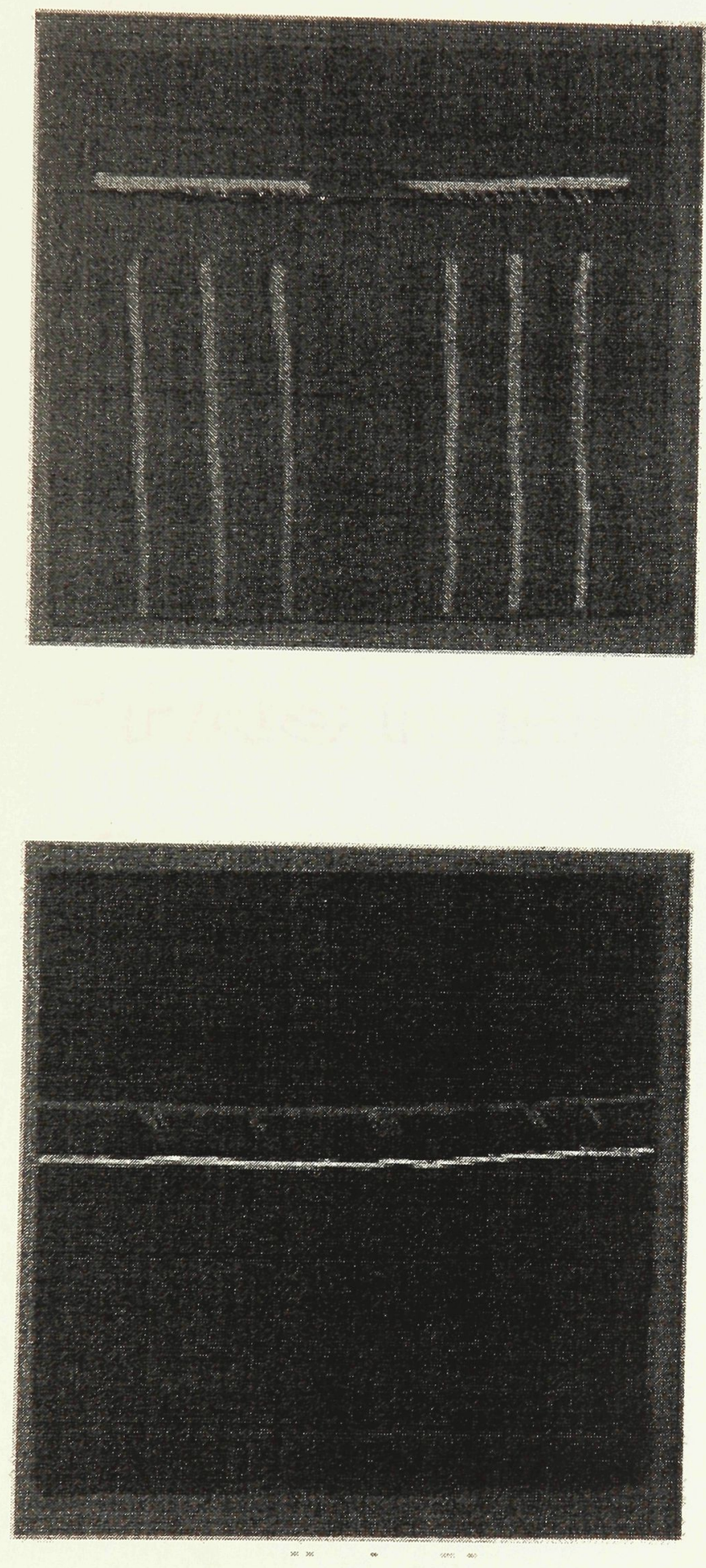

Fig. $11 \mathrm{~g} \& \mathrm{~h}$ 

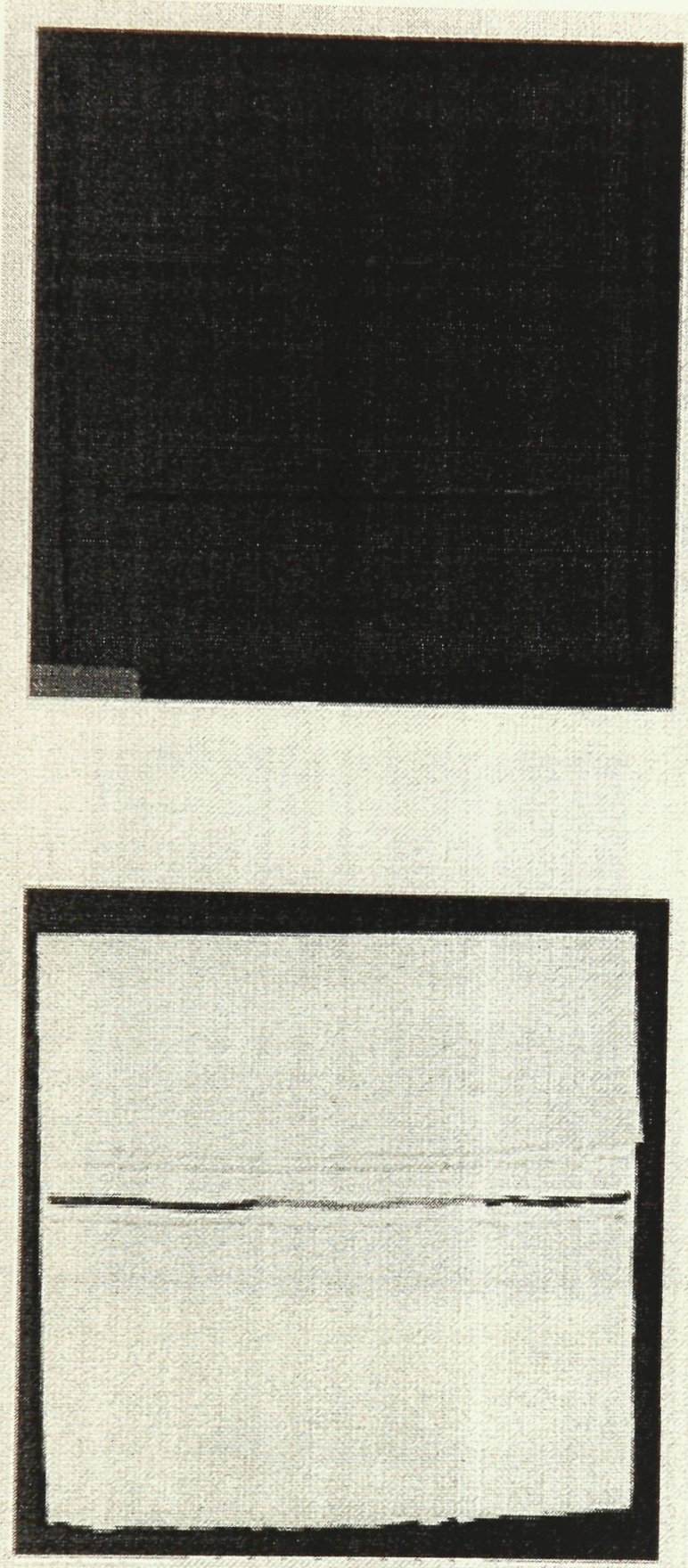

Fig. 11 i \& j 

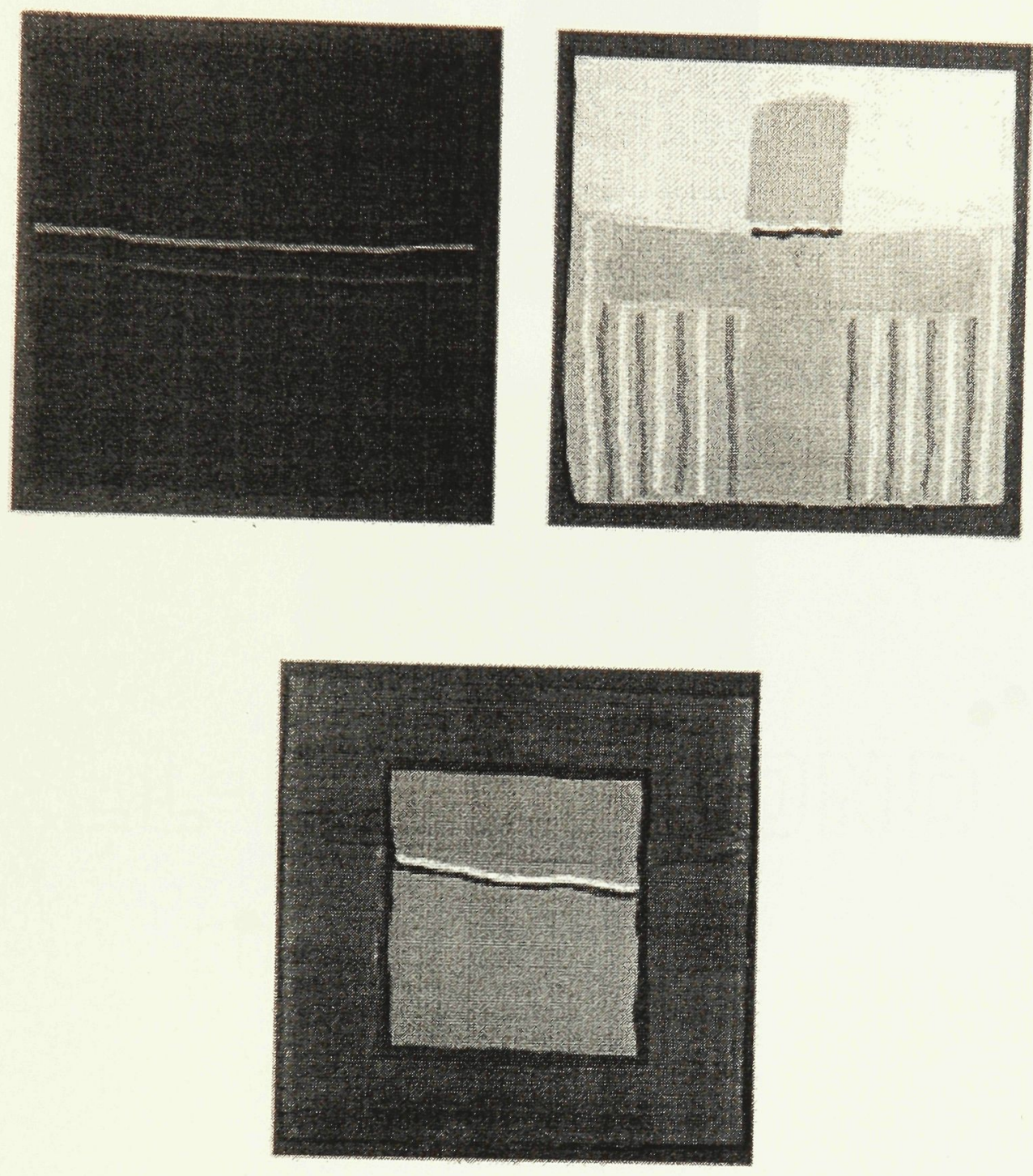

Fig. $11 \mathrm{k}, 1$ \& m 
$\leftarrow$ (top of painting)
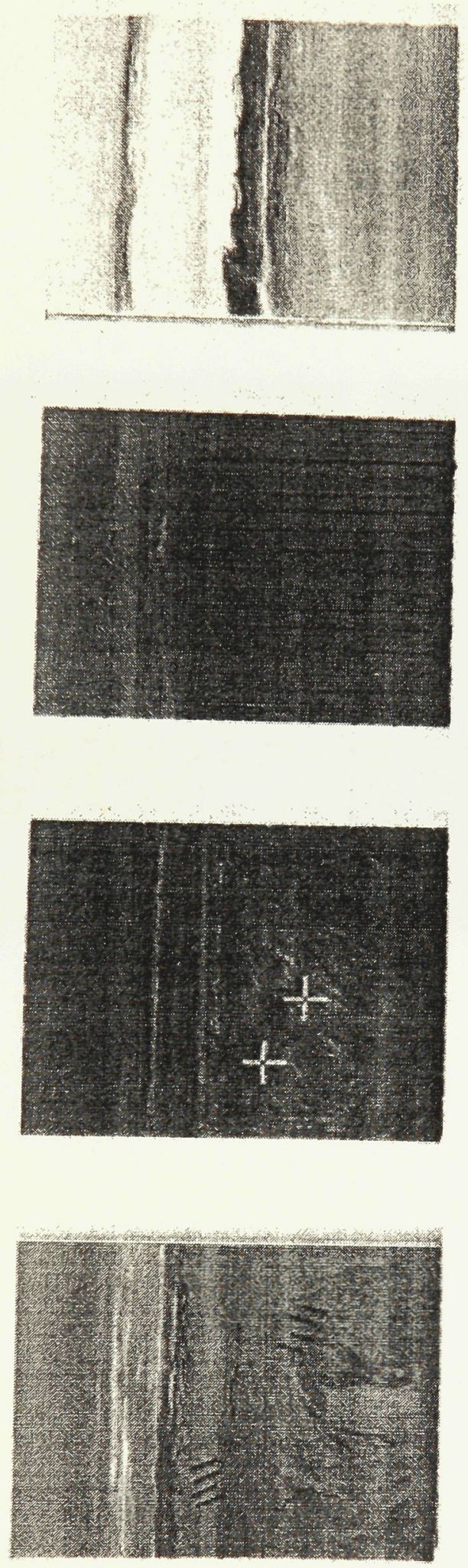

Fig. 12 


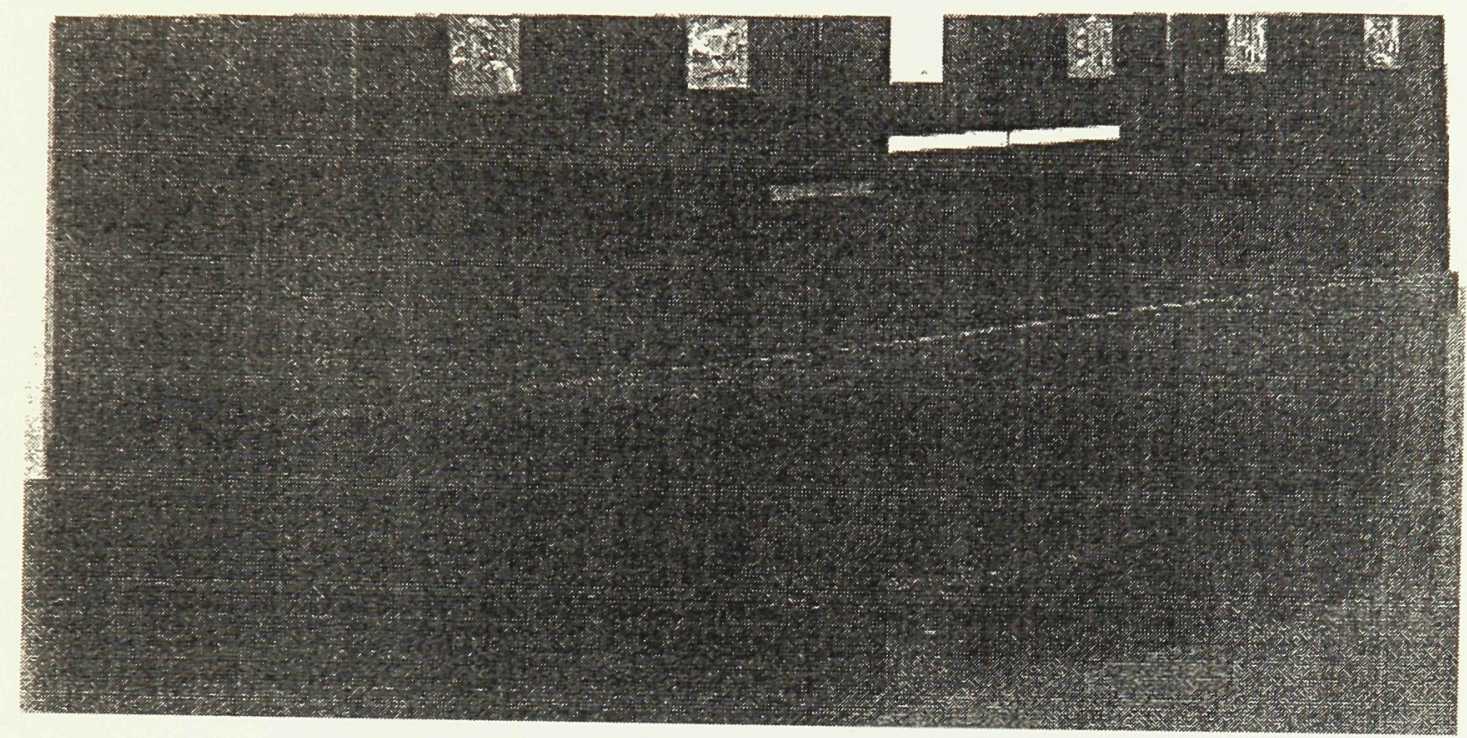

Fig. 13 


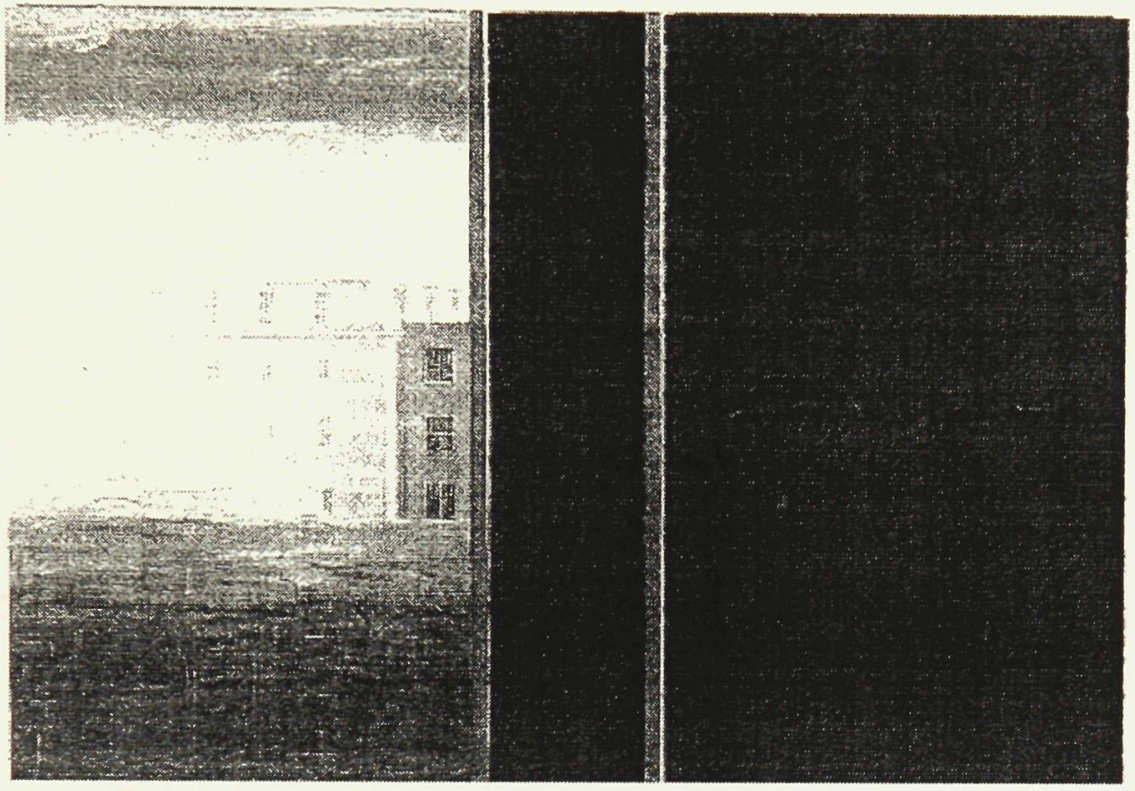

Fig. 14 


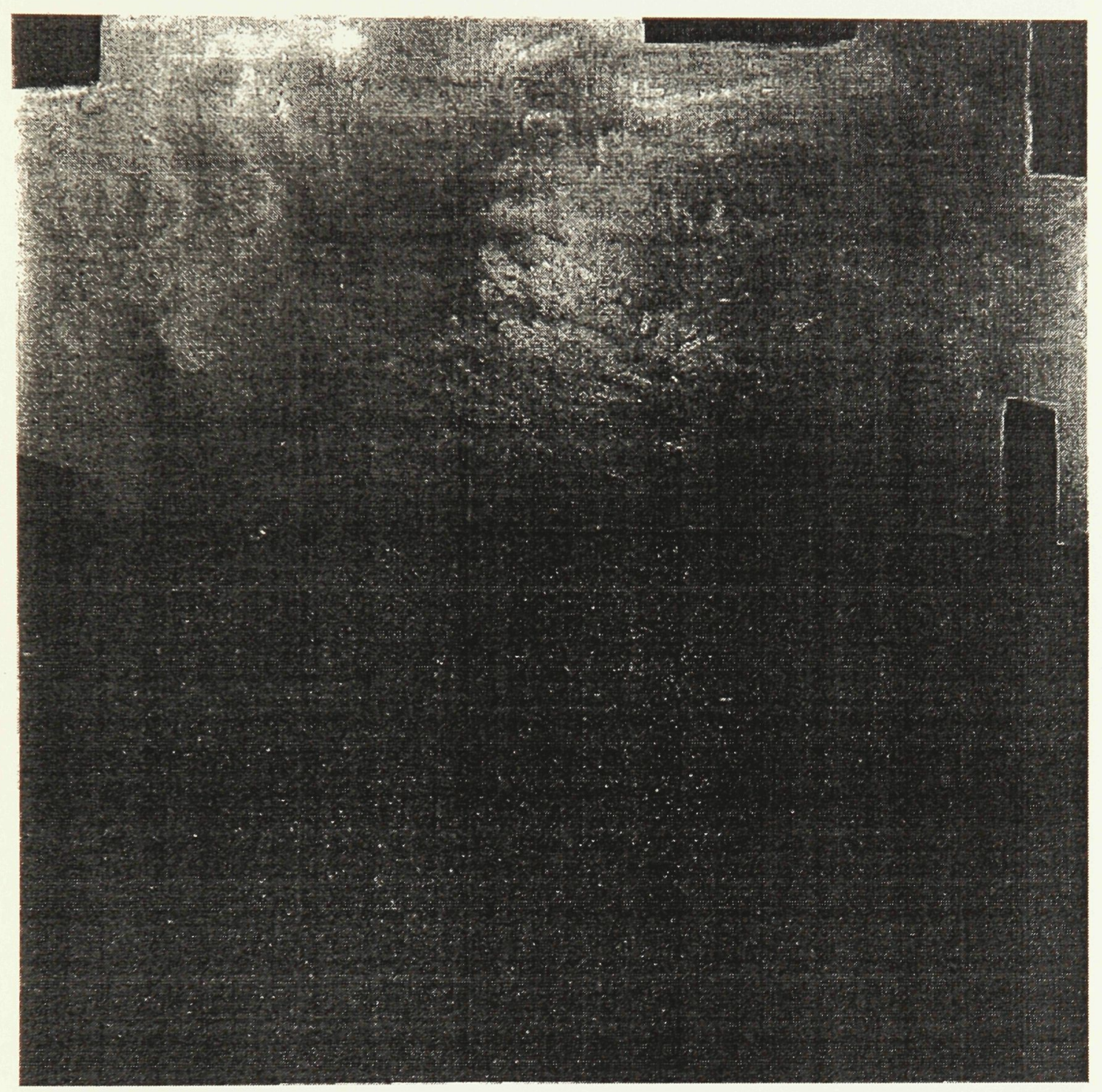

Fig. 15 


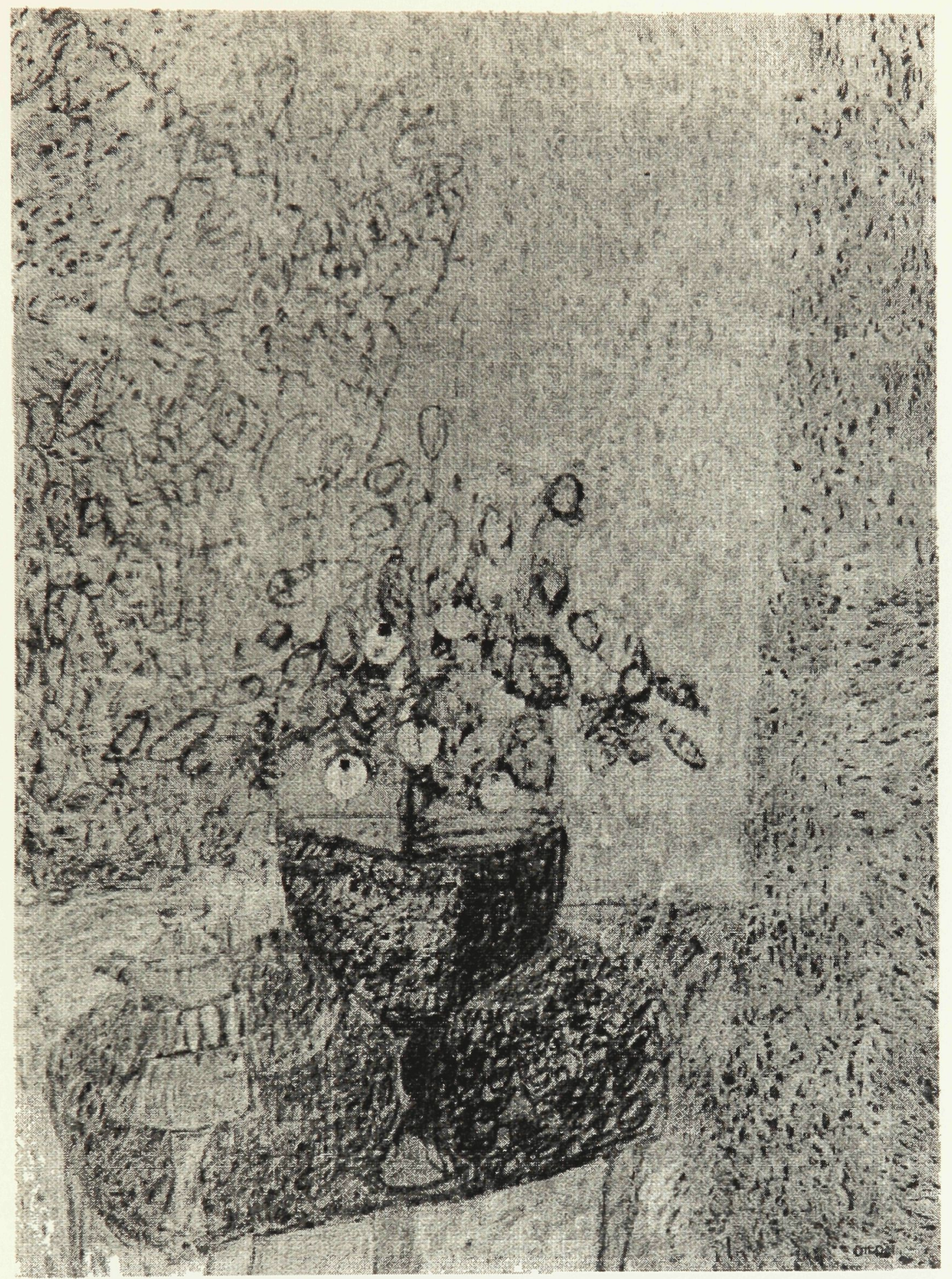

Fig. 16 


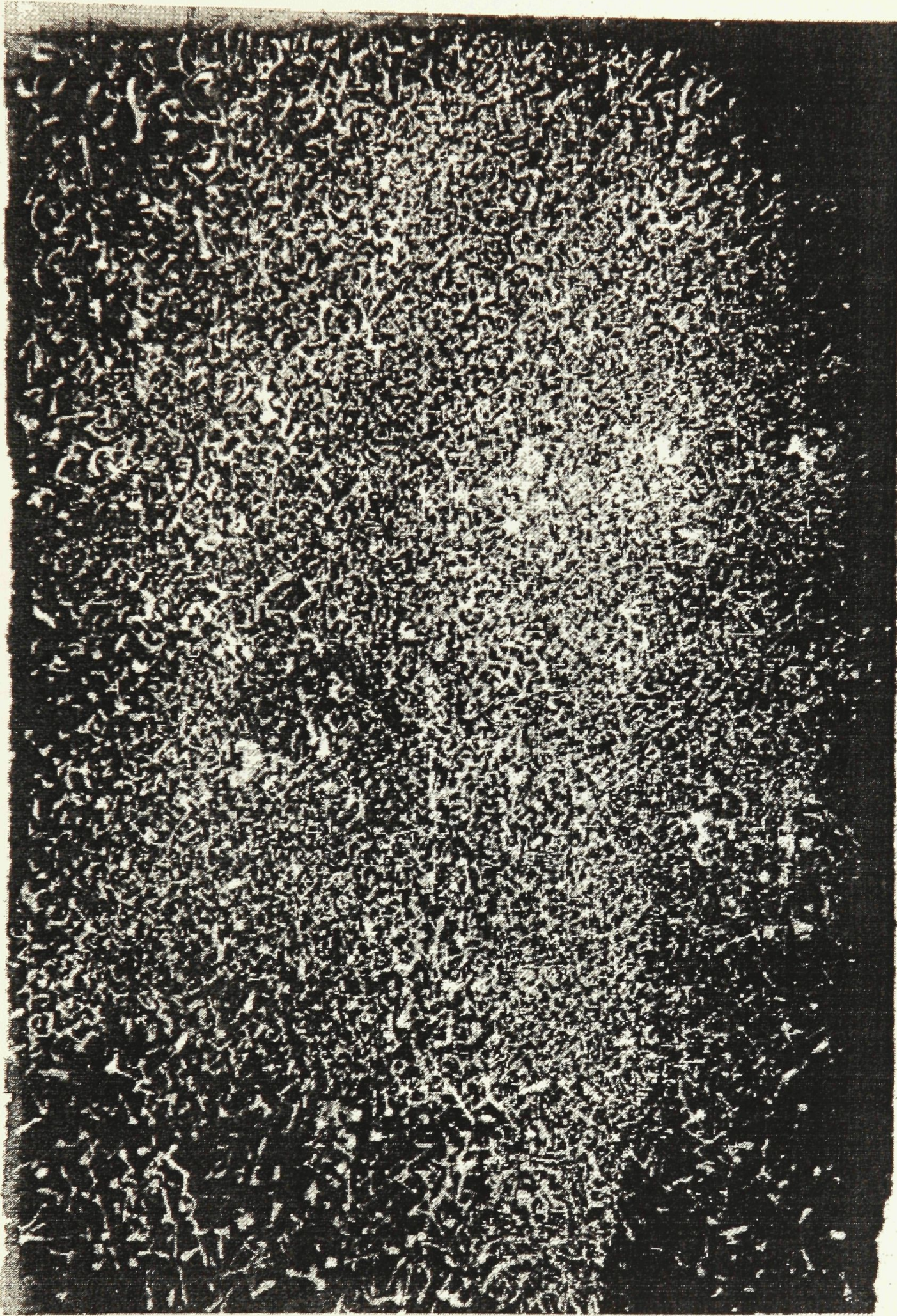

Fig. 17 


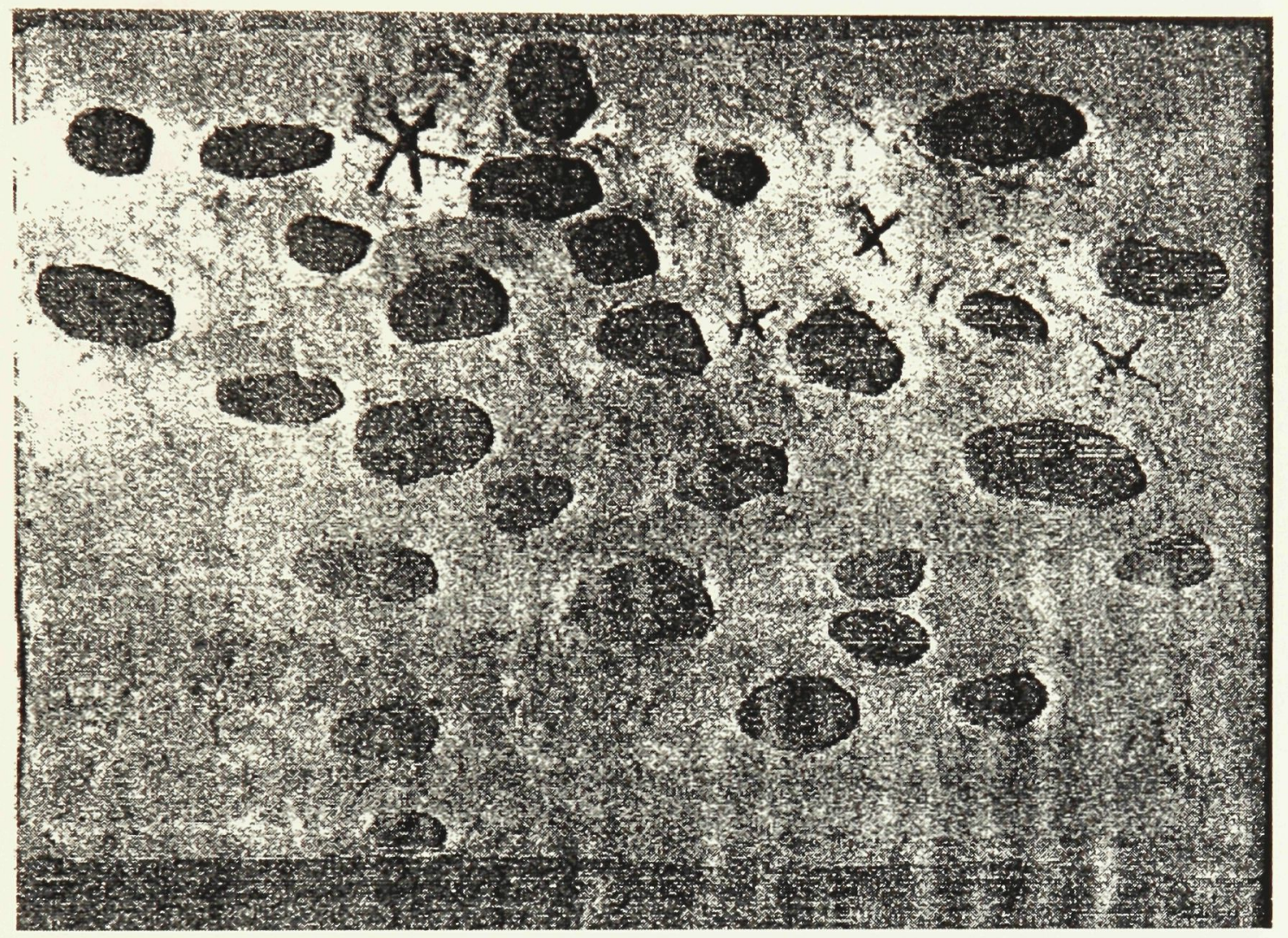

Fig. 18 


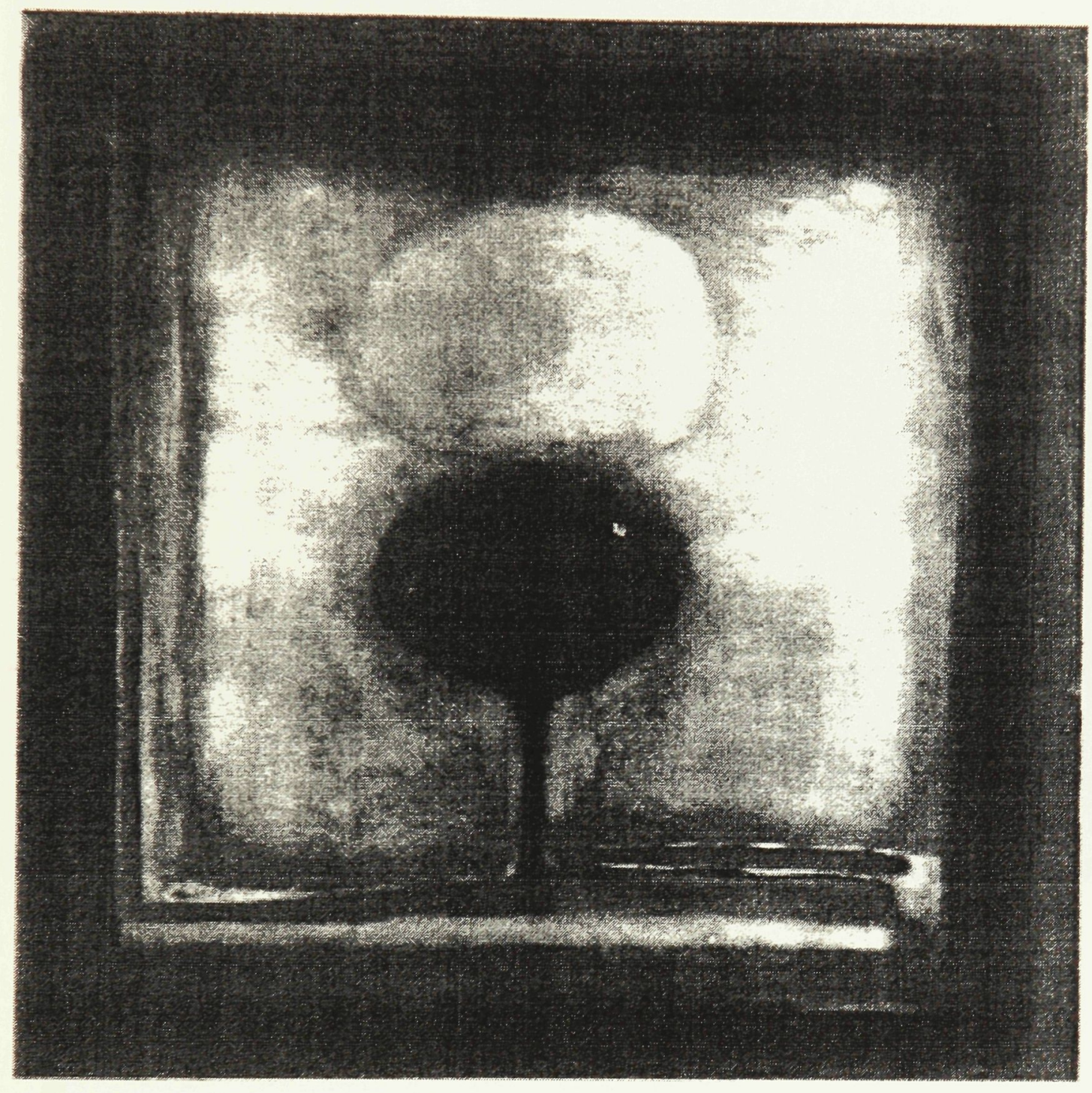

Fig. 19 


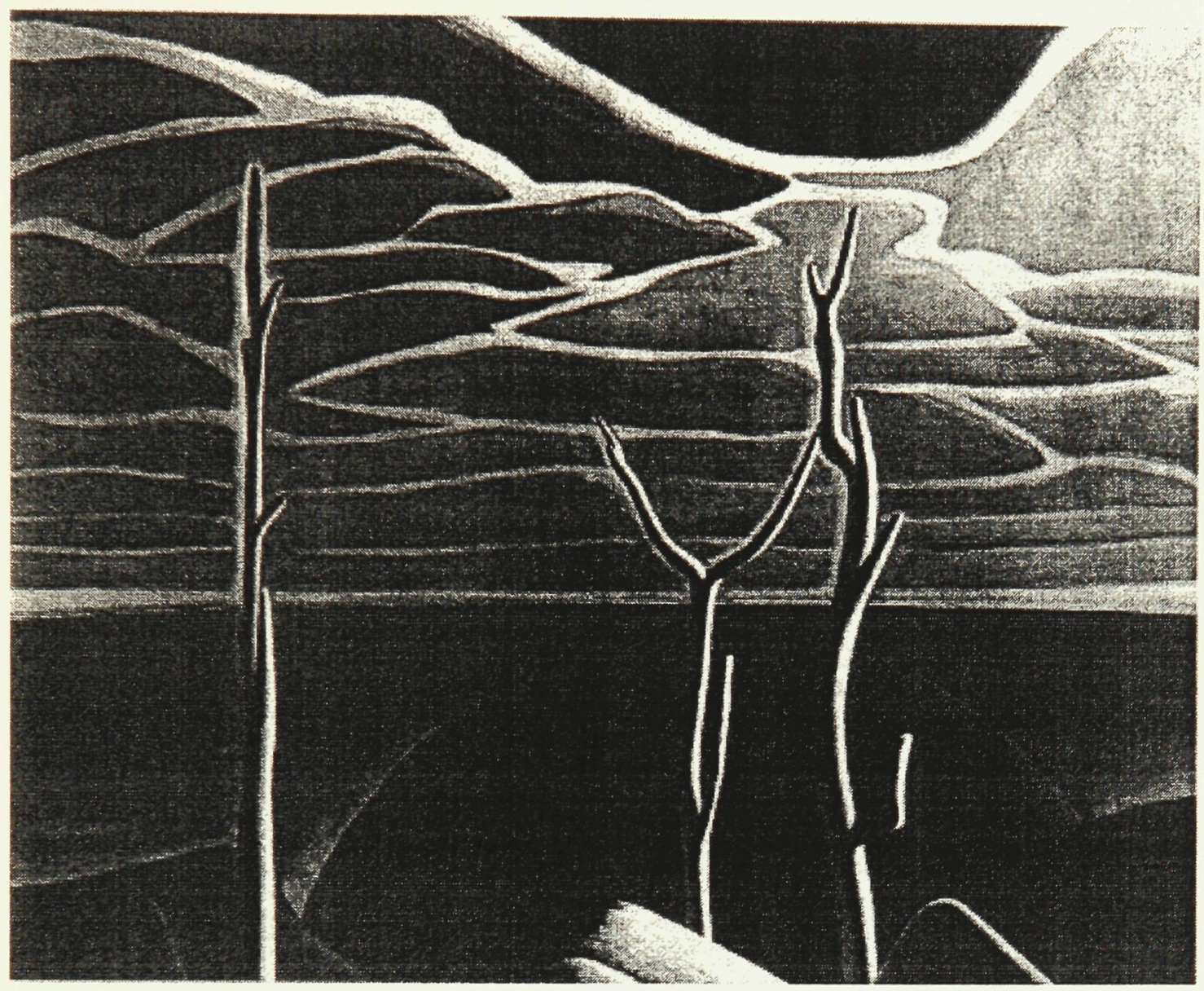

Fig. 20 


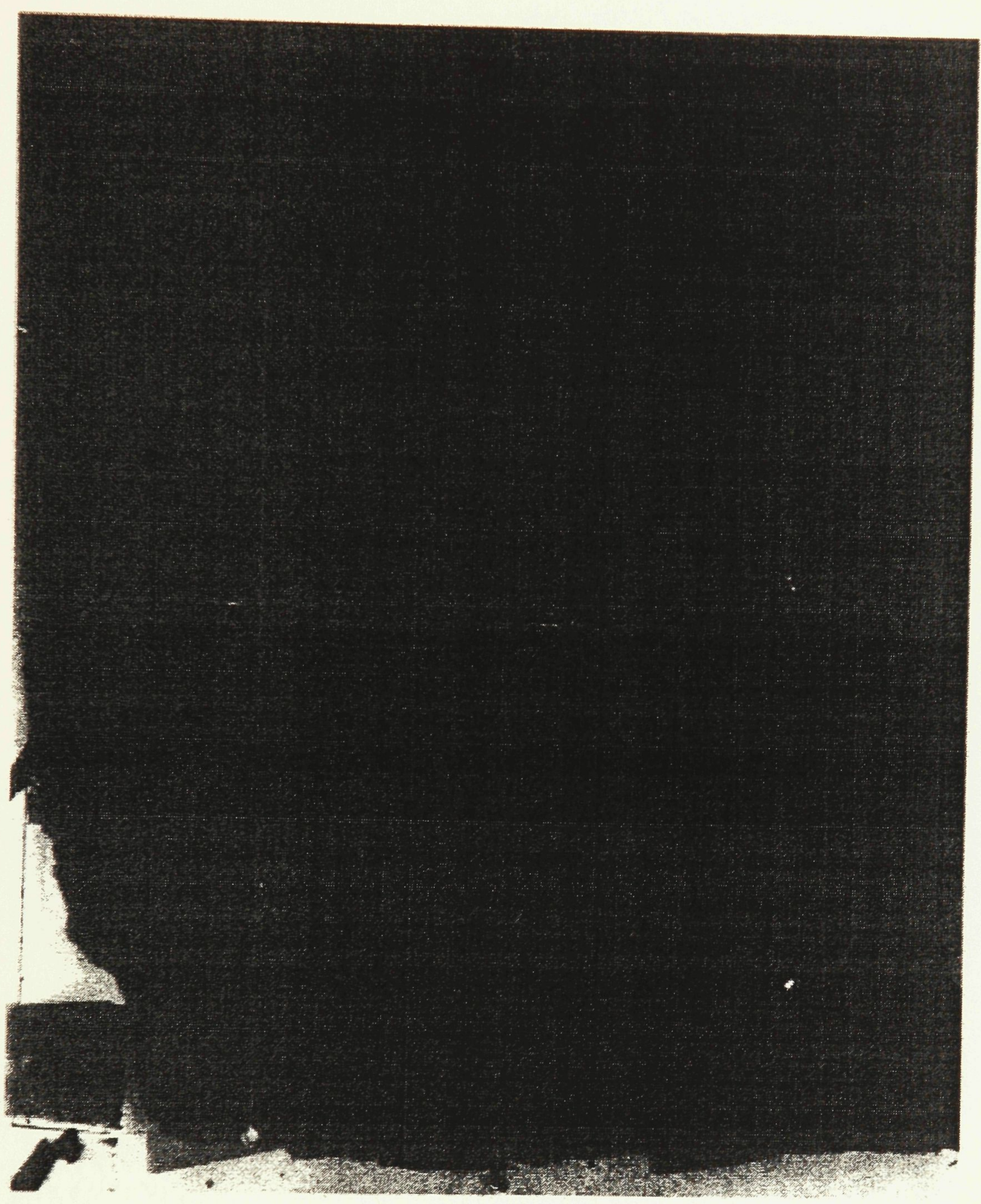

Fig. 21 


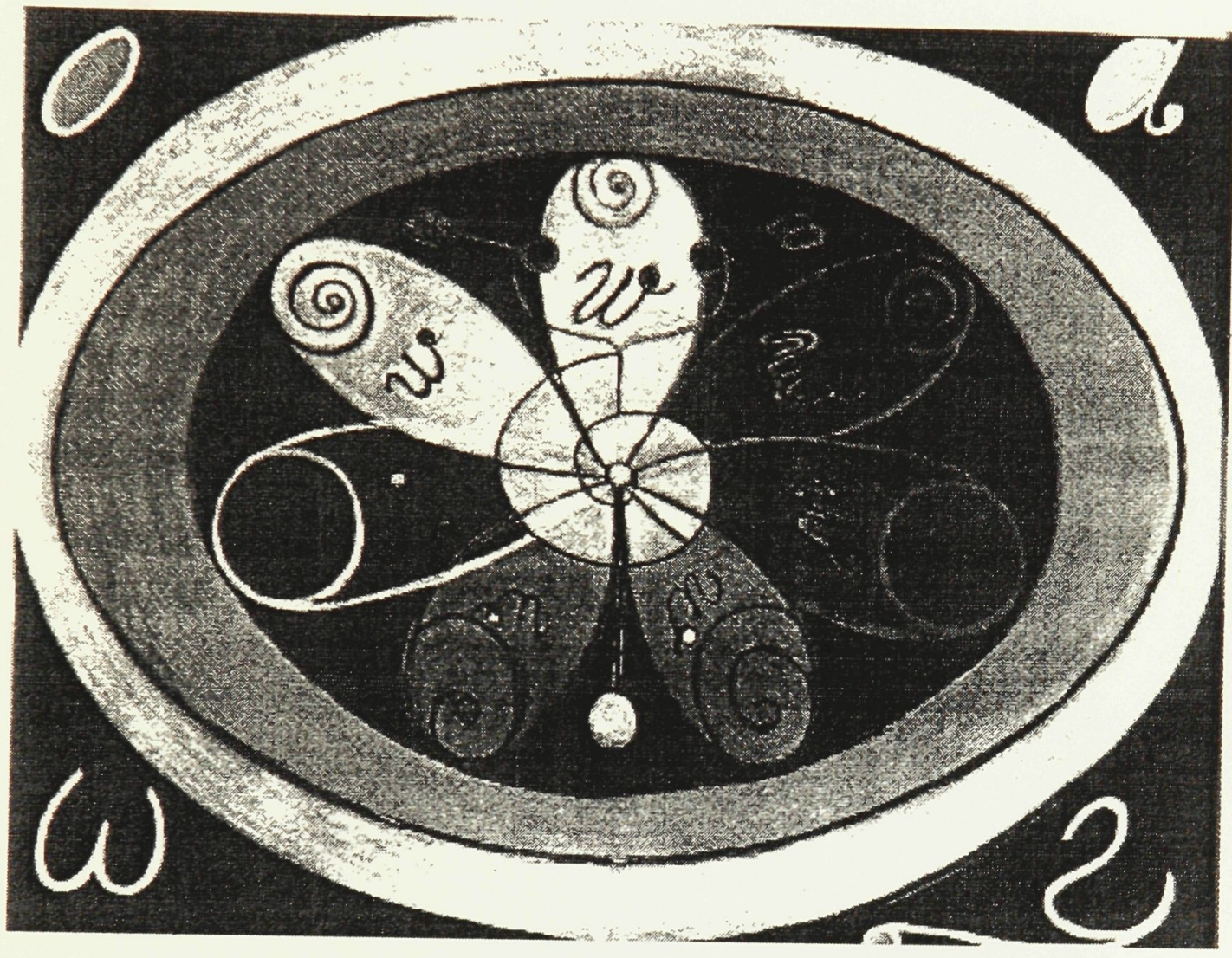

Fig. 22 


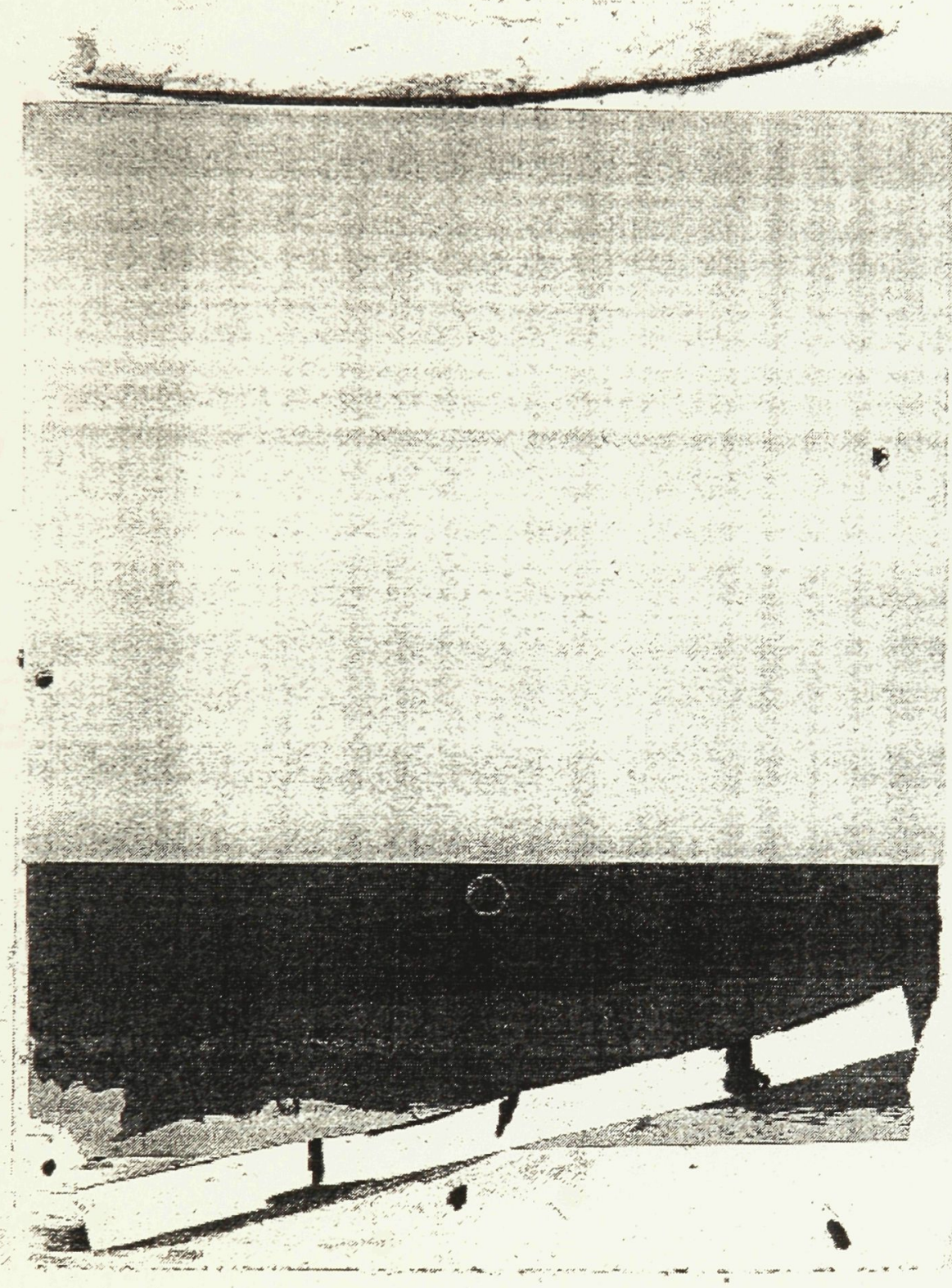

Fig. 23 


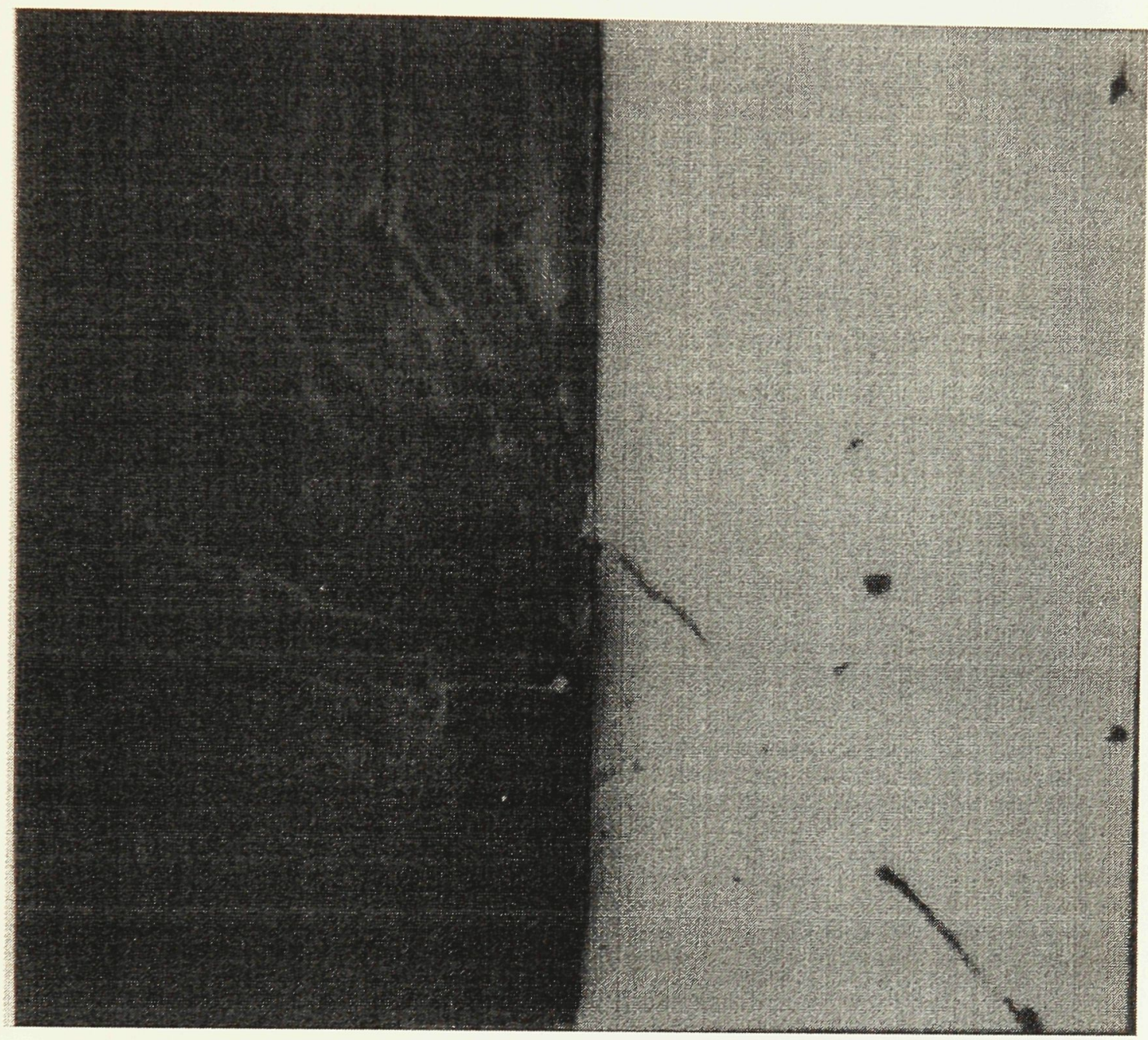

Fig. 24 


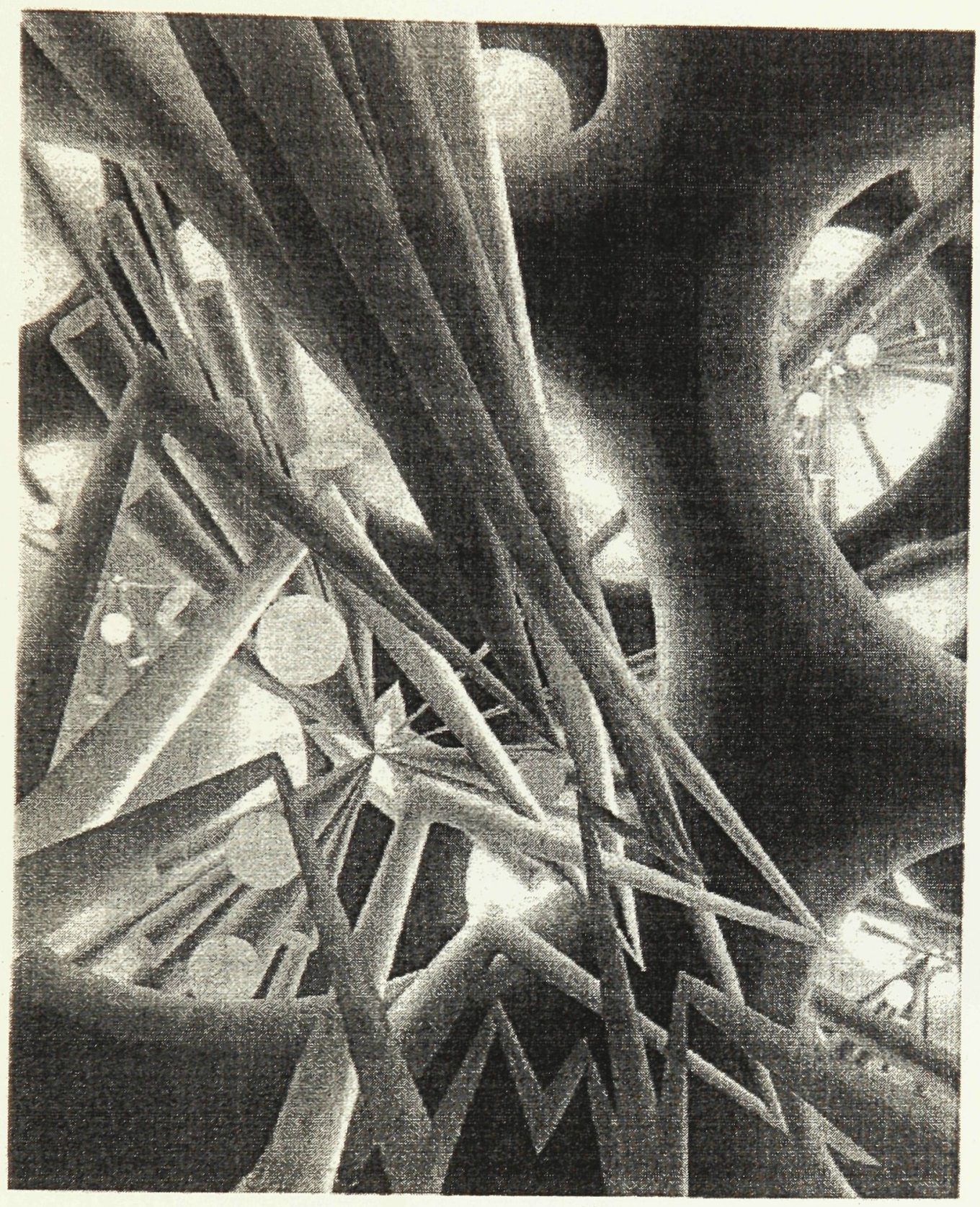

Fig. 25 


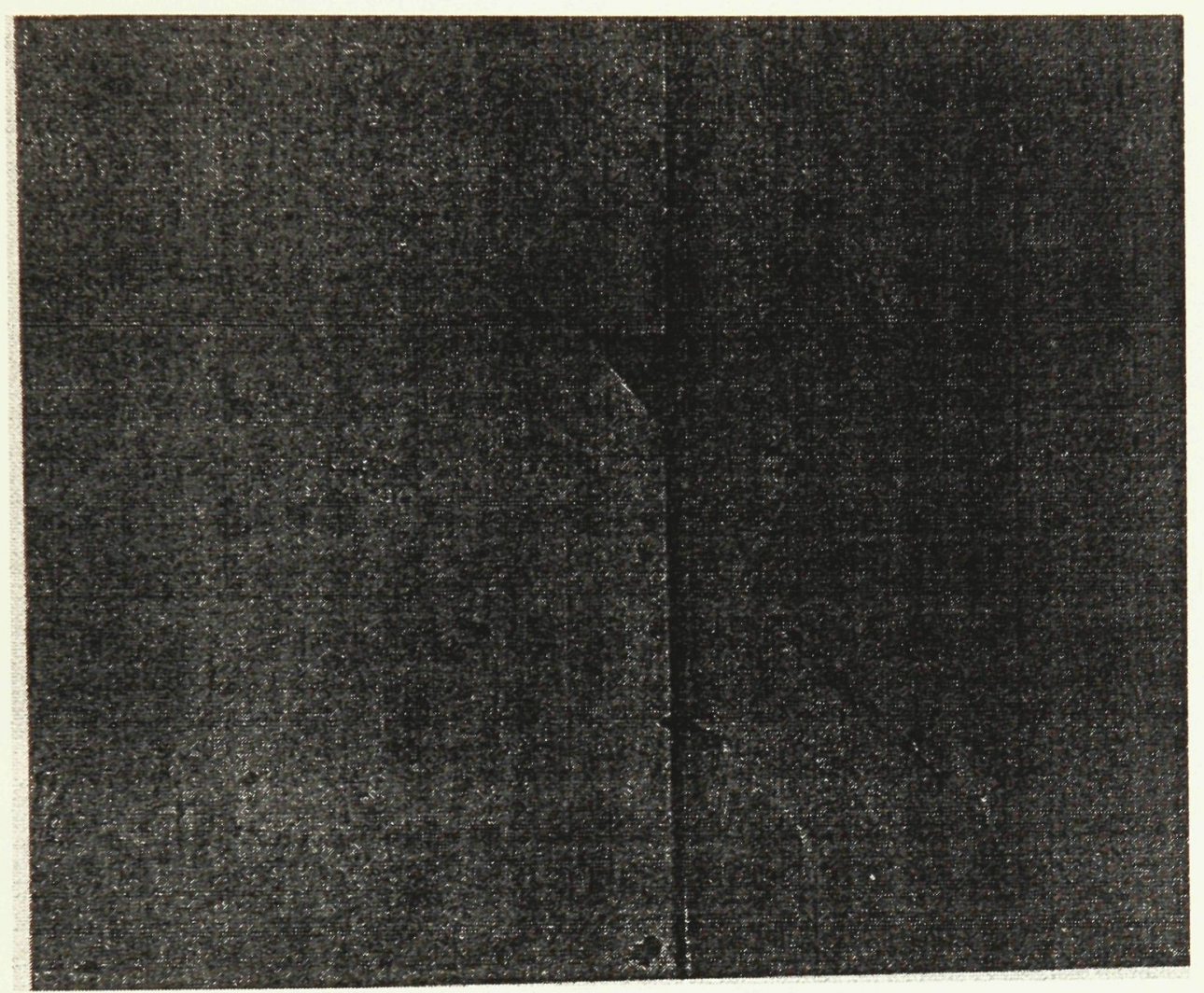

Fig. 26 


\section{APPENDIX I}

\section{Parfleches for the Last Supper}

Quotations from the Gospels describing the discourses during the Last Supper. ${ }^{1}$

Parfleche \# 1 Matthew

"In the world you will have trouble,

But be brave:

I have conquered the world." (John 17:33)

Parfleche \# 2 James the Less

"In a short time you will no longer see me, and then a short time later you will see me again."

(John 16:16)

Parfleche \# 3 Jude

"If anyone loves me he will keep my word, and my Father will love him, and we shall come to him

and make our home with him." (John 14:23)

Parfleche \# 4 Simon

"I have told you all this

so that your faith may not be shaken." (John 16:1)

Parfleche \# 5 Philip

"To have seen me is to have seen the Father so how can you say, 'Let us see the Father?"'

(John 14:9)

Parfleche \# 6 Andrew

"A man can have no greater love

than to lay down his life for his friends."

(John 15:13)

Parfleche \# 7 Bartholomew

"If the world hates you,

remember that it hated me before you."

(John 15:18)

Parfleche \# 8 Thomas

"I am the Way, the Truth and the Life.

No one can come to the Father except

through me." (John 13:16)

\footnotetext{
${ }^{1}$ Winnipeg Art Gallery, Robert Houle: Indians from A to Z, (Winnipeg, 1990), pp. 45-46.
} 
Parfleche \# 9 James

"I tell you most solemnly,

no servant is greater than his master,

no messenger is greater than the man

who sent him." (John 13:16)

Parfleche \# 10 John

"I give you a new commandment:

Love one another;

just as I have loved you,

you also must love one another." (John 14:34)

parfleche \# 11 Judas

"And yet, here with me on the table is the

hand of the man who betrays me." (Luke 22:21)

Parfleche \# 12 Jesus

"Then he took some bread and when he had given

thanks, broke it and gave it to them, saying, 'This

is my body which will be given for you; do this as a

memorial of me." (Luke 22:19)

Parfleche \# 13 Peter

"I tell you, Peter, by the time the cock crows

today you will have denied three times that you

know me." (Luke 22:34) 


\section{SELECTED BIBLIOGRAPHY}

'Abdu'l-Bahá. Paris Talks: Addresses given by 'Abdu'l-Bahá in 1911. $12^{\text {th }}$ ed. London: The Bahá'í Publishing Trust, 1995. Some Answered Questions. Collected \& translated from the Persian by Laura
Clifford Barney. $5^{\text {th }}$ ed. Wilmette, IL: Bahá'í Publishing Trust, 1984 .

Selections from the Writings of 'Abdu'l-Bahá. Comp. Research Department of the Universal House of Justice. Trans. Committee at the Bahá'í World Centre and Marzieh Gail. Haifa, Israel: Bahá'í World Centre, 1978.

Adamson, Jeremy. Lawren S. Harris: Urban Scenes and Wilderness Landscapes 19061930. Toronto: Art Gallery of Ontario, 1978.

Alloway, Lawrence. Barnett Newman: The Stations of the Cross. New York: The Solomon R. Guggenheim Museum, 1966.

Arnheim, Rudolf. "Introduction." The Power of the Center: A Study of Composition in the Visual Arts. Berkeley: University of California Press, 1988.

Bahá'í International Community Office of Public Information. The Bahá'i Statement on Nature. Oakham, Leicestershire: Bahá'í Publishing Trust, c. 1987. [As part of the Network on Conservation and Religion of the World Wide Fund for Nature.]

Bahá'u'lláh. Epistle to the Son of Wolf. Translated by Shoghi Effendi. $3^{\text {rd }}$ ed. Wilmette, IL: Bahá'í Publishing Trust, 1988.

- Kitáb-i-Íqán-The Book of Certitude. Trans. Shoghi Effendi. Wilmette, IL: Bahá'í Publishing Trust, 1983.

. Gleanings from the Writings of Bahá 'u'lláh. rev.ed. London: Bahá'í Publishing Trust, 1978.

Tablets of Bahá'u'lláh Revealed after the Kitáb-i-Aqdas. Comp. Research Department of the Universal House of Justice. Trans. Habib Taherzadeh with the assistance of a Committee at the Bahá'í World Centre. Haifa, Israel: Bahá'í World Centre, 1978.

Baigell, Matthew. "Barnett Newman's Stripe Paintings and Kabbalah: A Jewish Take." American Art 8, no. 2 (spring 1994): 32-43.

Barbour, Ian G. "Experiencing and Interpreting Nature in Science and Religion." Zygon: Journal of Religion and Science 29, no. 4 (Dec. 1994): 457-487. 
Berlo, Janet C. \& Phillips, Ruth B. Native North American Art. Oxford: Oxford University Press, 1998.

Blomfield, Lady. The Chosen Highway. Wilmette, IL: Bahá'í Publishing Trust, 1954.

Brown, Joseph Epes. The Spiritual Legacy of the American Indian. New York: Crossroad, 1988.

Bull, Linda R. "Indian Residential Schooling: The Native Perspective." Canadian Journal of Native Education 18 (1991): 5-64.

Cajete, Gregory A. "Ensoulment of Nature." In Hirschfelder, Arlene. ed. Native Heritage: Personal Accounts by American Indians 1790 to the Present. New York: Macmillan, 1995.

Conservation of the Earth's Resources: A Compilation of Extracts from the Baha' 'i Writings. Prepared by the Research Department of the Universal House of Justice. London: The Bahá'í Publishing Trust, 1990.

Dahl, Arthur Lyon. Unless and Until: A Bahá'í Focus on the Environment. London: Bahá'í Publishing Trust, 1990. et. al. Mark Tobey: Art and Belief. Oxford: George Ronald, 1984.

Davis, Ann. The Logic of Ecstasy: Canadian Mystical Painting 1920-1940. Toronto: University of Toronto Press, 1992.

- "An Apprehended Vision: The Philosophy of the Group of Seven." Ph.D. diss., York University, 1973.

Effendi, Shoghi. The World Order of Bahá'u'lláh-Selected Letters. $4^{\text {th }}$ ed. Wilmette, IL: Bahá'í Publishing Trust, 1991.

Exley, Roy. "Tending the Abyss: the Sublime Edge in Recent Art." Contemporary Visual Arts (Focus on the sublime) issue 19 (1998) 34-39.

Frye, Northrop. “The myth of light," Artscanada, 25, no. 5 (Dec 1968): 8.

Gilkey, Langdon. "Nature as the Image of God: Reflections on the Signs of the Sacred." Zygon: Journal of Religion and Science 29, no. 4 (Dec. 1994): 489-505.

Goldwater, Robert. Symbolism. New York: Harper \& Row, 1979.

Gordon Atkinson, Anne. "The Dilemma of the Artist: A Perspective on the Development of Bahá'í Aesthetics." The Creative Circle: Art, Literature, and Music in Bahá'í Perspective. Edited by Michael Fitzgerald. Los Angeles: Kalimat Press, 1989. 
Hallowell, Alfred Irving. The Ojibway of Berens River, Manitoba. Case Studies in Cultural Anthropology. Edited by Jennifer S.H. Brown. Fort Worth: Harcourt Brace Jovanovich College Publishers, 1992.

Hanley, Paul. "Agriculture: A Fundamental Principle." The Journal of Bahá'i Studies. 3, no. 1 (1990-1991): 1-17.

Hatcher, John S. The Purpose of Physical Reality: The Kingdom of Names. Wilmette, Illinois: Bahá'í Publishing Trust, 1987.

Hess, Thomas. Barnett Newman. New York: Museum of Modern Art, 1971.

Historic Resources Branch. "The Origin of the Name Manitoba." Manitoba Culture, Heritage and Citizenship Historic Resources. Manitoba, [n.d.].

Hoffmann, Gerhard. "Postmodern Culture and Indian Art." Canadian Museum of Civilization. ed. In the Shadow of the Sun: Perspectives on Contemporary Native Art. Hull, Quebec, 1993.

Holst, Wayne Alfred. "Aboriginal Spirituality and Environmental Respect: A Perspective on Traditional Amerindian Views of Nature with Special Reference to the Meaning of 'the Land' in Northern Cultures." Social Compass 44, no.1 (1997): 145-156.

Houle, Robert. "The Spiritual Legacy of the Ancient Ones." In Nemiroff, Diana, Robert Houle, and Charlotte Townsend-Gault, Land, Spirit, Power: First Nations at the National Gallery of Canada. Ottawa: National Gallery of Canada, 1992.

Hultkrantz, Åke. Native Religions of North America: The Power of Visions and Fertility. San Francisco: Harper \& Row, 1987.

. "Feelings for Nature among the North American Indians." In Vecsey, Christopher. ed. Belief and Worship in Native North America. New York: Syracuse University Press, 1981.

Jackson, Christopher. North by West: The Arctic and Rocky Mountain Paintings of Lawren Harris 1924-1931. Calgary: Glenbow Museum, 1991.

Johnson, Lowell. ed. Reginald Turvey: Life and Art. Oxford: George Ronald, 1986.

Johnston, Basil. The Manitous: The Spiritual World of the Ojibway. New York: Harper Collins, 1995.

Indian School Days. Toronto: Key Porter Books, 1988. 
Korp, Maureen E. Sacred Art of the Earth: Ancient and Contemporary Earthworks.
New York: Continuum, 1997.

in North America." Ph.D. diss., University of Ottawa, 1991.

Koster, Donald N. Transcendentalism in America. Boston: Twayne Publishers, 1975.

Kozloff, Max. "Light as Surface," Artforum (Feb. 1968): 26-30.

Kuspit, Donald. "Concerning the Spiritual in Contemporary Art." In Maurice Tuchman, et.al. The Spiritual in Art: Abstract Painting 1890-1985. New York: Abbeville Press,
1986.

Lalonde, Roxanne. "Unity in Diversity: A Conceptual Framework for a Global Ethic of Environmental Sustainability." The Journal of Bahá'i Studies 6, no. 3 (Sep.-Dec. 1994):
39-73.

Larisey, Peter. Light for a Cold Land; Lawren Harris's Life and Work: An Interpretation. Toronto: Dundurn Press, 1993.

Lewis, Clare. "Sublime Spaces: Being and Nothingness in Contemporary Installation." Contemporary Visual Arts (Focus on the sublime) issue 19 (1998): 20-25.

Lilburne, Geoffrey R. A Sense of Place: A Christian Theology of the Land. Nashville: Abingdon Press, 1989.

Lipsey, Roger. An Art of Our Own: the Spiritual in Twentieth Century Art. Boston: Shambhala, 1988.

Lovejoy, Arthur O. The Great Chain of Being: A Study of the History of an Idea. The William James Lectures delivered at Harvard University, 1933. Cambridge, MA: Harvard University Press, 1936.

Lyotard, Jean-Francois. "The Sublime and the Avant-Garde." Artforum 22 (Apr. 1984): 36-43.

McNairn, Ian ed. Lawren Harris: Retrospective Exhibition, 1963. Ottawa: National Gallery of Canada, 1963.

Mendel Art Gallery. The Flat Side of the Landscape: The Emma Lake Artists' Workshop. Edited by John O'Brian. Saskatoon, Saskatchewan: Mendel Art Gallery, 1989.

Mesley, Roger J. "The Mystic North." RACAR (Revue d'art canadienne/Canadian Art Review) 11, no. 1-2 (1984): 124-130. 
1978): $12-18$

Morley, Simon. "The Friedrich Factor: the German Romantic's Legacy." Contemporary Visual Arts (Focus on the sublime) issue 19 (1998): 26-33.

—. "Light as Surface," Contemporary Visual Arts issue 15 (1997): 30-32.

Nakhjavání, Bahíyyih. "Artist, Seeker and Seer: A Vocabulary and a Perspective for the Appreciation and Creation of Art Inspired by the Bahá'í Writings." Bahá 'í Studies, no. 10 (1982): 2-20.

Nasgaard, Roald. The Mystic North: Symbolist Landscape Painting in Northern Europe and North America 1890-1940. Toronto: University of Toronto Press, 1984.

Nemiroff, Diana, Robert Houle, and Charlotte Townsend-Gault. Land Spirit Power: First Nations at the National Gallery of Canada. Ottawa: National Gallery of Canada, 1992.

Parke-Taylor, Michael. The Later Work of L. LeMoine FitzGerald, 1942 to 1956. Winnipeg: Winnipeg Art Gallery, 1988.

Peers, Laura. The Ojibwa of Western Canada 1780 to 1870. Winnipeg: University of Manitoba Press, 1994.

Reid, Dennis. Atma Buddhi Manas: The Later Work of Lawren S. Harris. Toronto: Art Gallery of Ontario, 1985.

—. "Lawren Harris." Artscanada 25, no 5 (Dec. 1968): 9-16.

Research Department of the Universal House of Justice. The Importance of the Arts in Promoting the Faith-A Compilation. Thornhill, Ontario: Bahá'í Canada Publications, 1999.

Ringbom, Sixten. "Transcending the Visible: The Generation of the Abstract Pioneers." In Maurice Tuchman, et.al. The Spiritual in Art: Abstract Painting 1890-1985. New York: Abbeville Press, 1986.

. The Sounding Cosmos: A Study in the Spiritualism of Kandinsky and the Genesis of Abstract Painting. Åbo, Finland: Acta Academiae Aboensis, Ser, A. 1970.

—. "Art in the 'Epoch of the Great Spiritual': Occult Elements in the Early Theory of Abstract Painting." Journal of the Warburg and Courtauld Institutes 29, (1966): 386418. 
Robsjohn-Gibbings, Terrence Harold. Mona Lisa's Mustache: A Dissection of Modern Art. New York: Alfred A. Knopf, 1947.

Rosenblum, Robert. Modern Painting and the Northern Romantic Tradition: From Friedrich to Rothko. New York: Harper \& Row, 1975.

Sahba, Fariburz. "Art and Architecture: A Bahá'í Perspective." The Journal of Bahá 'í Studies 7, no. 3 (Mar.-June 1997): 53-82.

Schama, Simon. Landscape and Memory. New York: Vintage Books, 1995.

Schmied, Wieland \& Schilling, Jürgen. GegenwartEwigkeit: Spuren des Transzendenten in der Kunst unserer Zeit. exh. cat. Stuttgart: Cantz, 1990.

Seitz, William C. "Tobey's World View." Dahl, Arthur L. et. al. Mark Tobey: Art and Belief. Oxford: George Ronald, 1984. Originally published in William C. Seitz, Mark Tobey (New York: The Museum of Modern Art, 1962).

Shaul, Sandra. "Lawren Harris and the Dilemma of Nationalism vs Abstraction." In Edmonton Art Gallery. The Modern Image: Cubism and the Realist Tradition. exh. cat. Edmonton, 1982.

Sieber, S. A. The Saulteaux Indians. St. Boniface, Manitoba: [s.n.], 1948.

Steinbring, Jack H. "Saulteaux of Lake Winnipeg." In Helm, June. vol. ed. Handbook of North American Indians, Vol. 6, Washington, D.C.: Smithsonian Institution, 1981.

Tarasoff, Koozma J. Persistent Ceremonialism: the Plains Cree and Saulteaux. Ottawa, Ontario: National Museums of Canada, 1980. Mercury Series, Canadian Ethnology Service, Paper, No. 69.

Treat, James ed. Native and Christian: Indigenous Voices on Religious Identity in the United States and Canada. New York: Routledge, 1996.

Trevithick, Scott. "Native Residential Schooling in Canada: A Review of Literature." The Canadian Journal of Native Studies 18, no. 1 (1998): 49-86.

Tuchman, Maurice. et.al. The Spiritual in Art: Abstract Painting 1890-1985. New York: Abbeville Press, 1986.

—. "Hidden Meanings in Abstract Art." In Tuchman, Maurice. et.al. The Spiritual in Art: Abstract Painting 1890-1985. New York: Abbeville Press, 1986.

Vecsey, Christopher. Traditional Ojibwa Religion and its Historical Changes.

Philadelphia: The American Philosophical Society, 1983. 
University Press, 1981.

_. "American Indian Environmental Religions." In Vecsey, Christopher, and Robert W. Venables, eds. American Indian Environments: Ecological Issues in Native American History. New York: Syracuse University Press, 1980.

WalkingStick, Kay. "Seeking the Spiritual." Rushing III, Jackson ed. Native American Art in the Twentieth Century: Makers, Meanings, Histories. London: Routledge, 1999.

Washton Long, Rose-Carol. Kandinsky: The Development of an Abstract Style. Oxford: Clarendon Press, 1980.

. "Kandinsky and Abstraction: The Role of the Hidden Image." Artforum 10 (June 1972): 42-49.

Wax, Murray L. and Rosalie H. Wax. "Religion among the American Indians." The Annals of the American Academy of Political and Social Science 436 (Mar 1978): 27-39.

Weinberg, Robert. ed., Spinning the Clay into Stars: Bernard Leach and the Bahá'í Faith. Oxford: George Ronald, 1999.

Welsh, Robert P. Piet Mondrian 1872-1944. Toronto: Art Gallery of Toronto, 1966.

- "Mondrian and Theosophy." In Piet Mondrian 1872-1944: A Centennial Exhibition. New York: Solomon R. Guggenheim Museum, 1971.

White, Robert A. Spiritual Foundations for an Ecologically Sustainable Society. New York: Bahá'í International Community, 1989. First published in The Journal of Bahá 'i Studies 2, no. 1 (1989-90): 33-57.

Wylie, Elizabeth. "The Development of Spirituality in the Work of Lionel LeMoine FitzGerald 1890-1956." Master's thesis, Concordia University, Montreal, 1981.

Zemans, Joyce. "First Fruit: The World and the Spirit Paintings." Provincial Essays 7 (1989): 17-37.

. "The art and Weltanschauung of Bertram Brooker." Artscanada (Feb./Mar. 1973): 65-68.

\section{Literature on Robert Houle}

Baele, Nancy. "Robert Houle: the spirit and power of the native artist." The Ottawa Citizen. 17 Oct. 1992.

—. "Native art deserves to be seen." The Ottawa Citizen, [1991?]. 
Citizen. 1 Dec. 1991.

—. "Cultural extinction and renewal." The Ottawa Citizen. 29 Mar. 1990.

- "Indian adds to Mondrian." The Ottawa Citizen. 4 June 1983. Bell, Michael. Kanata: Robert Houle's Histories. Ottawa: Carleton University Art
Gallery, 1993.

- Robert Houle: Zero Hour. Kingston: Agnes Etherington Art Centre, 1992.

Bentley Mays, John. "Making visual sense of a mixed heritage." The Globe \& Mail. 29
Nov. 1991.

Campbell, Donald. "Toronto Artist Houle settles in WAG cellar." Winnipeg Free Press. Winnipeg, Manitoba, 18 [or $8^{\text {th }}$ ] Jan. 1989.

Corbeil, Carole. "Beyond cultural apartheid: Art-making as an act of personal and political exorcism." The Globe \& Mail. 19 Apr. 1986.

Devine, Bonnie. "Ways of Telling: Sandy Bay." In Winnipeg Art Gallery, Robert Houle: Sovereignty over Subjectivity. Winnipeg, 1999

Douglas, Susan. "Crossroads Visualism: Robert Houle." Parachute, no. 80 (Oct.-Dec. 1995): 43-46.

Gale, Peggy. "Robert Houle: Recording." In Winnipeg Art Gallery, Robert Houle: Sovereignty over Subjectivity. Winnipeg, 1999.

Garnet, Carla. Press Release-Robert Houle 'Premises for Self Rule'." Garnet Press Gallery, Toronto, Sept. 1994.

Hanna, Deirdre. "Robert Houle's secret reserve.” NOW Magazine (20 Jan. 2000).

(29 "Robert Houle's cool Self-Rule taps artistic and native roots." NOW Magazine (29 Sept. 1994).

. "Robert Houle: Daring Hochelaga exhibit raises disturbing issues about native sovereignty and Quebec." NOW Magazine (19-25 Nov. 1992): 24.

Hargittay, Clara. "Robert Houle: Identity and Multiplicity." Real Fictions: Four Canadian Artists Stan Douglas, Robert Houle, Ken Lum, Liz Magor. exh. cat. Sydney, Australia: Museum of Contemporary Art, 1996. 

. "Robert Houle: His Creative and Spiritual Journey, 1980-1990." In Winnipeg
Art Gallery, Robert Houle: Indians from A to Z. Winnipeg, 1990.

Hargittay, Clara, and Robert Houle. "The Struggle Against Cultural Apartheid." Muse (autumn 1988): 58-60. Hume, Christopher. "An activist recedes, an artist emerges." The Toronto Star. 11 July
1996.

Lacey, Liam. "Reconciling cultural differences." The Globe \& Mail. 13 Feb. 1990.

Kritzwiser, Kay. "Robert Houle: a native artist with a weakness for Mondrian." The Globe \& Mail. 21 July 1978.

Littman, Sol. "Native artists straddle two worlds." Sunday Star. 10 Feb. 1980.

Madill, Shirley. "Coming Home." In Winnipeg Art Gallery, Robert Houle: Sovereignty over Subjectivity. Winnipeg, 1999.

. "Robert Houle: A Dual State of Being." In Winnipeg Art Gallery, Robert Houle: Indians from A to Z. Winnipeg, 1990.

McMaster, Gerald. "Reading the Boarding School experience." Lippard, Lucy R. ed. Partial Recall: Photographs of Native North Americans. New York: The New Press, 1992. 77-87

. "The Persistence of Land Claims." In Winnipeg Art Gallery, Robert Houle: Indians from A to $Z$. Winnipeg, 1990.

Michael, Linda. Real Fictions: Four Canadian Artists Stan Douglas, Robert Houle, Ken Lum, Liz Magor. exh. cat. Sydney, Australia: Museum of Contemporary Art, 1996.

Musiol, Marie-Jeanne. "Houle and the Ojibway leaves." The Native Perspective 2, no. 10 (1978): 21-23.

Payne, Carol. Displaced Histories. Ottawa: Canadian Museum of Contemporary Photography, 1995.

Podedworny, Carol. "Trajectories of Meaning...the work of Isaac Applebaum and Robert Houle." Garnet Press Gallery, Toronto (Jan. 1993).

—. "Robert Houle: Indians from A to Z." Fuse (fall 1991): 59.

Robertson Galleries. "Press Release-Robert Houle '1981 Works on Paper'." Ottawa, 9 Oct. 1981. 
Stanley, Patrice. "Indians from A to Z: Abstract Expressionism, the Last Supper and Native medicine bundles are combined in a new exhibit by Robert Houle." Metro (Nov.
1991): 24 .

Stedelijk Museum. Notion of Conflict: A Selection of Contemporary Canadian Art. Amsterdam, 1995.

Taylor, Kate. "Examining the Power and Tyranny of Images." The Globe \& Mail. 5 Feb. 1993.

Trevelyan, Amelia. Lost Tribes-Robert Houle. exh. cat. Frederick, Maryland: Hood College, 1991.

Gallery, 1990.

Ufundi Gallery. "Divas - Robert Houle." Press release. Ottawa, 2-21 Oct. 1992. Artist's file, National Gallery of Canada, Ottawa.

_. "Mohawk Summer: Collages by Robert Houle.” Press release, Ottawa, 1991.

—. "New scrap iron works Robert Houle." Press release, Ottawa, 1990.

_. "Robert Houle Numbers and Tribes." Ottawa, 1988.

Wesseling, Janneke. "Honest Canadian Engagement in Stedelijk." NRC Handelsblad. The Netherlands, 1995. [curatorial file NGC]

Winnipeg Art Gallery. Robert Houle: Sovereignty over Subjectivity. Winnipeg, Manitoba, 1999.

- Prairietheism: Internalizing the Prairie Landscape. Winnipeg, Manitoba, 1996.

Robert Houle: Indians from A to Z. Winnipeg, Manitoba, 1990.

\section{Articles written by Robert Houle}

Houle, Robert. "The Spiritual Legacy of the Ancient Ones." In Nemiroff, Diana, Robert Houle, and Charlotte Townsend-Gault, Land Spirit Power: First Nations at the National Gallery of Canada. Ottawa: National Gallery of Canada, 1992.

—. "Artist's Statement." in Bell, Michael, Robert Houle: Zero Hour. Kingston: Agnes Etherington Art Centre, 1992.

_. "Artist's Statement." in Trevelyan, Amelia. Lost Tribes-Robert Houle. exh. cat. Frederick, Maryland: Hood College, 1991. 
—. "Sovereignty over Subjectivity." C Magazine, no. 30 (summer 1991): 28-35.

Hargittay, Clara, and Robert Houle. "The Struggle Against Cultural Apartheid." Muse (autumn 1988): 58-60.

Robert Houle. "The Emergence of a New Aesthetic Tradition." New Work by a New Generation. Regina, Saskatchewan: Norman Mackenzie Art Gallery, 1982.

. "Artist's statement." New Work by a New Generation. Regina, Saskatchewan: Norman Mackenzie Art Gallery, 1982.

—. "Search for Identity." Tawow 2, no 2, (summer 1971): 3.

C. "The Great Dreamers." Undated [ca. 1970/71], artist's file National Gallery of Canada, Ottawa.

\section{Literature on Otto Rogers}

Acker, Laura. "Otto Rogers: Mira Godard Gallery September 22-October 13." Artscanada 36 (Dec. 1979/Jan. 1980)

Agnes Etherington Art Centre. Painting now 76/77-Otto Rogers. Kingston, Ontario: Queens University, 1977.

Artmagazine. "Otto Rogers Recent Works." 21 (spring 1975): 51.

Bell, Keith. Otto Rogers. Regina, Saskatchewan: Norman Mackenzie Art Gallery, University of Regina, 1977.

- "Otto Donald Rogers." In Saskatchewan Arts Board. Five from Saskatchewan: Bornstein, Fafard, Knowles, Lindner, Rogers. Saskatchewan, 1983.

Bell, Lynne. "A Message of Celebration and Supplication." Arts West 3 (Nov./Dec. 1978): 18-22.

Bentley Mays, John. "Otto Rogers: recent paintings at the Mira Godard Gallery." The Globe \& Mail. (7 Oct. 1988)

. "Abstractionist Otto Rogers follows two artistic tracks." The Globe \& Mail. (8 Oct. 1981) cols. 1-2.

Boyles, Ann. "Attracting a Condition of Love: The Art of Otto Rogers." Buschlen Mowatt Gallery. Otto Donald Rogers. Vancouver, 1998. 
Burke, Lora. "Two exhibitions displayed." The Leader-Post. (Regina, Saskatchewan)
(9 Mar. 1977): 5.

Burnett, David. “Otto Rogers: Mira Godard Gallery May 7-28." Artscanada 34

Carson, Sarah. "Otto Rogers." in Wale, George. Selected Canadian Landscapes.
Burlington, Ontario: Burlington Art Centre 1995.

Contemporary Canadian Artists. Toronto: Gale Canada, 1997.

Dault, Gary Michael. "Otto Rogers goes behind the surface.” n.p., n.d. [Globe \& Mail ?, 1977?]. Artist's file, Robert McLaughlin Gallery, Oshawa, Ontario.

Enright, Robert. "Landscapes of the soul." MacLean's, (11 Oct. 1982): 71.

Gustafson, Paula. "Interview-Otto Donald Rogers." Artichoke. (summer 1996): 27-30.

1996). "Painterly Planes of Prairie Light." Georgia Straight. (Vancouver), (20 June

Heath, Terrence. "The Cosmic Landscapes of Otto Rogers." Artscanada 30 no. 1 (Feb./Mar. 1973): 28-33.

Hudson, Andrew. "Otto Rogers at James Art Studio Gallery, Saskatoon." Canadian Art 19 (summer 1962): 324.

(Sept./Oct. 1963): 260-261.

Humphries, D. "Introduction." Otto Rogers. Swift Current National Exhibition Centre, Swift Current, Saskatchewan 1986.

I.M. "Otto Rogers-artist-sculptor-New Head University of Saskatchewan Art

Department." Folio [a bi-monthly publication of the Mendel Art Gallery, Saskatoon, Saskatchewan] (Sept. 1973).

Joyner, Brooks. "Rodgers [sic]—personal triumph." Calgary Albertan. (7 Jan. 1979).

Kritzwiser, Kay. "Rogers' faith is his inspiration." The Globe \& Mail. (28 Apr. 1979):25, cols. 1-3.

(23 May 1975). 
Lehmann, Henry and Georges Bogard. "Otto Rogers displays impressive vision: Prairie variation out of New York." Montreal Star. (7 May 1975).

McConnell, Clyde. "Otto Rogers." Artscanada 28, no. 1 (Feb./Mar. 1971): 52.

Millard, Peter. "At the Cross-Roads: Painting in Saskatoon." Arts Manitoba 2, no. 2 (winter 1983): 26-32.

—_. "Otto Rogers: Mira Godard Gallery, May 7-28.” Toronto, 1977.

_. "Fallen between two schools." The Sheaf (12 Nov. 1969)

Moppett, George. "Otto Rogers: Paintings, Collages and Assemblages 1973-1982." In Mendel Art Gallery. Otto Rogers: A Survey 1973-1982. Saskatoon, Saskatchewan, 1982. . Selected Saskatchewan Drawings. Saskatoon, Saskatchewan: Mendel Art
Gallery, 1977.

Murray, Joan. The Best Contemporary Canadian Art. Edmonton, Alberta: Hurtig Publishers, 1987.

Purdie, James. "Rogers switching on the age's light." The Globe \& Mail. (16 May 1977).

Ring, Dan. Tradition and Innovation: Saskatoon Art and the 1950s. Saskatoon, Saskatchewan: Mendel Art Gallery, 1987.

Robertson, Sheila. "Otto Rogers invites scrutiny of paintings." Star-Phoenix (Saskatoon, Saskatchewan). (2 Oct. 1982).

Savage, Laurie. "Rogers featured in Sask. Series." The Commentator. (26 Sept. 1982): 8.

Shuebrook, Ron. New Paintings by Otto Rogers. Calgary, Alberta: Glenbow-Alberta Art Gallery, 1973.

Southern Alberta Art Gallery. Otto Rogers: New Paintings and Sculpture 1977-78. Lethbridge, Alberta, 1978.

Tousley, Nancy. "Spiriting the Seen and the Imagined." Border Crossings 18, no. 2 (May 1999): 52-53.

1982).

"Prairie painter explores mysticism and spirituality." Calgary Herald. (19 June 
(Dec. 1980/Jan. 1981): 40-41.
(Dotto Rogers: Mira Godard Gay May 7 to May 28 1977." Artscanada 37

Dec. 1978).

“'Otto Rogers: New Paintings and Sculpture 1977-78." Calgary Herald. (21

Winnipeg Art Gallery. Two Artists from Saskatoon: Dorothy Knowles [and] Otto Rogers. Winnipeg, Manitoba, 1969.

Woodman, Ross. A Celebration of the Human Spirit: Five Canadian Artists. London, Ontario: McIntosh Gallery, 1988.

Wylie, Liz [Elizabeth]. "Otto Rogers' Mementos.” Vie des Arts (Montreal) 28, no. 3 (summer, 1983): 77-78.

Zepp, Norman. "Formalism, landscape and religion in the painting of Otto Rogers." In Otto Rogers: A Survey 1973-1982. Saskatoon, Saskatchewan: Mendel Art Gallery, 1982.

\section{Articles written by Otto Rogers}

Rogers, Otto Donald. "Artist's Statement." Buschlen-Mowatt Gallery. Otto Donald Rogers. Vancouver, British Columbia, 1998.

- "Divine Influence and Human Response." Transcript of a talk given at the Bahá'í World Centre, Haifa, Israel, 30 Aug. 1996.

- "A Short Essay in Nine Parts." In Canadian Art Galleries. An Exhibition of New Paintings and an Essay by Otto Donald Rogers. Calgary, Alberta, 1991.

- "The Effect of Revelation on Artistic Expression." Bahá'í Studies, no. 10 (1982): 52-59.

_. " 'Trees for your thoughts' artist's questionnaire." Sarnia Public Library and Art Gallery, Sarnia, Ontario, 1980. [Artist's file Mendel Art Gallery.]

- "Reflections on the Spiritual Quest of the Artist." In Southern Alberta Art Gallery. Otto Rogers: New Paintings and Sculpture 1977-78. Lethbridge, Alberta, 1978.

\section{Works of Art, Curatorial and Artist's Files}

were consulted at the following institutions:

National Gallery of Canada, Ottawa

Art Gallery of Ontario, Toronto

Winnipeg Art Gallery, Winnipeg

Mendel Art Gallery, Saskatoon

Hamilton Art Gallery, Hamilton, Ontario 
McMichael Canadian Art Collection, Kleinburg, Ontario

Robert McLaughlin Art Gallery, Oshawa, Ontario

Canada Council Art Bank, Ottawa

Canadian Museum of Civilization, Hull, Quebec

Kenderdine Gallery, University of Saskatchewan, Saskatoon

As well as:

Victoria Henry, collection of papers on Robert Houle

\section{Interviews and Conversations}

Personal interview with Robert Houle, Toronto, 25 Jan 2000

Personal conversation with Robert Houle, Toronto, 8 Oct 1999

Personal conversation with Otto Rogers, Haifa, Israel, 25 Dec 1997

Personal phone interview with Otto Rogers, 26 June 2000

Phone conversation with Robert Christie, Saskatoon, 14 Aug 1999

\section{Audio and Video materials}

Film Crew Production. Approach to a Sacred Place: The Art of Otto Donald Rogers.

Director, Davidson, Tom. Producer, Donnelly, Clark. [Videocassette, 57:50], Regina, Saskatchewan, 1992

Taped interview with Otto Rogers, June 1982, Mendel Art Gallery archives

Taped interview with Otto Rogers, June 1973, Mendel Art Gallery archives 